Revue des patrimoines

\title{
Entre inventaire et propagande : les destructions du patrimoine en Picardie vues par la Section photographique et cinématographique de l'armée (SPCA)
}

\section{Lieutenant David Sbrava}

\section{(2) OpenEdition}

Journals

Édition électronique

URL : http://journals.openedition.org/insitu/11012

DOI : $10.4000 /$ insitu. 11012

ISSN : 1630-7305

Éditeur

Ministère de la culture

\section{Référence électronique}

Lieutenant David Sbrava, «Entre inventaire et propagande : les destructions du patrimoine en Picardie vues par la Section photographique et cinématographique de l'armée (SPCA) », In Situ [En ligne],

23 | 2014, mis en ligne le 24 mars 2014, consulté le 19 avril 2019. URL : http://

journals.openedition.org/insitu/11012 ; DOI : 10.4000/insitu.11012

Ce document a été généré automatiquement le 19 avril 2019.

\section{(i) $\odot$

In Situ Revues des patrimoines est mis à disposition selon les termes de la licence Creative Commons Attribution - Pas d'Utilisation Commerciale - Pas de Modification 4.0 International. 


\title{
Entre inventaire et propagande: les destructions du patrimoine en Picardie vues par la Section photographique et cinématographique de l'armée (SPCA)
}

\author{
Lieutenant David Sbrava
}

1 En mars 1917, à la surprise du commandement français et britannique, les forces allemandes affaiblies par les batailles de l'année 1916 opèrent un large repli stratégique en Picardie. En effet, il s'agit pour le haut-commandement allemand de réduire la longueur du front pour mieux le défendre sur une ligne prédéfinie, nécessitant moins de combattants. Cette opération, baptisée Alberich, est lourde de conséquences sur les territoires picards occupés par les armées allemandes depuis le mois d'octobre 1914. De la Somme à l'Aisne, les autorités allemandes ordonnent aux troupes de pratiquer une politique de la "terre brûlée ». De nombreux ponts, maisons, églises, routes ou encore terrains agricoles sont alors la cible de destructions par le feu ou l'explosif, laissant les soldats alliés découvrir un spectacle de désolation. Lors de cette phase méconnue de la guerre, rapidement balayée par la suite des événements militaires du printemps et de l'été 1917, une partie substantielle du patrimoine architectural, culturel et économique de la région picarde, principalement entre Noyon et Chauny, disparaît à jamais, laissant une profonde cicatrice dans les mémoires et dans le paysage.

Quelques semaines auparavant, en janvier 1917, à Paris, la Section photographique et cinématographique de l'armée (SPCA) a connu une importante réorganisation de ses moyens. Désormais, l'armée française dispose de son propre outil de captation et de diffusion des images prises au front par ses opérateurs. Contrôlées et validées, elles sont diffusées dans la presse écrite, ainsi que dans un numéro d'actualités filmées né au même moment et édité sous le nom d'Annales de la guerre. À l'annonce du retrait des forces allemandes d'une partie de la Picardie, la section est immédiatement mandatée pour couvrir les événements et montrer l'avancée des soldats français à travers un pays ravagé 
par les destructions. À l'occasion de ce déploiement, les opérateurs militaires rapportent des milliers d'images fixes ainsi que des dizaines d'heures de rushes. Cette production s'étend sur plusieurs mois, mobilisant d'importants moyens de tournage et de prises de vues.

Les événements suivis par la SPCA sont largement relayés par la presse où sont confirmés, images à l'appui, les actes de "barbarie » commis sur le sol de Picardie. Dynamitage d'églises, incendie de villages et déportation de civils sont ainsi exposés aux yeux de l'opinion publique tout au long de l'année 1917, mobilisant les esprits vers l'objectif de vaincre à tout prix l'Allemagne ${ }^{1}$. Dépendant notamment du ministère de l'Instruction publique et des Beaux-Arts, la SPCA joue également un rôle crucial dans le projet de reconstruction des régions dévastées par la guerre, en réalisant, par la même occasion, l'inventaire en images des destructions commises sur le patrimoine civil, religieux, militaire, rural ou industriel. Ces images d'exactions, qui constituent une large partie de la production de la SPCA, trouvent, au lendemain de l'armistice, une place de choix dans l'affirmation des revendications françaises auprès des plénipotentiaires allemands lors du traité de Versailles, ainsi que dans la transmission de la mémoire du conflit et de ses combattants auprès des générations futures.

\section{LE RÔLE dE LA SECTION PHOTOgRAPHIQUE ET CINÉMATOgRAPHIQUE DE L'ARMÉE (SPCA)}

4 Constituée au printemps de l'année 1915, la Section photographique de l'armée (SPA) et la Section cinématographique de l'armée (SCA) ont pour mission de réaliser les images fixes et animées qui témoignent des actions menées par les armées françaises et leurs alliés. Ces deux entités sont déployées sur l'ensemble des territoires où sont engagées des forces, du front occidental au front d'Orient, et sur les théâtres d'opérations tels que le Proche-Orient, l'Arabie, l'Afrique, jusqu'aux confins de la Russie en 1919.

5 Ces deux sections sont nées d'un constat affirmé dès l'entrée en guerre par les professionnels de la presse écrite et filmée. Ne disposant pas de documents officiels, ces derniers, qui ont un besoin impérieux de montrer au public les péripéties de la guerre, ont recours à des sources amateurs et étrangères dont les origines peuvent être incertaines et sujettes à caution. En effet, la production allemande d'images de guerre, instaurée dès le début du conflit, inonde la presse étrangère via le circuit des pays neutres tels que la Suisse et la Hollande. De nombreux documents allemands sont donc utilisés par les organes de presse afin d'illustrer le début des opérations ${ }^{2}$. Malgré des réticences exprimées par les plus hautes instances militaires, le ministère de la Guerre, en accord avec le ministère de l'Instruction publique et des Beaux-Arts et celui des Affaires étrangères, autorise en avril et mai 1915 la mise en œuvre d'unités spécialisées dans la prise de vue ${ }^{3}$.

6 Les objectifs assignés à la SPA et à la SCA sont de constituer un fonds documentaire permettant de montrer l'action des forces armées, de participer à la constitution des futures archives du conflit et enfin d'entreprendre l'inventaire des destructions subies par le patrimoine immobilier et mobilier au sein des régions touchées par la guerre ${ }^{4}$. Pour remplir ces missions essentielles, les sections disposent de moyens de prise de vue et de tournage importants fournis par le sous-secrétariat aux Beaux-Arts, ainsi que d'un bureau chargé d'assurer l'archivage et la diffusion des images. Le commandement de la SPA est 
confié au sous-lieutenant Pierre-Marcel Lévi ${ }^{5}$, ancien professeur à l'École des beaux-arts. La SCA est dirigée par le lieutenant Jean-Louis Croze, ancien critique de cinéma.

7 Peu de temps après la création des sections, Pierre-Marcel Lévi insiste dans la revue Les Annales politiques et littéraires sur cette mission d'inventaire :

[La SPA] ne se bornera pas, en effet, à enregistrer des actions militaires, à constater les dommages dans les régions envahies, à fixer les faits de guerre dans leur beauté ou leur violence; elle montrera encore l'effort industriel sans précédent dont la France offre le spectacle. [...] Puisse le monument que ses archives constitueront à perpétuer pour nous, qui les avons connues et admirées avec tendresse, le souvenir des merveilles anéanties par le barbare et fixer pour le monde, dans le temps, le vestige de tant de trésors souillés et bouleversés ! 6

8 Peu expérimentée dans le domaine de l'audiovisuel, l'armée décide de s'appuyer sur le secteur privé, signant des conventions avec les représentants des chambres syndicales de la photographie et de la cinématographie. Ces dernières sont naturellement associées et fournissent à la fois le personnel qualifié, enrôlé dans l'armée et versé dans la $20^{\mathrm{e}}$ section des secrétaires d'état-major, et le matériel nécessaire à la réalisation des reportages ${ }^{7}$. En échange, le ministère de la Guerre autorise l'accès à la zone des armées. Rapidement, ce mode de fonctionnement est remis en question ${ }^{8}$. Au mois d'octobre 1915, après plusieurs incidents relevés sur le terrain, le ministère décide de mettre un terme à l'association avec le secteur privé. Les sections photographique et cinématographique répondent désormais aux seuls ordres du cabinet du ministre de la Guerre, par l'entremise du bureau militaire d'information (BMI) qui œuvre dans le cadre de la propagande par l'image en France et à l'étranger.

Installé au numéro 3 de la rue de Valois, dans le premier arrondissement de Paris, le siège de la SPA et de la SCA organise le départ des équipes vers le front, encadrées par un officier d'état-major qui les oriente sur le terrain et dispose d'un pouvoir de sanction en cas de non-respect des consignes 9 . Une fois les vues fixes ou animées réalisées, elles sont visées par une commission chargée de statuer sur leur communicabilité. Ce comité de censure, composé d'un membre de la SPA et de personnels du bureau d'information presse $^{10}$ (BIP), autorise ou interdit la diffusion des images, décision mentionnée sur le registre d'archivage. Celui-ci s'opère en deux phases. Tout d'abord, chaque document dispose d'une référence provisoire attribuée dès sa réception par la SPA, définitive lorsqu'il est rattaché à la série de photographies qui correspond au travail de l'opérateur ${ }^{11}$ . Par la suite, les documents photographiques sont tirés en plusieurs exemplaires, présentés au sein d'un salon de consultation, également installé rue de Valois, où le public des journalistes et des correspondants de presse peuvent, sans obligation, venir commander les vues. La section exerce également un rôle de commanditaire dans la diffusion de ses vues par divers médias, tels que la presse écrite, la presse illustrée et la carte postale.

10 La collaboration avec le monde du cinéma apparaît en revanche plus simple. Les quatre maisons d'édition cinématographique présentes à l'époque, Pathé, Gaumont, Éclair et Éclipse, fournissent le matériel et les opérateurs nécessaires au fonctionnement de la SCA. Le contrôle de leur contenu est également organisé et confié à un comité de censure composé de militaires et de civils, qui autorise ou non la diffusion des images tournées au front. Ce mode de fonctionnement évolue en février $1917^{12}$, au moment où le ministère de la Guerre, dirigé par le général Hubert Lyautey, engage un rapide processus de rationalisation des moyens dans le but de concentrer dans les mains de l'autorité militaire l'ensemble des procédés de création et de diffusion des images. Rebaptisé 
Section photographique et cinématographique de l'armée (SPCA), le service devient le propriétaire exclusif de ses épreuves de tournage ${ }^{13}$ et diffuse un hebdomadaire d'actualités intitulé Les Annales de la guerre sur l'ensemble du territoire national et à l'étranger.

\section{L'OPÉRATION ALBERICH OU LE RETRAIT ALLEMAND EN PICARDIE DU 25 FÉVRIER AU 5 AVRIL 1917}

11 Sur le théâtre des opérations, l'année 1916 est marquée par les batailles de la Somme et de Verdun, qui provoquent la perte de centaines de milliers de combattants de part et d'autre. Ces offensives ont saigné une grande partie des effectifs, ce qui entraine d'importantes réorganisations. Du côté français, la fin de l'année 1916 voit les conséquences du changement du commandement, incarné depuis le début du conflit par le général Joseph Joffre. Ce dernier est démis de ses fonctions et remplacé par le général Robert Georges Nivelle, ancien commandant de la $2^{\mathrm{e}}$ armée française. Nivelle, nommé commandant en chef des armées du Nord et du Nord-Est, espère reprendre l'avantage sur les forces allemandes et élabore pour cela un plan d'attaque sur le front de Picardie, de la Somme à l'Aisne. Durant plusieurs semaines, les troupes du groupe d'armées centre (GAC) préparent l'offensive lorsqu'un événement vient changer le déroulement des opérations et bouleverser les projets d'attaque.

12 Au début de l'année 1917, les forces allemandes sont confrontées à plusieurs contraintes stratégiques. Les pertes humaines subies depuis le début de la guerre contraignent le haut-commandement à réduire la longueur du front du Pas-de-Calais et de Picardie, où les saillants de Bapaume et de Roye nécessitent le déploiement d'une grande quantité de troupes et de moyens pour garantir sa défense. Afin de préparer leur retrait stratégique, les Allemands lancent, dans le plus grand secret, dès le mois de septembre 1916, la construction d'une nouvelle ligne défensive, baptisée par les Alliés «ligne Hindenburg » et protégée par des réseaux de blockhaus pour canons et mitrailleuses, ainsi que par de longs réseaux de barbelés. Cette nouvelle ligne, aménagée avec les prisonniers russes et les civils réquisitionnés des régions concernées, s'étend de l'est $d^{\prime}$ Arras au nord de Soissons, en passant par Cambrai et Saint-Quentin ${ }^{14}\left(\right.$ fig. $\left.\mathbf{n}^{\circ} \mathbf{1}\right)$. Elle doit permettre de réduire le front, et donc de diminuer le nombre de combattants nécessaire à sa défense. 


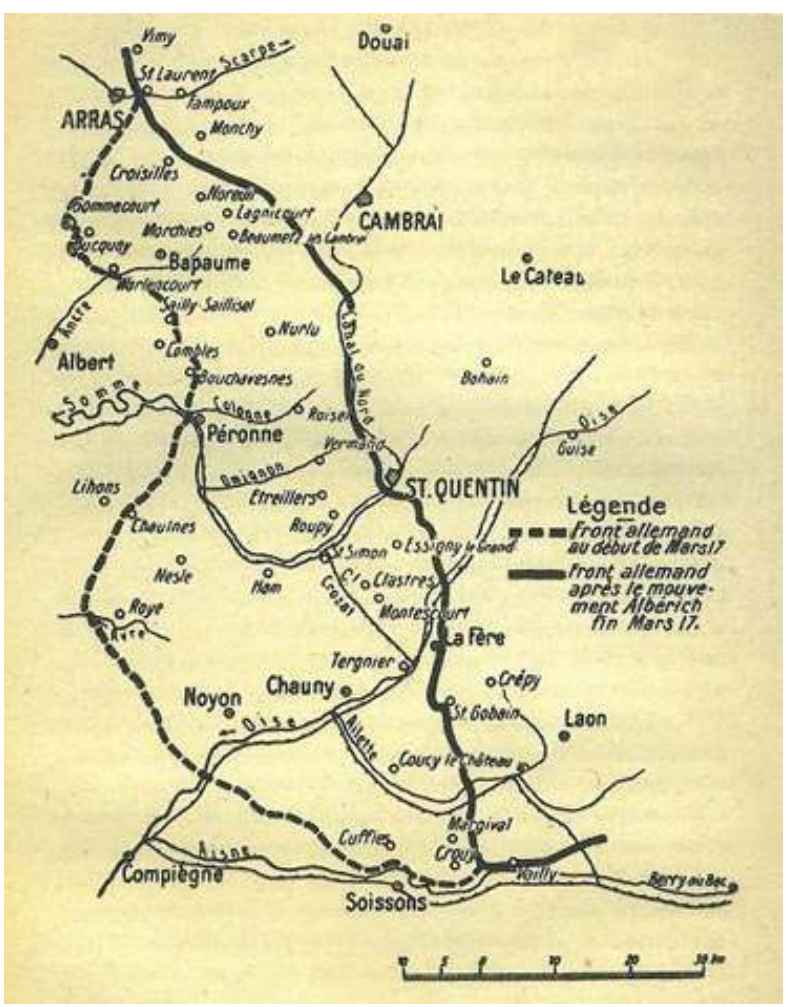

Carte montrant le retrait des forces allemandes de la Somme, l'Oise et l'Aisne, entre le 16 mars et le 7 avril 1917. BUFFETAUT, Yves. Arras, Vimy, Le Chemin des Dames, les grandes offensives du printemps 1977. Paris : éd. Histoire et Collections, 1997, p. 14.

L'opération Alberich, baptisée du nom d'un sorcier légendaire invisible issu de la mythologie germanique, débute le 2525 février 1917 par le retrait progressif des troupes allemandes d'une large partie du Pas-de-Calais, de la Somme, de l'Oise et de l'Aisne. Le commandement laisse des forces d'arrière-garde pour faire croire aux patrouilles alliées et ceci jusqu'au dernier instant - à la présence de ses soldats dans les tranchées. Malgré ces précautions, des doutes apparaissent dans les états-majors alliés où des renseignements collectés grâce à des missions d'observation aériennes et auprès de prisonniers allemands trahissent les préparatifs d'un retrait. Dès le 2 mars, des patrouilles françaises rapportent des mouvements suspects dans les lignes ennemies. Le général Franchet d'Esperey, commandant du GAC alors concerné par cette partie du front, demande au général Nivelle la permission de lancer des attaques destinées à surprendre l'adversaire dans sa retraite. Nul ordre de poursuite n'arrive du Grand Quartier général (GQG), qui reste sceptique sur les intentions de l'armée adverse et poursuit la planification de l'offensive prévue dans ce secteur ${ }^{15}$. Or, ce retrait rend irrémédiablement caduc l'ensemble des plans français. Le 15 mars, devant l'assurance du repli ennemi, l'ordre est donné aux unités du GAC d'engager la poursuite. De leur côté, les forces britanniques de la $4^{\mathrm{e}}$ armée s'élancent en direction de Bapaume, tandis que les troupes de la $3^{\mathrm{e}}$ armée française progressent en direction de Saint-Quentin, libérant tour à tour plusieurs villes de la Somme, de l'Oise et de l'Aisne. Au cours de cette course de cinquante kilomètres, les troupes britanniques et françaises ne parviennent pas à déborder les forces allemandes qui les tiennent en respect. En effet, l'ensemble des ponts et des nœuds 
de communication ont été dynamités par les sapeurs allemands, ralentissant de façon considérable la progression des Alliés.

Un spectacle apocalyptique attend les soldats français et britanniques qui traversent des dizaines de localités en grande partie dévastées. Durant leurs semaines de préparatifs, les troupes allemandes se sont livrées à la destruction systématique des habitations et des infrastructures, afin de ne laisser derrière eux qu'un désert de ruines, où toute installation de troupes sera longue et difficile. Cette tactique de la "terre brûlée", ordonnée par le haut-commandement allemand, vise à priver les forces alliées de tout avantage stratégique en les obligeant à consacrer d'importants moyens pour remettre en état les axes de communication et les localités, les empêchant de ce fait de projeter toute nouvelle offensive. De plus, l'ennemi a dynamité de nombreuses églises, supprimant les postes d'observation que sont les clochers (fig. $\left.\mathbf{n}^{\circ} \mathbf{2}\right)$ (fig. $\left.\mathbf{n}^{\circ} \mathbf{3}\right)$.

Figure 2

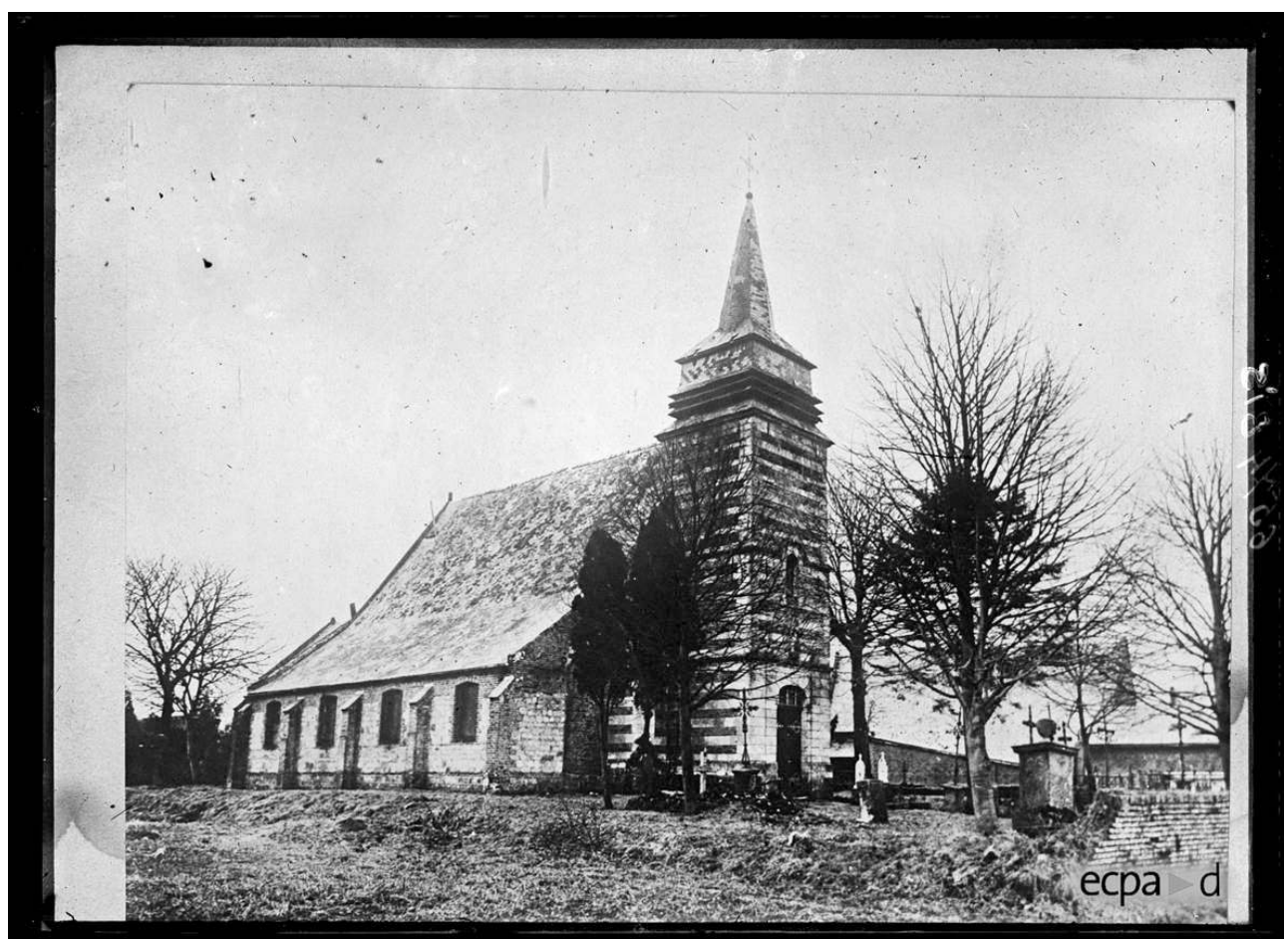

Document allemand. Le dynamitage d'une église picarde.

Phot. Inconnu. (C) ECPAD. Date inconnue. Réf. SPA 101 CT 6574BIS. 


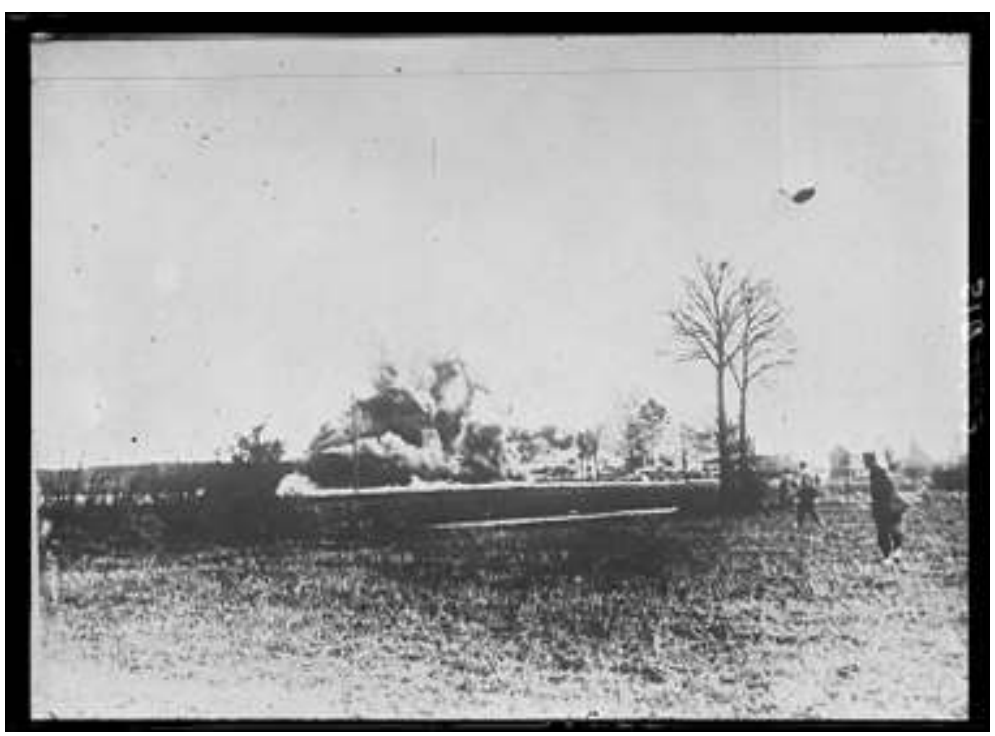

Document allemand montrant le dynamitage d'une église picarde. Phot. Inconnu. ( ) ECPAD. Date inconnue. Réf. SPA 101 CT 6576BIS.

Lors de cette opération de retraite, les habitants des localités occupées par les Allemands connaissent une nouvelle épreuve. Hommes et femmes jugés utiles pour l'effort de guerre allemand - c'est-à-dire susceptibles de servir de main-d'œuvre dans l'agriculture et l'industrie - sont évacués au sein de convois qui partent notamment pour la Belgique. Les personnes âgées, les enfants et les malades, considérés comme des bouches supplémentaires à nourrir, sont abandonnés sur place dans le dénuement (fig. $\left.\mathbf{n}^{\circ} \mathbf{4}\right)$.

\section{Figure 4}

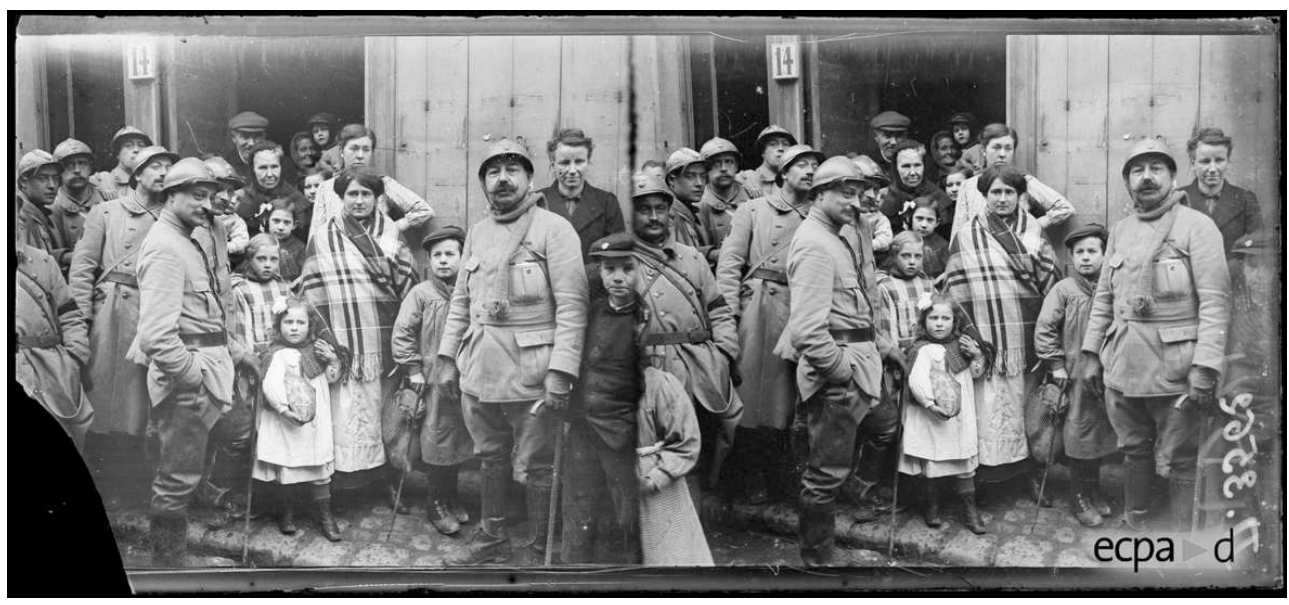

Roye (Somme), civils restés dans la ville.

PHOT. BRISSY, ÉDOUARD. @ ECPAD, 18 MARS 1917. RÉF. SPA 44 D 3562.

Les opérateurs de la SPCA situés en première ligne sur le front de Picardie vont découvrir peu à peu l'ampleur des destructions qui touchent de nombreux trésors d'architecture dans une région au riche patrimoine, notamment ses nombreux édifices gothiques. Ces dommages témoignent de la radicalisation du conflit dans lequel, face à l'imminente entrée en guerre des États-Unis, l'Allemagne sait qu'elle doit redoubler d'efforts en peu de 
temps pour espérer arracher une victoire. Cette stratégie conduit son armée à ne laisser aucun avantage à ses adversaires, dévastant les sols et les habitations susceptibles d'abriter des troupes.

\section{LES ÉQUIPES DE LA SPCA, TÉMOINS DES DESTRUCTIONS DU PATRIMOINE PICARD}

17 La fin de l'année 1916 connaît un relatif retour au calme sur le front de la Somme, marqué par l'immense bataille qui s'est déroulée durant l'été et l'automne. Édouard Brissy, opérateur de la Section photographique de l'armée, est détaché au sein de la $3^{\mathrm{e}}$ armée du général Humbert, chargée de défendre la partie du front qui serpente au niveau des départements de la Somme, de l'Oise et d'une petite partie de l'Aisne. Il opère donc en cette fin d'année 1916 dans la Somme où il réalise, avec René Meunier, caméraman au sein de la Section cinématographique, plusieurs reportages sur la prise du village de Beuvraignes ${ }^{16}$, enjeu d'importants combats. Les deux hommes sont en première ligne lors du déclenchement du repli allemand et, de ce fait, progressent en même temps que les soldats français sur un axe reliant Roye à Saint-Quentin. De mars à avril 1917, ils travaillent côte à côte à la réalisation de reportages consacrés aux destructions, sillonnant les villes de Roye, Noyon, Lassigny, Chauny, jusqu'aux ruines du château de Coucy, dans l'Aisne.

18 À l'instar de ses collègues photographes, l'ensemble de la production d'Édouard Brissy est envoyé au siège de la SPCA à Paris, où le service des archives classe les prises de vues dans la série $\mathrm{D}$. Ces photographies ont été réalisées à partir de négatifs au gélatino-bromure d'argent couché sur des plaques de verre à l'aide de différents formats $(13 \mathrm{x} 18 \mathrm{~cm}, 9 \mathrm{x}$ $12 \mathrm{~cm}$ et $6 \times 13 \mathrm{~cm})$. Au vu de leur nombre, ces deux derniers formats semblent ceux que préfère l'opérateur. Les appareils adéquats peuvent être tenus à main levée et, ne nécessitant pas de trépied, offrent donc une plus grande liberté de mouvement. Beaucoup de clichés suivent d'ailleurs la progression des troupes. En outre, la qualité du rendu obtenue avec ces formats satisfait pleinement aux exigences de la presse.

Quant au matériel de prise de vue utilisé par Édouard Brissy, il ne peut être déterminé avec certitude ${ }^{17}$. Au cours d'un reportage réalisé dans les ruines de la ville de Roye le 18 mars, il est filmé par René Meunier, son collègue caméraman. Il apparaît à l'écran, photographiant des civils et des soldats rassemblés au bord d'un cratère formé par l'explosion d'une mine allemande à un carrefour. L'appareil qu'il tient semble être un Gaumont Spido 1900 stéréoscopique $6 \times 13 \mathrm{~cm}$ (fig. n5). Édouard Brissy réalise une quarantaine d'images montrant l'avancée des soldats français dans les décombres de la ville, ainsi que les rencontres avec la population restée sur place. Dans ce même reportage, le format $6 \times 13 \mathrm{~cm}$ (fig. $\mathbf{n}^{\circ} \mathbf{6}$ ) lui permet de privilégier les vues panoramiques ${ }^{18}$, qui montrent sans doute mieux l'étendue des destructions allemandes. Le même jour, il photographie son co-équipier filmant un groupe de civils et de soldats posant autour du panneau de la Kommandantur de Roye (fig. $\mathbf{n}^{\circ} 7$ ). René Meunier utilise une caméra Gaumont Chrono négatif $35 \mathrm{~mm}$, datant de $1913^{19}$. Lors de ces missions, le caméraman emporte avec lui un trépied, robuste et facilement pliable, ainsi que dix magasins pouvant contenir chacun une bande de film d'une longueur de cent vingt mètres, qui permet d'impressionner environ cinq minutes d'images. 
Figure 5

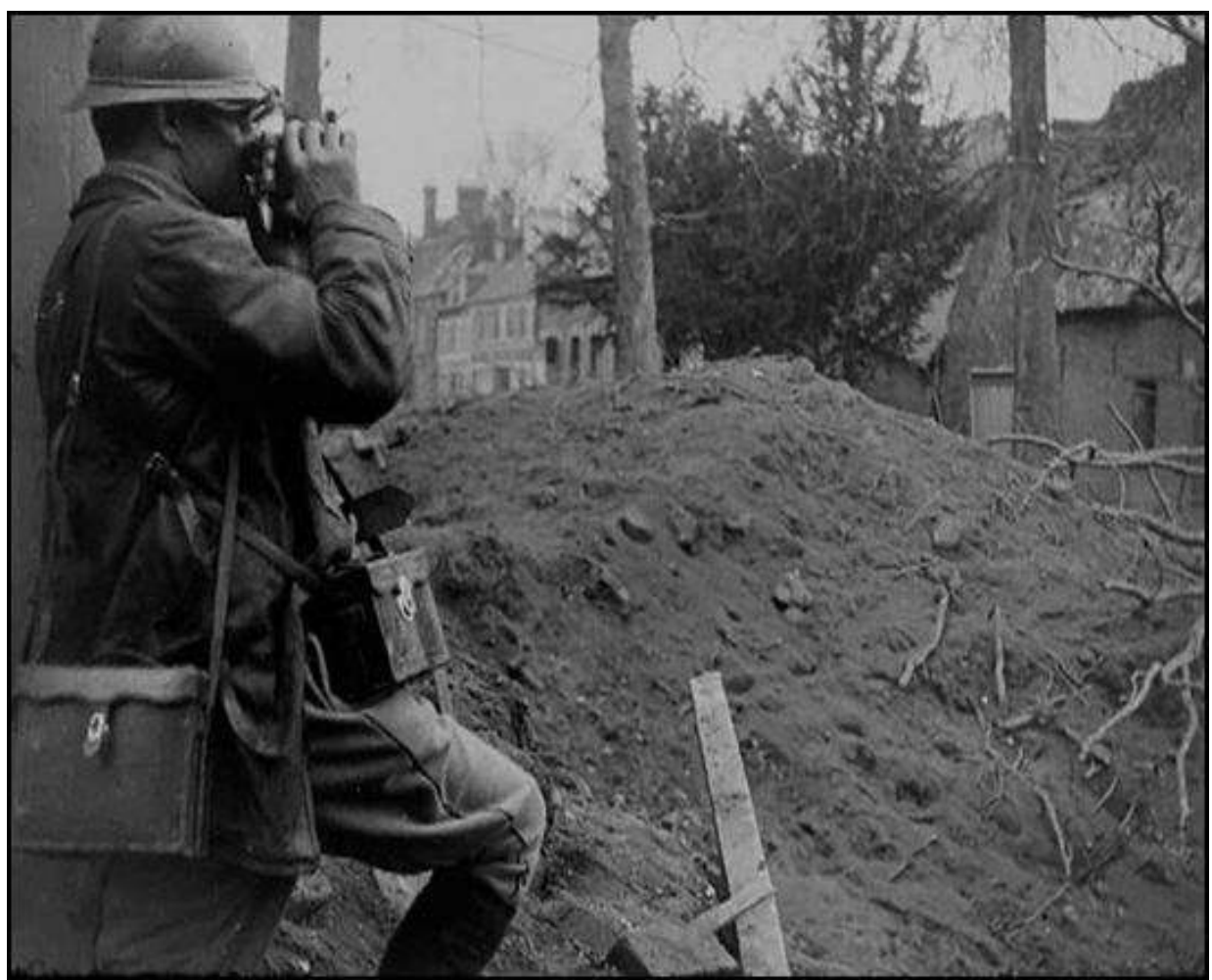

Extrait du film Dans les ruines de Roye libérée. Réal. SCA. Opé. René Meunier. (c) ECPAD. 18 mars 1917. Réf. 14.18 A 290 (tci 00 :04:22).

\section{Figure 6}

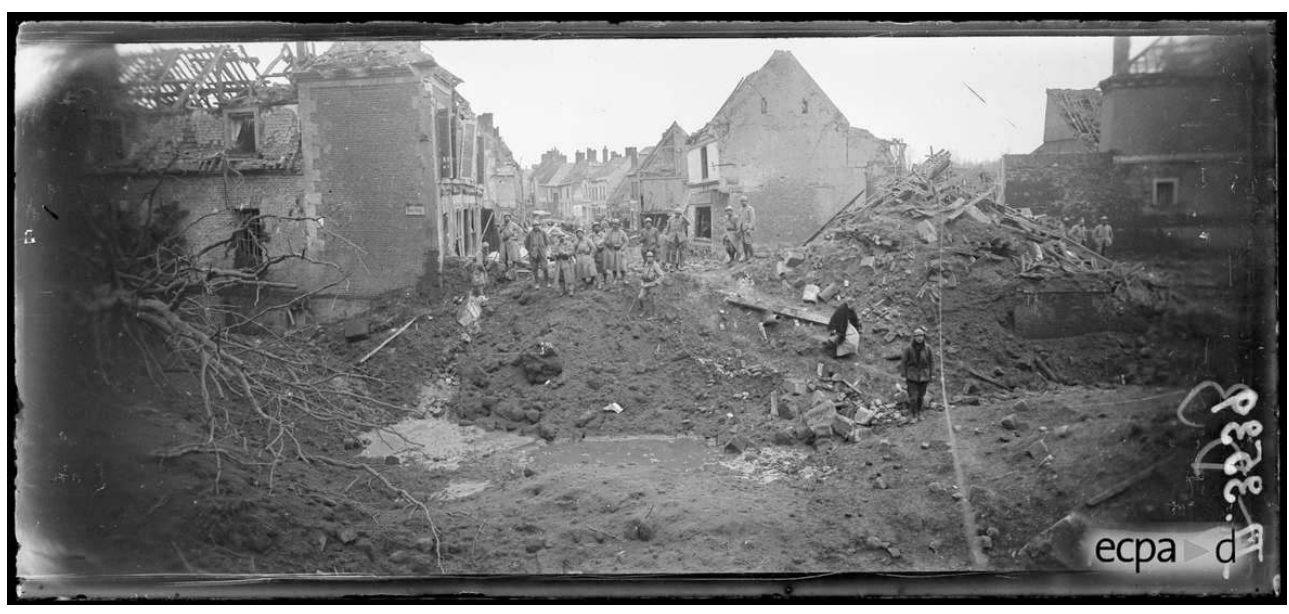

Roye (Somme), cratère à l'entrée de la ville.

PHOT. BRISSY, ÉDOUARD. @ ECPAD. 18 MARS 1917. RÉF. SPA 44 D 3539. 


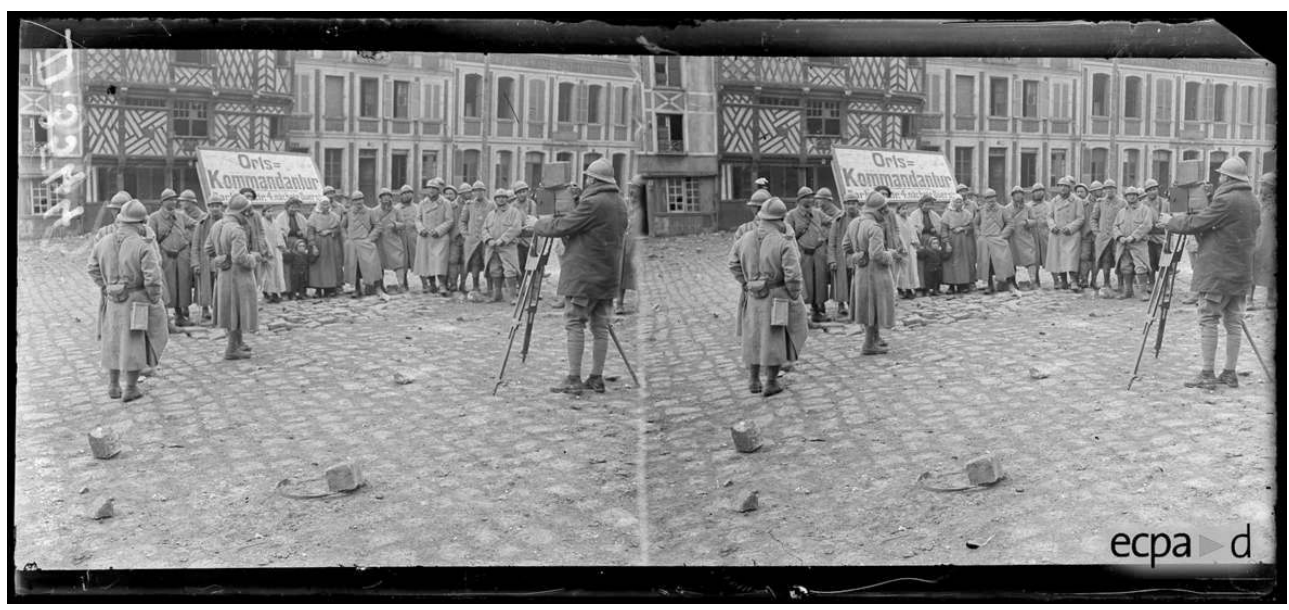

L'opérateur Meunier en action dans la ville de Roye libérée.

Phot. Brissy, Édouard. (c) ECPAD. 18 mars 1917.Réf. SPA 44 D 3544.

L'annonce par la presse du repli des troupes allemandes fait figure de première victoire dans l'opinion publique. Présenté comme l'aveu d'un échec, cet épisode de la guerre est massivement relayé dans les quotidiens français et étrangers. Ainsi, Édouard Brissy et René Meunier, qui ont suivi les premières heures de la progression française, sont-ils rapidement rejoints par d'autres opérateurs, dont Alfred Machin ${ }^{20}$. Caméraman expérimenté de la firme Pathé, il est l'un des quatre premiers opérateurs à intégrer la SCA lors de sa création au printemps 1915. Au début du mois de mars 1917, il est présent dans le secteur de Montdidier, dans la Somme, lorsque l'annonce du repli est effective. Immédiatement, il rejoint l'équipe Brissy-Meunier, arrivant pour couvrir la visite du président de la République Raymond Poincaré à Noyon, le 24 mars 1917. Il reste ainsi plus de deux mois dans la région dévastée pour montrer les ruines laissées par l'ennemi, filmant notamment les décombres de la forteresse médiévale de Coucy-le-Château dans l'Aisne. En reconnaissance de ce travail de prise de vue, Alfred Machin est cité à l'ordre de la $3^{\mathrm{e}}$ armée française. Enfin, l'opérateur Maurice Boulay (série BO), présent dans la ville de Compiègne pour rendre compte du crash d'un zeppelin allemand, rejoint la première équipe pour témoigner, dans un reportage ${ }^{21}$ d'une centaine de clichés, des destructions commises dans la ville de Noyon. 


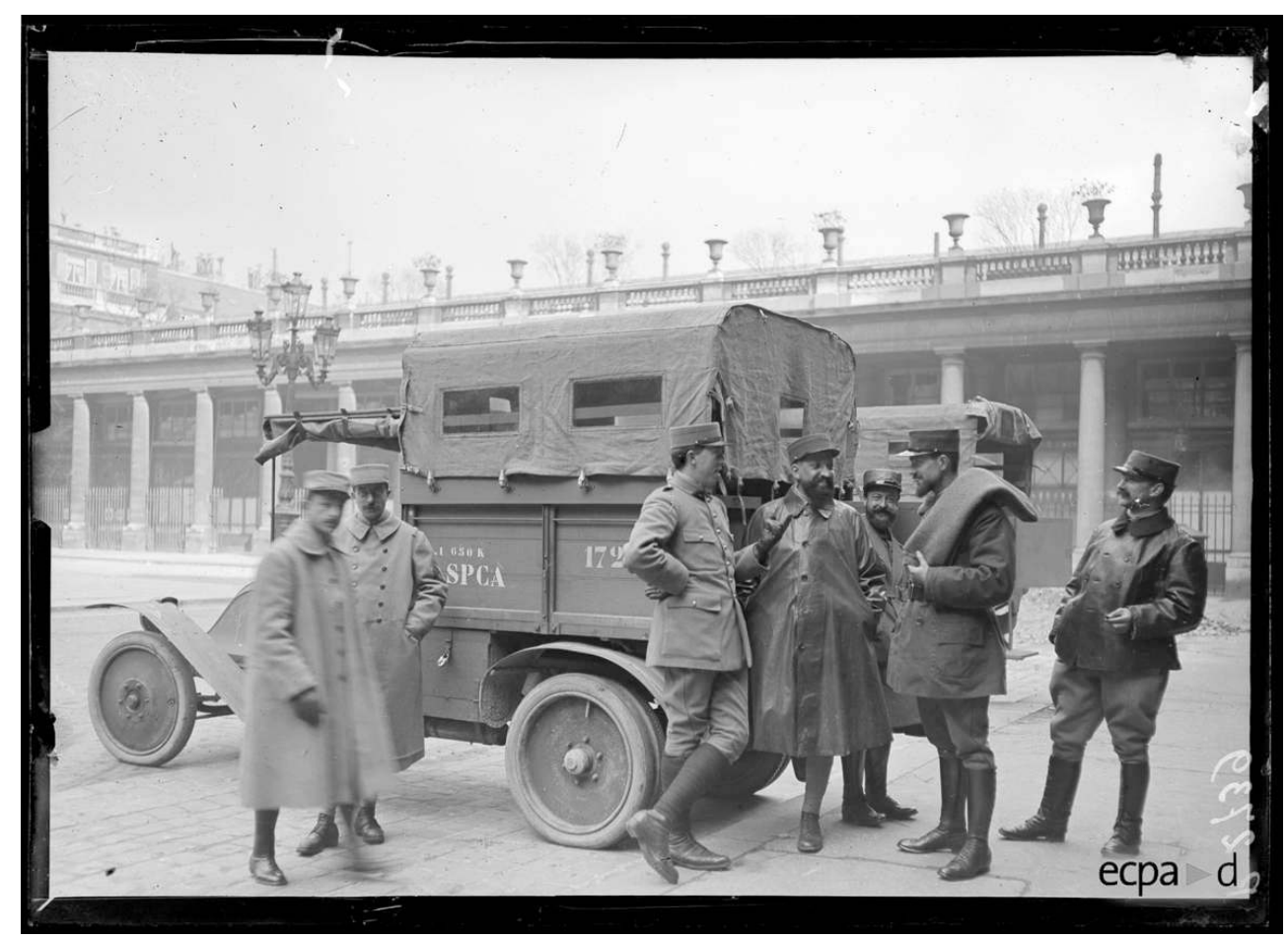

Départ des camionnettes de la SPCA pour les armées.

Phot. Famechon, Edmond. (c) ECPAD. 22 mars 1917. Réf. SPA 69 R 2739.

Cependant, face à l'ampleur des destructions, une seconde équipe, composée des photographes Paul Queste (série B) et Albert Moreau (série M), est dépêchée dans la région dès le 22 mars 1917 (fig. $\mathbf{n}^{\circ} \mathbf{8}$ ). Elle arrive le lendemain à Noyon pour préparer la visite présidentielle. Après plusieurs aller-retours avec la capitale, Paul Queste (fig. $\mathbf{n}^{\circ} \mathbf{9}$ ) réalise quatre autres reportages qui comprennent chacun une centaine d'images. Du 22 mars au 10 avril 1917, il traverse les villes de Roye, Ham, Lassigny, Chauny et Soissons ainsi que le village de Tracy-le-Val, dont les alentours sont dévastés, fixant sur négatifs 13 $\mathrm{x} 18 \mathrm{~cm}$ les bâtiments endommagés et l'aspect des anciens lieux de combat. Aux mêmes dates, l'opérateur Albert Moreau photographie ${ }^{22}$ les ruines situées en secteur britannique, dans les environs d'Albert et de Péronne, libérée par les troupes australiennes le 18 mars. Il accompagne précisément la visite de la région de Péronne par Albert Dalimier, soussecrétaire d'État aux Beaux-Arts et Paul Léon, chef de la division d'Architecture au soussecrétariat d'État, venus constater les dégâts commis sur le patrimoine architectural. Le 24 mars, le groupe arpente l'ancien champ de bataille de Tracy-le-Val, dans l'Oise, au nord de Compiègne. Après un retour à Paris, Albert Moreau réalise un second reportage ${ }^{23}$ en Picardie, photographiant sur plaque $13 \times 18 \mathrm{~cm}$ les paysages dévastés des alentours de Ham, Chauny, Tergnier, Lassigny, Thiescourt ou encore de l'abbaye d'Ourscamp, au sud de Noyon. 
Figure 9

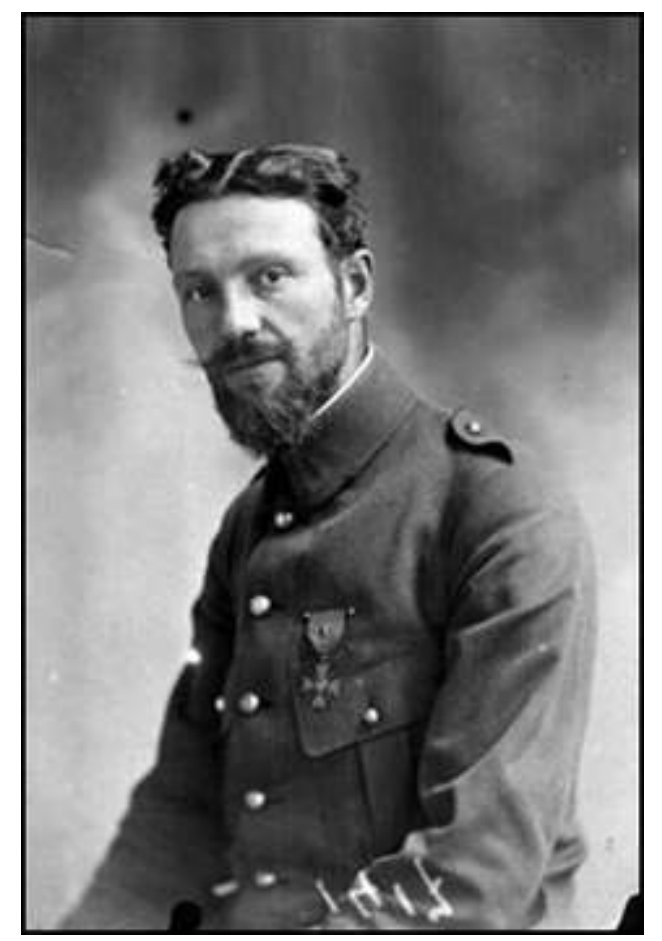

Portrait de l'opérateur photographe Paul Queste. Non daté.

(C) Archives photographiques de l'ECPAD.

Au cours de l'été et de l'automne 1917, plusieurs photographes de la SPCA liés au travail d'inventaire en images des Archives de la planète ${ }^{24}$ réalisent des reportages en noir et blanc et en couleur sur les destructions de Picardie. Plusieurs photographes qui officient pour Albert Kahn se retrouvent enrôlés dans la SPCA, à travailler à la fois pour les Archives de la planète et pour l'armée. Parmi eux figurent Edmond Famechon et Fernand Cuville. Ils sont alors amenés à réaliser un reportage sur les destructions provoquées par la guerre et lors de la retraite allemande en Picardie.

Edmond Famechon (série R) réalise entre les mois de mai et juin 1917 plus d'une centaine de documents montrant les dégradations des secteurs de Roye, Nesle, Ham, Flavy-leMartel, Champien, Tergnier, Chauny, Noyon et Guiscard. Il s'attarde particulièrement sur les destructions commises dans les usines de Roye et les nombreuses sucreries que compte la région. La mise à sac des exploitations agricoles est également soulignée dans ces reportages où il photographie en noir et blanc du matériel saboté par les Allemands. En juin 1917, il se rend dans le village de Sermaize, au nord-ouest de Noyon dans l'Oise, où il photographie une famille d'agriculteurs posant à côté de ses machines saccagées par les soldats ennemis (fig. $\left.\mathbf{n}^{\circ} \mathbf{1 0}\right)$. 
Figure 10

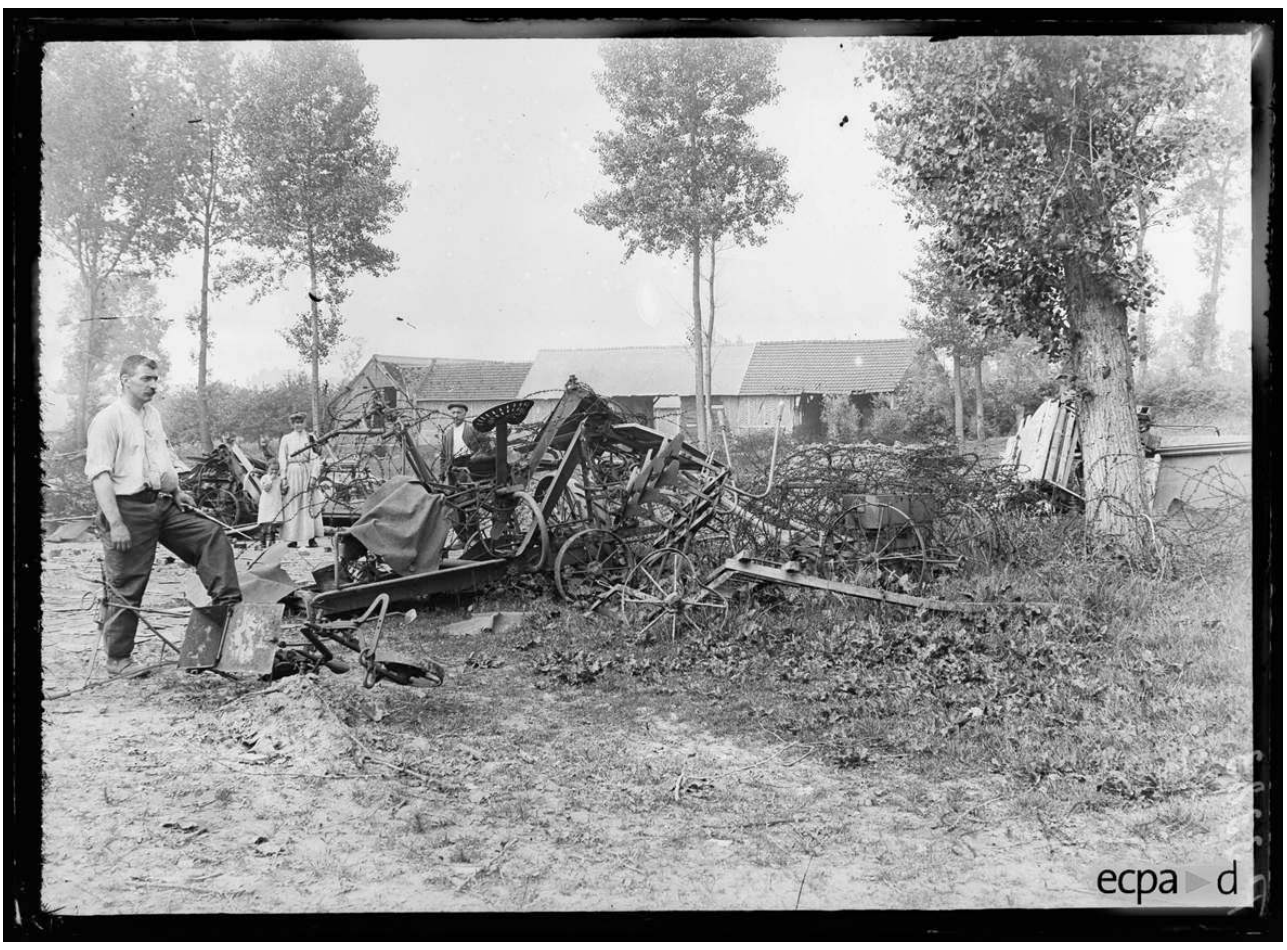

Sermaize (Oise), instruments agricoles détruits par les Allemands.

PHOT. FAMECHON, EDMOND. (C ECPAD. JUIN 1917. RÉF. SPA 92 R 3383.

Fernand Cuville participe aussi à cette entreprise. Il saisit en couleur à l'aide de plaques autochromes Lumière ${ }^{25}$ les ruines de Picardie et son patrimoine abîmé ou resté miraculeusement intact. Entre le 20 septembre et le début du mois d'octobre 1917, il sillonne à son tour les villes de Noyon, Chauny et Tergnier, où il réalise une centaine de documents en couleur. À Noyon, il photographie la cathédrale et la bibliothèque du chapitre restées intactes (fig. $\left.\mathbf{n}^{\circ} \mathbf{1 1}\right)$ (fig. $\left.\mathbf{n}^{\circ} \mathbf{1 2}\right)$. À Chauny, où les destructions ont été systématiques, il saisit les décombres de la mairie, du palais de justice et de l'église SaintMartin au clocher dynamité (fig. $\mathbf{n}^{\circ} \mathbf{1 3}$ ). 
Figure 11

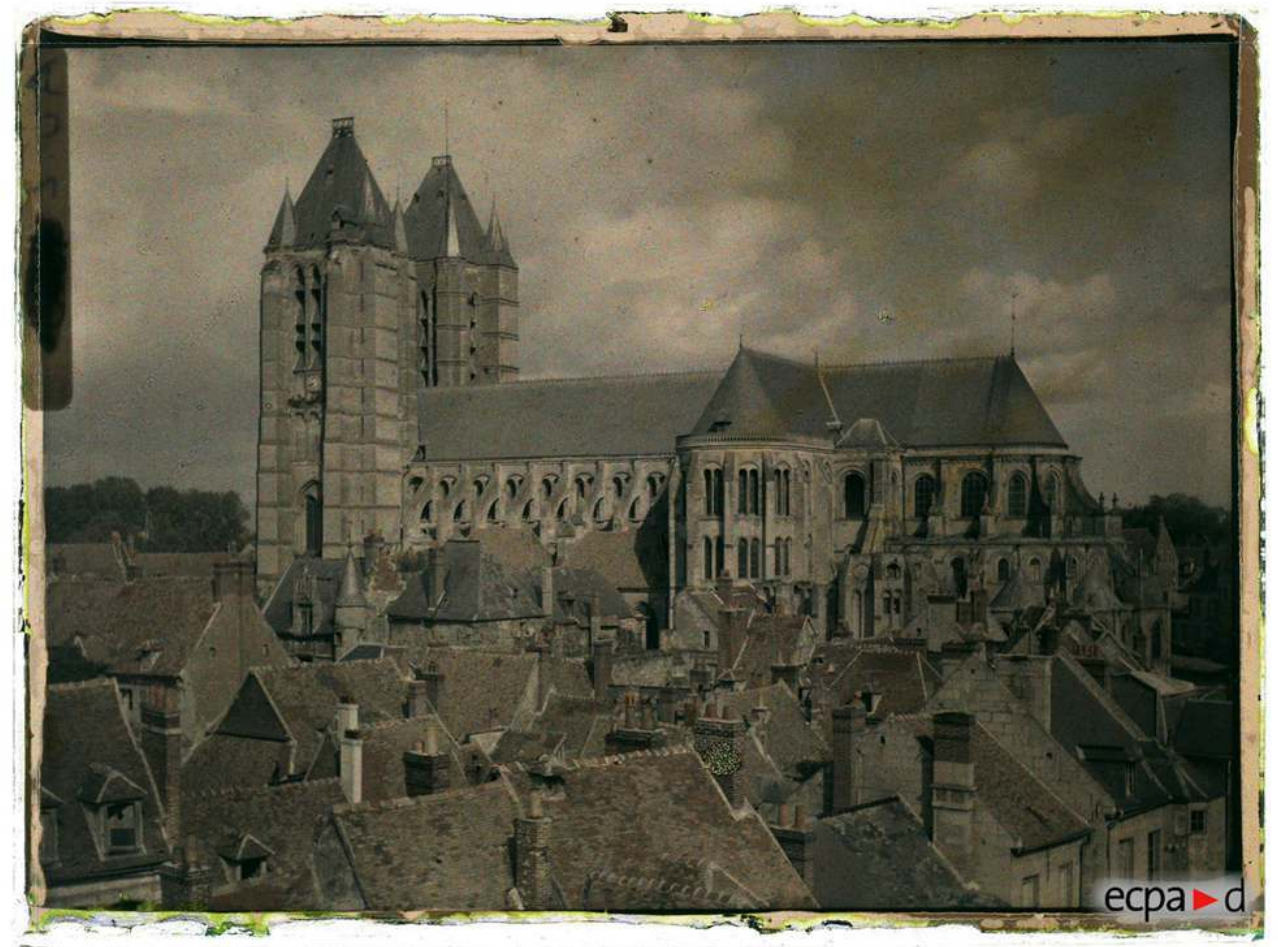

Noyon (Oise), cathédrale, vue extérieure.

Phot. Cuville, Fernand. ( ) ECPAD. 5 octobre 1917. Réf. AUL 455 
Figure 12

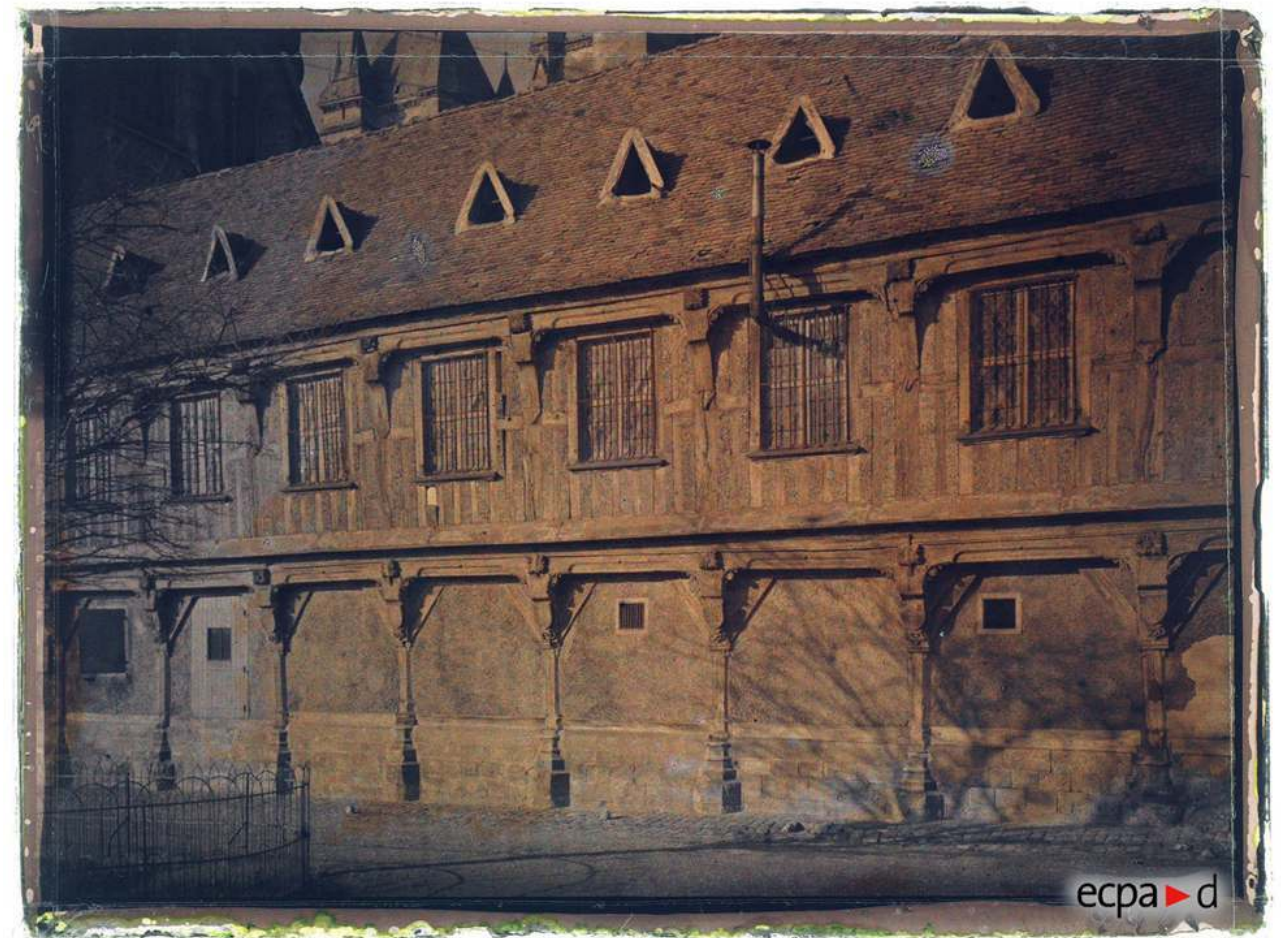

Noyon (Oise), bibliothèque du chapitre.

Phot. Cuville, Fernand. (C) ECPAD. 5 octobre 1917. Réf. AUL 549. 


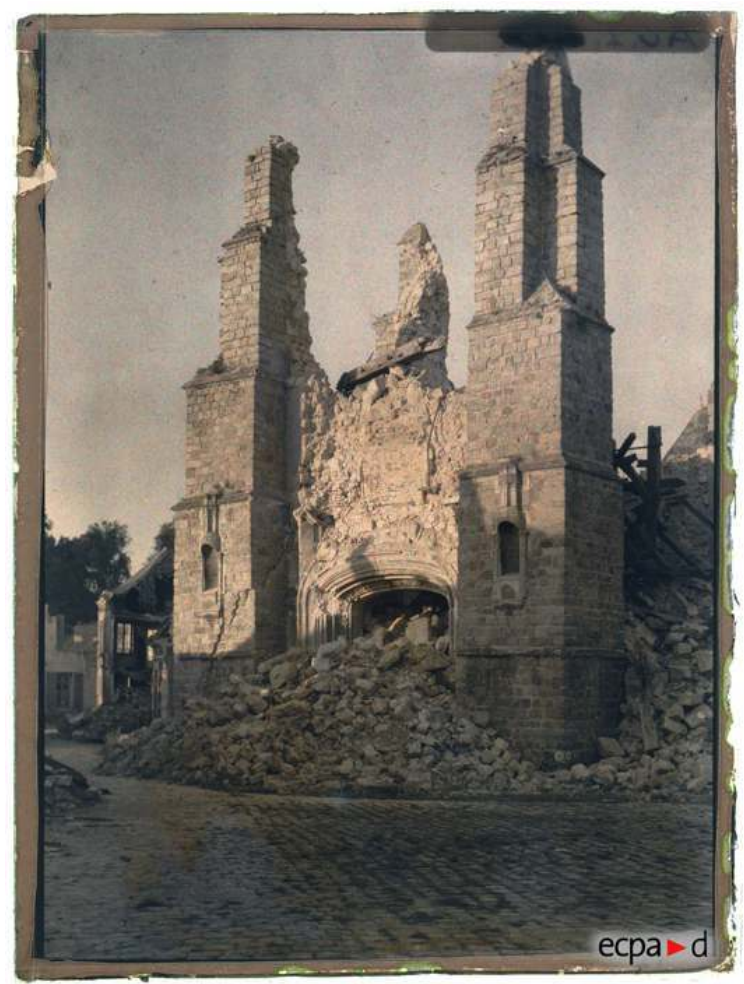

Chauny (Aisne), clocher de l'église Saint-Martin.

Phot. Cuville, Fernand. (c) ECPAD. 24 septembre 1917. Réf. AUL 429.

Bien qu'ils traitent tous des mêmes sujets, chacun des opérateurs envoyés sur le front de Picardie au lendemain de l'opération Alberich a sa méthode de travail, qu'il adapte aux lieux et au contexte opérationnel. Ainsi, dans les premiers reportages réalisés au début du repli, entre les mois de mars et avril 1917, les photographes utilisent essentiellement des négatifs sur plaques de taille $6 \times 13 \mathrm{~cm}$ et $9 \times 12 \mathrm{~cm}$, plus légers. Ils ont en effet besoin de se mouvoir parmi les régiments engagés dans la poursuite des forces allemandes. Comme on peut le constater dans le travail laissé par les opérateurs Édouard Brissy et Maurice Boulay, les négatifs $6 \times 13 \mathrm{~cm}$ et les appareils qui les contiennent autorisent la prise de vue panoramique. Ce type d'images permet de mieux rendre compte, sur un même cliché, de l'ampleur de la catastrophe. Dans le reportage laissé par Maurice Boulay, les vues panoramiques montrent les habitants de Noyon et les soldats français s'attelant à la remise en état des voies de circulation dynamitées par les Allemands. D'immenses explosions ont emporté les carrefours routiers, détruisant les maisons environnantes (fig. $\mathbf{n}^{\circ} \mathbf{1 4}$ ). Sur une autre vue, les allées d'arbres centenaires qui encadraient certaines rues ont été coupées, écrasant dans leur chute plusieurs toitures de maisons (fig. $\mathbf{n}^{\circ}{ }^{15}$ ). Dans une seconde phase chronologique, de mai à novembre 1917, marquée par la fin de la progression des Alliés et la reprise de la guerre de position, les opérateurs de la SPCA se voient confier des missions d'inventaire photographique des destructions engendrées par la guerre. Les négatifs de dimension $13 \times 18 \mathrm{~cm}$, plus adaptés aux prises de vues de paysages, sont davantage utilisés. Les opérateurs cinématographes suivent les pas de leurs collègues, en ayant recours à des plans panoramiques qu'ils enchaînent à la suite de plans de situation. 
Figure 14

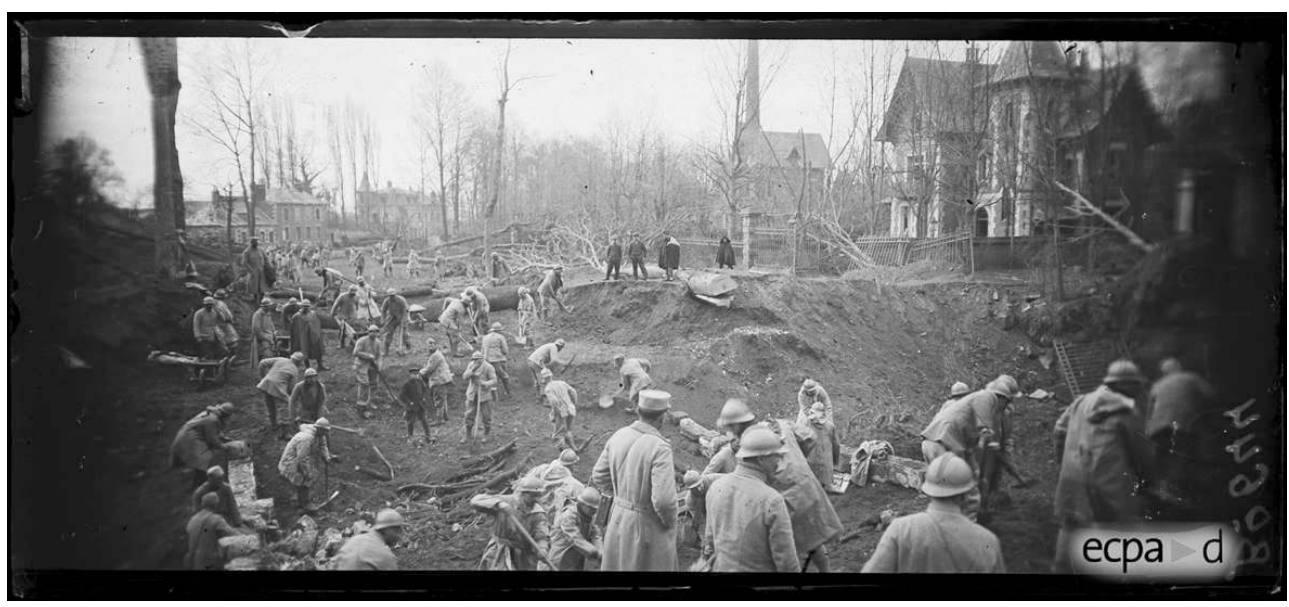

NOYON (OISE), LE BOULEVARD CARNOT dÉFONCÉ PAR LES MINES ALLEMANDES. SOLDATS dU gÉNIE TRAVAILLANT AU RÉTABLISSEMENT DE LA ROUTE.

Phot. Boulay, Maurice. (C) ECPAD. 20 mars 1917. Réf. SPA 11 BO 644.

Figure 15

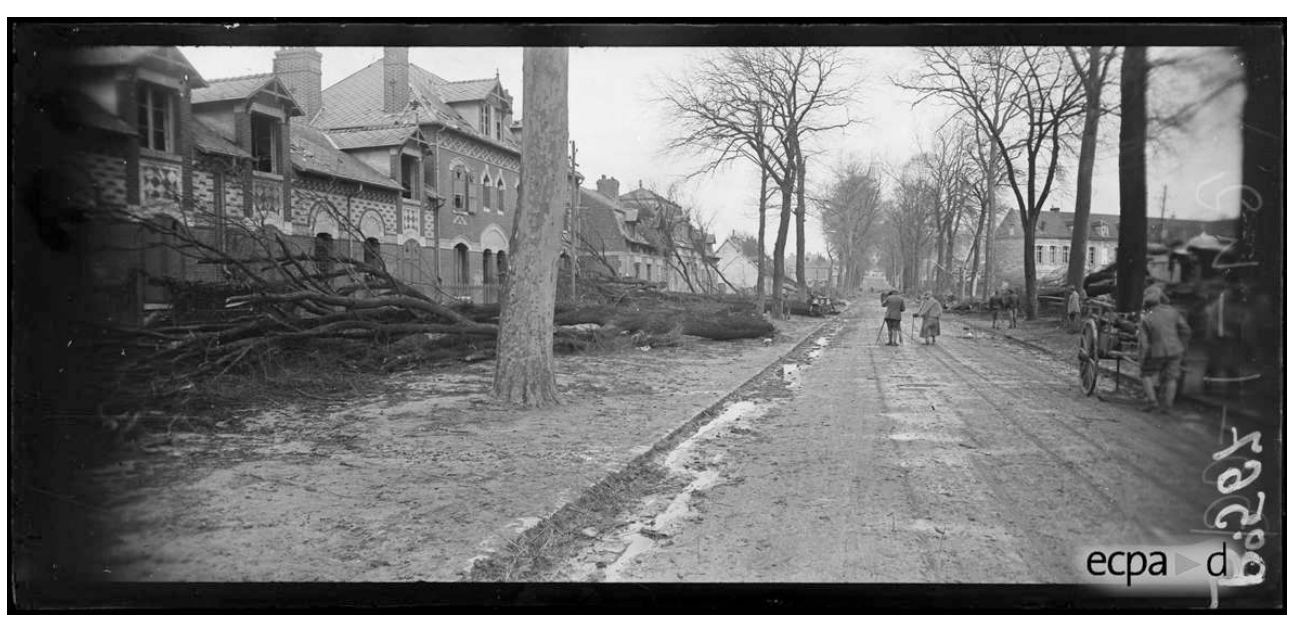

Noyon (Oise), arbres abattus le long d'un boulevard.

Phot. Boulay, Maurice. (c) ECPAD. 20 mars 1917. Réf. SPA 11 BO 567.

\section{Picardie, 1917 : inventaire d'un patrimoine en péril et des vestiges de la guerre}

Omniprésent dans la mission des opérateurs, l'inventaire du patrimoine en péril trouve une résonance particulière en Picardie, l'une des régions les plus touchées du nord et de l'est de la France ${ }^{26}$. Les chiffres fournis par le ministère des Régions libérées sont éloquents ${ }^{27}$. Le département de l'Aisne compte 139 villages entièrements détruits, 461 qui le sont à $50 \%$ et 235 partiellement endommagés. L'Oise compte six localités complètement rasées, 205 détruites à $50 \%$ et 381 endommagées. Quant au département de la Somme, on y dénombre 109 villes et villages entièrement ruinés, 184 détruits à $50 \%$ et 88 endommagés. Les édifices religieux de la région ont particulièrement souffert, avec 
plus de huit cents églises anéanties ou endommagées ${ }^{28}$. Face à l'ampleur des destructions, les reporters de la SPCA sont mobilisés pour dresser un catalogue illustré des localités et de leur patrimoine historique et culturel menacé de disparition.

\section{LA SPCA DANS L'ACTION DE SAUVEgARDE DU PATRIMOINE DÉVASTÉ}

Les reportages de la SPCA contiennent donc un nombre important d'images d'édifices religieux ou civils présentant un intérêt historique ou architectural, menacés de disparition. Dresser l'inventaire des monuments en péril ou détruits fait intrinsèquement partie des missions de la SPCA, et ceci depuis sa création au printemps $1915^{29}$. En effet, la Section fonctionne également en accord et avec le concours de son deuxième organisme de tutelle, le ministère de l'Instruction publique et des Beaux-Arts. Ce dernier oriente considérablement le travail des opérateurs militaires, les invitant à dresser un état des lieux en images des localités ruinées par la guerre. Cette action a pour but de constituer non seulement un témoignage destiné à montrer aux générations futures l'ampleur des destructions mais également de préparer les chantiers de restauration et de reconstruction des monuments et habitations détruits par le feu de l'artillerie alliée et allemande. Le sous-secrétariat d'État aux Beaux-Arts, dirigé par Albert Dalimier, organise plusieurs visites des territoires touchés. Assisté de Paul Léon, chef de la division d'Architecture, Albert Dalimier se rend une première fois en mars 1917 dans la Somme, où il constate l'importance des dégâts dans les villes de Péronne, Roye et Ham. Au mois de septembre 1917, il revient sur les lieux des destructions allemandes, accompagnant une délégation du ministère de l'Instruction publique et des Beaux-Arts espagnol dans les ruines de l'église de Tracy-le-Val, dans l'Oise. Ces deux visites sont couvertes par l'opérateur Albert Moreau (fig. $\mathbf{n}^{\circ} \mathbf{1 6}$ ). 


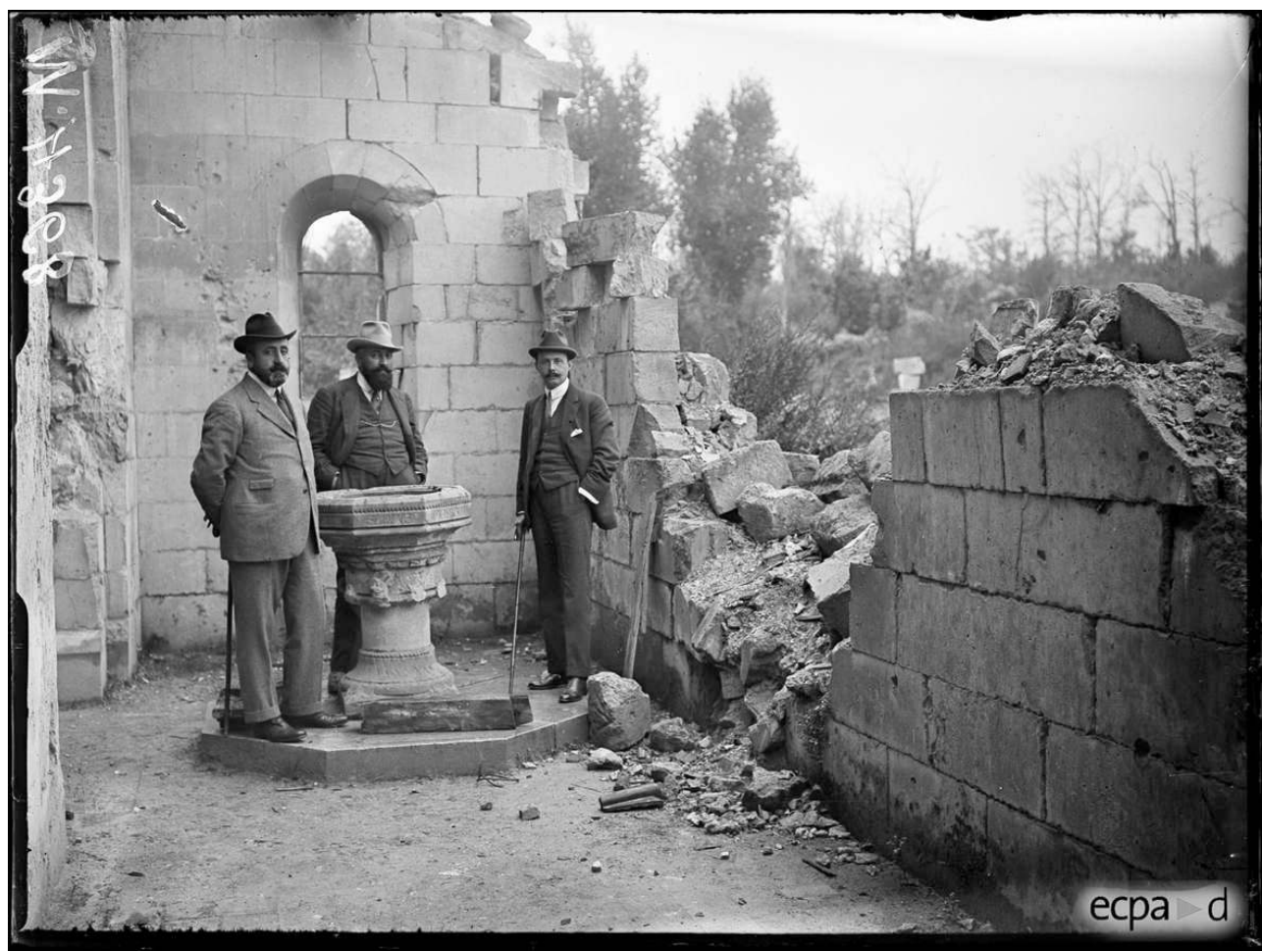

Tracy-le-Val (Oise), visite d'Albert Dalimier, sous-secrétaire d'État aux Beaux-Arts et du ministre espagnol des Beaux-Arts.

Phot. Moreau, Albert. ( ) ECPAD. 20 septembre 1917. Réf. SPA 221 M 4368.

Au cours du printemps et de l'été 1917, la mission d'inventaire du patrimoine dévasté se renforce. Elle prend notamment une nouvelle dimension avec les édifices religieux qui deviennent des sujets imposés (incontournables) pour les opérateurs de la SPCA. Datée du 13 juillet $1917^{30}$, une note édictée par le lieutenant Pierre-Marcel Lévi, devenu chef de la SPCA, ordonne que chaque église de la zone de guerre soit photographiée. Elle stipule que les opérateurs doivent prendre des vues extérieures et intérieures du bâtiment, ainsi que des détails d'architecture tels que les voûtes, les charpentes, les piliers, et également des éléments de décoration avec les statues, les bas-reliefs et le mobilier. La note se termine ainsi :

En ce qui concerne plus spécialement les églises très endommagées [...], les photographies devront représenter non seulement les parties en ruine, mais également celles qui subsistent plus ou moins détériorées. Ces derniers clichés renseignent la possibilité d'une restauration ultérieure du monument.

L'imposant travail de prise de vue mené dans les églises de Picardie - réalisé pendant toute la guerre et non pas seulement à l'occasion du repli allemand de mars 1917 entraine la production de plus d'un millier de photographies ${ }^{31}$, documentant de façon précise l'extérieur et l'intérieur des édifices religieux endommagés. Au lendemain de l'opération Alberich, les opérateurs français accentuent leur effort, multipliant les images d'églises en ruine, d'autels et de chœur éventrés, ou des éléments de décor à jamais défigurés par les obus. À l'instar d'autres opérateurs, Paul Queste saisit les ruines de l'église de Liancourt-Fosse dans la Somme, montrant son intérieur dévasté par les bombes (fig. $\left.n^{\circ} 17\right)$. 


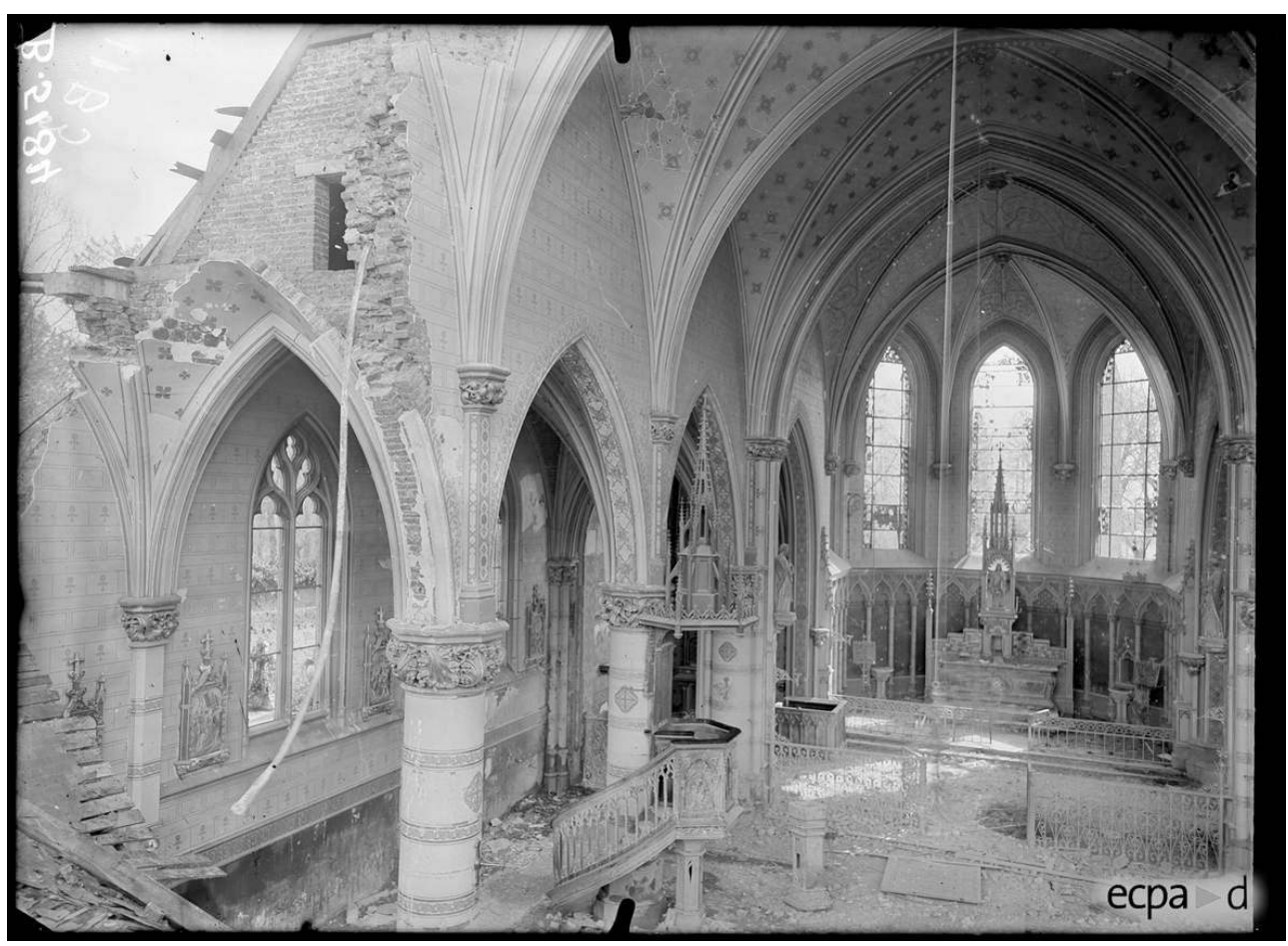

Liancourt-Fosse (Somme), le chœur de l'église.

Phot. Queste, Paul. (C) ECPAD. 10 avril 1917. Réf. SPA 93 B 5184.

Le travail d'inventaire initié par le sous-secrétariat d'État aux Beaux-Arts est soutenu par l'influence considérable exercée par les Archives de la planète, entreprise dirigée par Albert Kahn avec le concours du géographe Jean Brunhes. Amorcé dès 1909, ce projet a pour ambition de constituer un fonds d'archives photographiques et cinématographiques qui rassemble les images qui témoignent des activités humaines et des modes de vie traditionnels appelés à disparaître ou à s'adapter face à l'émergence d'une modernité apportée par l'ère industrielle. La fondation des Archives de la planète s'associe donc à la SPCA en fournissant à celle-ci des opérateurs qui participent aux campagnes de prises de vues de Picardie. Ces derniers apportent un regard sur les paysages de ruines qu'ils saisissent sur plaques de verre.

Les séries d'images en noir et blanc exécutées par Edmond Famechon, ou en couleur par Fernand Cuville, dans le Soissonnais et dans le Noyonnais entre l'été et l'automne 1917, reflètent parfaitement l'état d'esprit qui guide les opérateurs des Archives de la planète dans leur travail. Fruit de la réflexion menée par Jean Brunhes en 1910 dans son ouvrage intitulé La Géographie humaine : essai de classification positive, cette pensée fut synthétisée par Emmanuel de Martonne dans une nécrologie de Jean Brunhes publiée dans les Annales de géographie en 1930 :

Sa conception de la géographie est celle d'un professeur de géographie physique, curieux de tous les faits économiques et d'un observateur de cas concrets. Il envisage l'empreinte de l'activité humaine sur la surface de la planète plutôt que l'homme lui-même : maisons, chemins, villes, cultures, etc. plutôt que les races et les mœurs. Il cherche dans tous les faits observés l'influence du milieu plutôt que le terme d'une évolution dont le passé donne la clef ${ }^{32}$. 
Cette démarche humaniste se ressent dans le travail laissé par les photographes de l'armée, notamment Paul Queste et Édouard Brissy, ou les cameramen René Meunier et Alfred Machin. Les paysages qu'ils fixent sur plaque de verre ou sur pellicule témoignent du cataclysme subi par la Picardie et sa population, qui a perdu une grande partie de son patrimoine historique et économique. Lors de la réalisation de son reportage dans la ville de Tergnier en mars 1917, Édouard Brissy est frappé par l'immensité des ruines d'une cité qui comptait avant la guerre plus de huit mille habitants. Il photographie la rue de la Gare où seul subsiste un panneau indicateur déposé par les troupes allemandes, donnant à la scène la mesure des dévastations subies par cette ville de l'Aisne (fig. $\mathbf{n}^{\circ} \mathbf{1 8}$ ). Un autre exemple éloquent est celui laissé par l'opérateur Albert Moreau, qui montre la camionnette de la SPCA à l'arrêt sur une route dont les arbres ont été sciés par l'ennemi (fig. $\left.n^{\circ} 19\right)$.

Figure 18

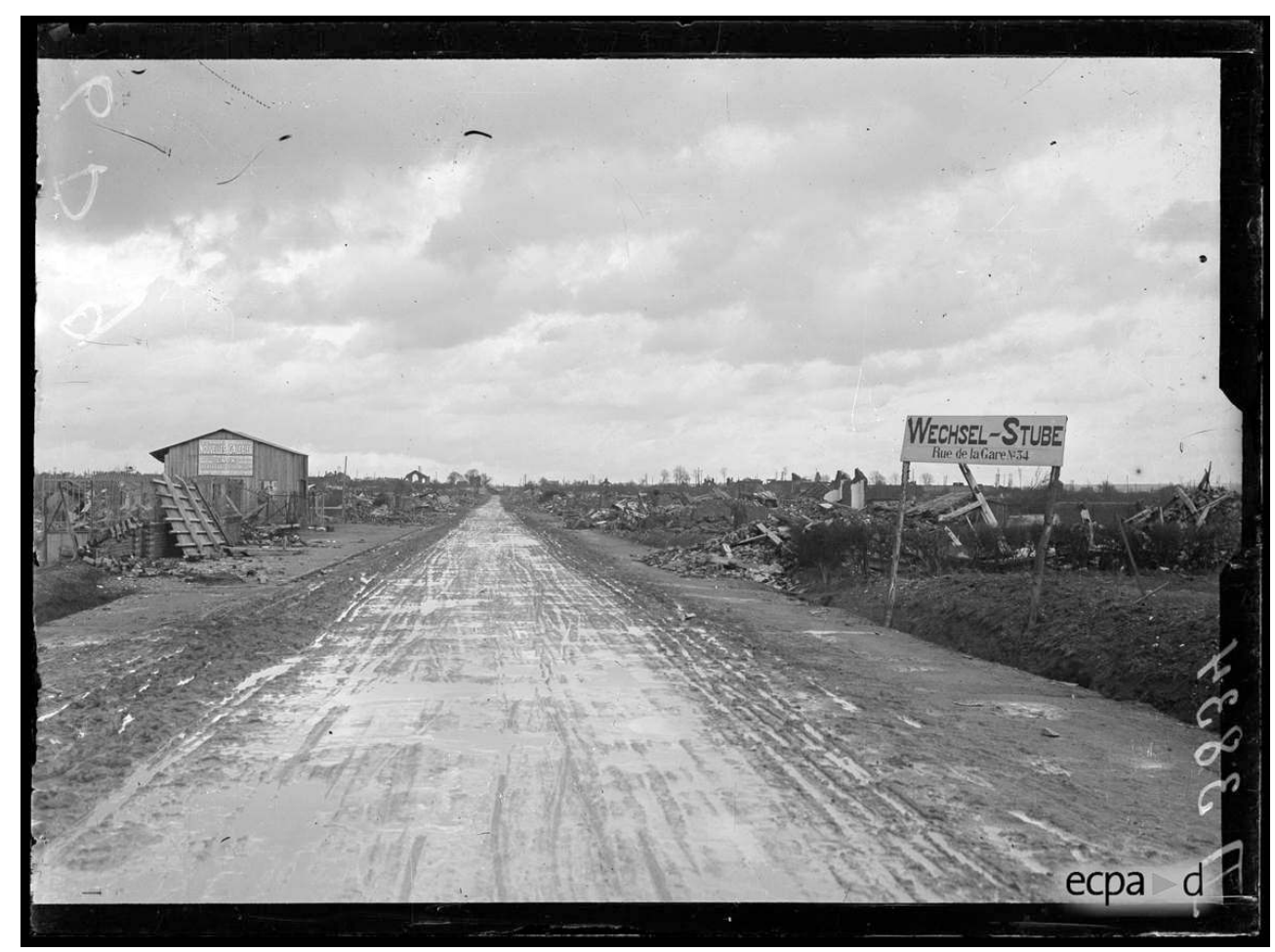

Tergnier (Aisne), entrée de la ville en venant de Chauny. Seul l'écriteau allemand subsiste. Phot. Brissy, Édouard. (c) ECPAD. 30 mars 1917. Réf. SPA 50 D 3834. 


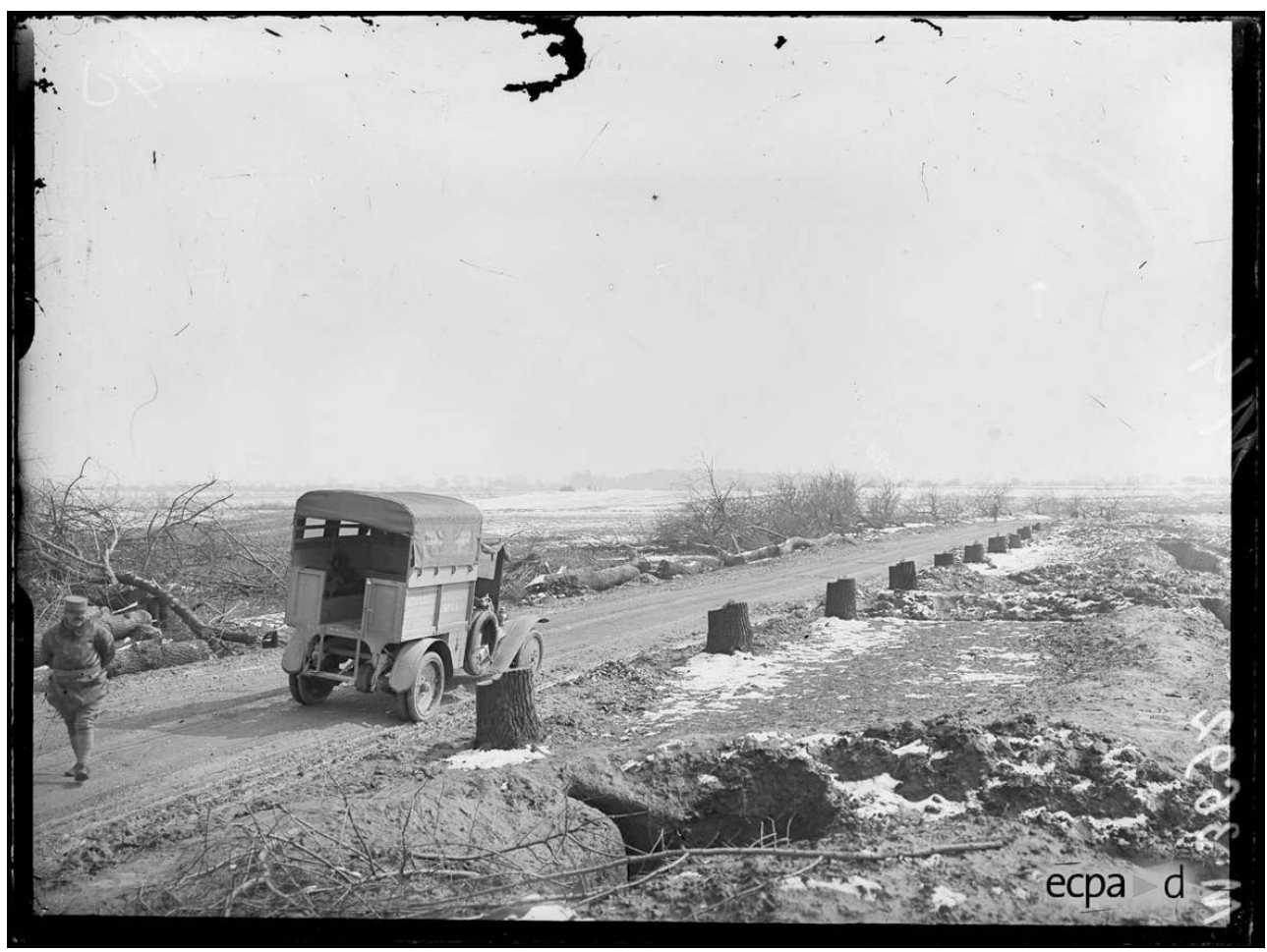

La camionnette de la SPCA sur la route d'Amy à Avricourt (Oise), bordée par des arbres sciés par les troupes allemandes lors de leur retraite.

Phot. Moreau, Albert. (C) ECPAD. 5 avril 1917. Réf. SPA 184 M 3692

Pour compléter ce travail d'inventaire du patrimoine dévasté, le service des archives de la SPCA entreprend, dès sa création, la collecte de plusieurs milliers de cartes postales et d'images provenant de fonds amateurs ou étrangers alors rassemblés dans une collection de contretypes ${ }^{33}$. Cet ensemble forme un fonds documentaire complémentaire aux clichés pris sur le terrain par les professionnels de l'armée. Elle permet, dans le cas de la Picardie, de connaitre l'état initial des monuments et bâtiments des villes et villages de la région avant leur destruction. Certaines images prises avant les bombardements et les pillages, notamment dans les villes de Roye ou de Péronne, dans la Somme, sont éloquentes. La ville de Roye possédait de nombreux monuments historiques : l'église Saint-Pierre ${ }^{34}$ qui datait des $\mathrm{XII}^{\mathrm{e}}, \mathrm{XVI}^{\mathrm{e}}$ et $\mathrm{XVII}{ }^{\mathrm{e}}$ siècles, est en grande partie effondrée lorsque les troupes françaises pénètrent dans la ville. Une carte postale d'avant-guerre (fig. $\mathbf{n}^{\circ} \mathbf{2 0}$ ), conservée sous la forme de contretype, montre l'édifice avant sa destruction partielle, intervenue dès l'hiver 1915 (fig. $\mathbf{n}^{\circ} \mathbf{2 1}$ ). Autre exemple, l'hôtel de ville de Péronne (fig. $\mathbf{n}^{\circ} \mathbf{2 2}$ ) : datant du XVI ${ }^{\mathrm{e}}$ siècle, il abritait les collections du musée Alfred-Danicourt ${ }^{35}$ et a été totalement éventré par les bombardements alliés après avoir subi la mise à sac des soldats allemands. Une pancarte laissée par ces derniers accueille les soldats britanniques par ces mots: Nicht ärgern, nur wundern ${ }^{36}$ (fig. $\mathbf{n}^{\circ} \mathbf{2 3}$ ). Une vue en est prise par l'opérateur Moreau, lors de la visite du sous-secrétaire d'État aux Beaux-Arts Albert Dalimier. Le bâtiment fut reconstruit après la guerre dans un style architectural identique. D'autres exemples frappent les observateurs contemporains par leur aspect spectaculaire. Le château d'Avricourt, dans l'Oise, datant du XVIII ${ }^{e}$ siècle, est dynamité par les troupes allemandes en mars 1917. Une carte postale illustre son état avant la guerre (fig. $\mathbf{n}^{\circ} \mathbf{2 4}$ ), un cliché de l'opérateur Brissy témoigne de son anéantissement (fig. $\mathbf{n}^{\circ} 25$ ). Même constat pour la 
forteresse de Ham, dans la Somme. Haut lieu historique du département, la forteresse de Ham fut dynamitée le 19 mars 1917, tout comme la forteresse de Coucy. Plusieurs documents témoignent de son état avant et après sa destruction (fig. $\left.\mathbf{n}^{\circ} \mathbf{2 6}\right)$ et (fig. $\left.\mathbf{n}^{\circ} \mathbf{2 7}\right)$.

Figure 20

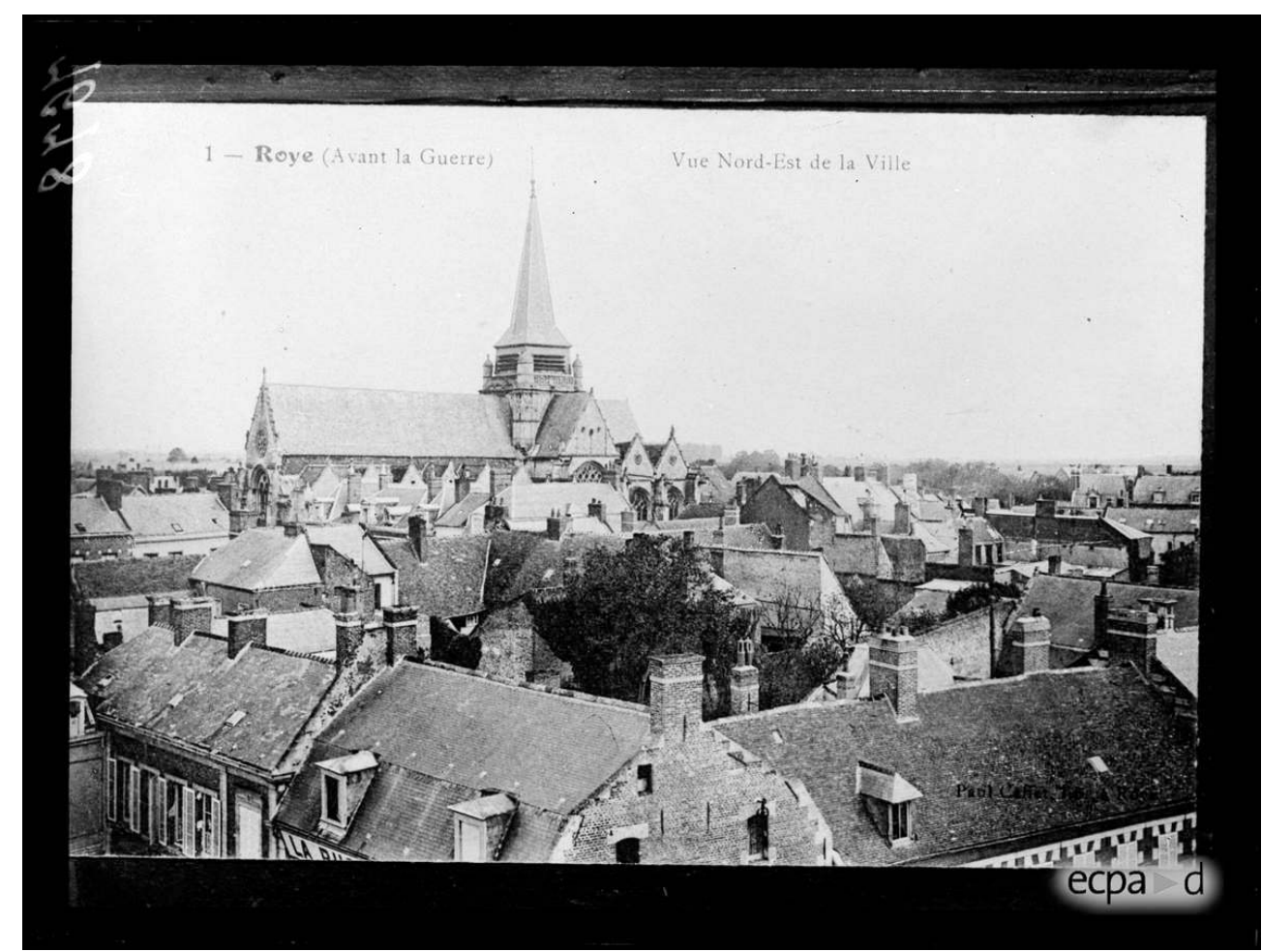

Roye (Somme), centre-ville. Carte postale.

Phot. Inconnu. (C) ECPAD. Réf. SPA 118 CT 7678. 
Figure 21

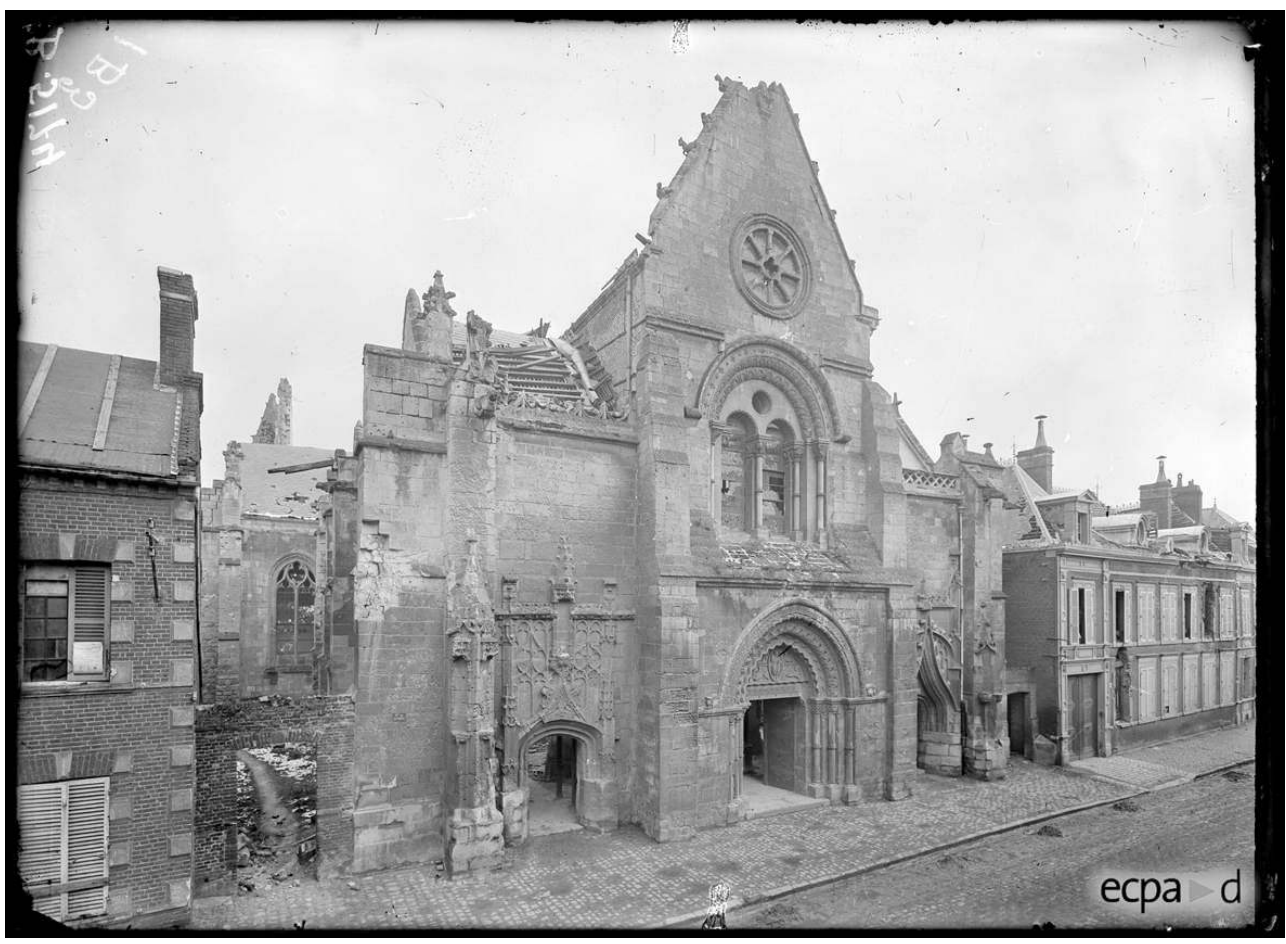

Roye (Somme), église Saint-Pierre.

Phot. Queste, Paul. (C) ECPAD. 2 avril 1917. Réf. SPA 93 B 5174. 
Figure 22

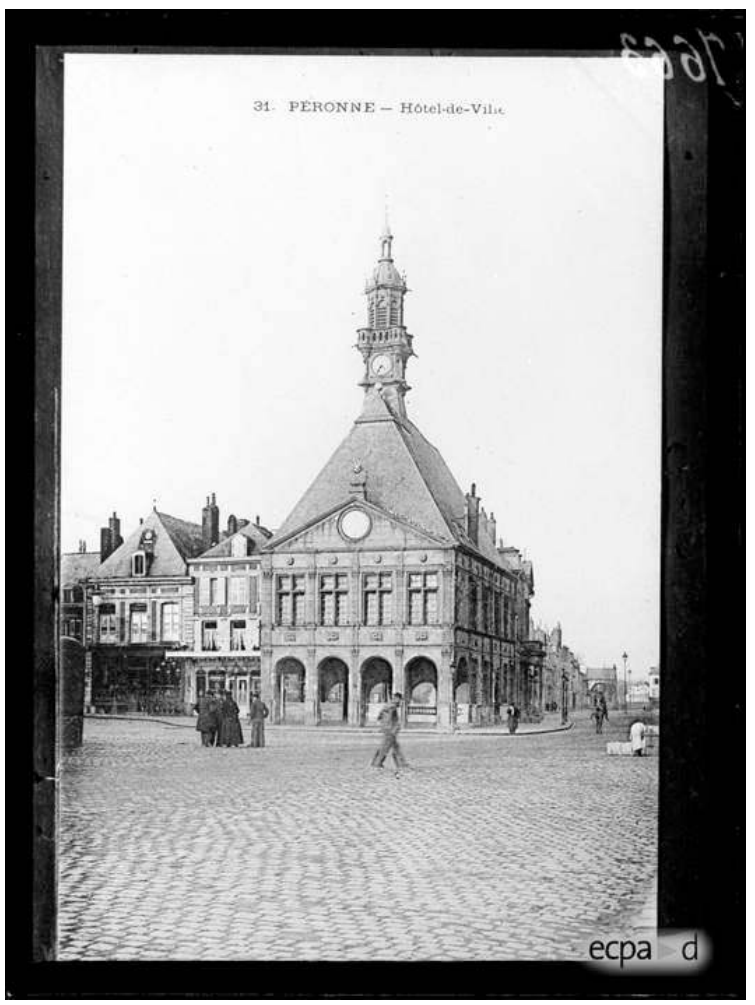

Péronne (Somme), hôtel de ville.

Phot. Inconnu. (C) ECPAD. Non daté Réf. SPA 118 CT 7663. 


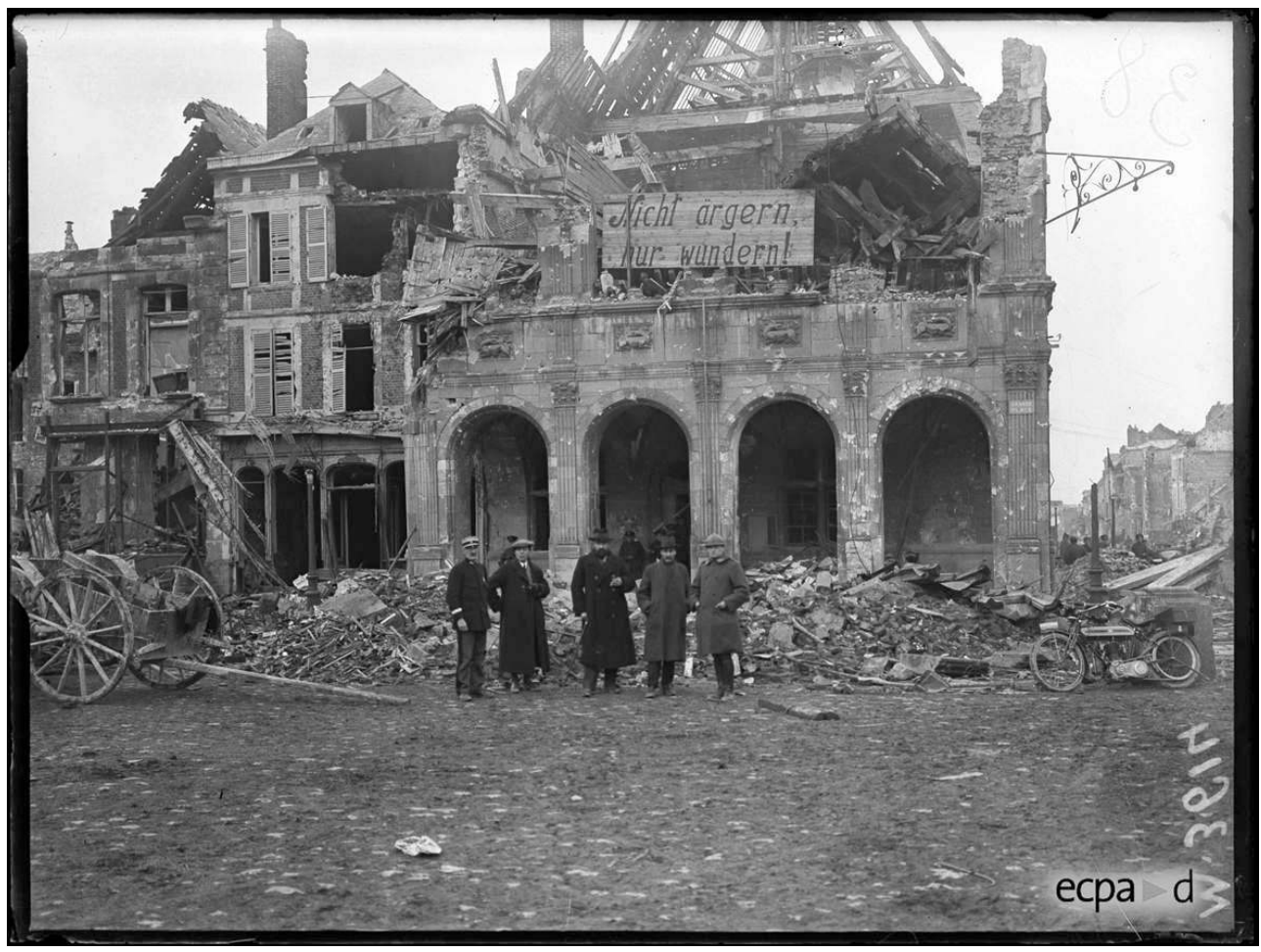

Péronne (Somme), place de l'hôtel de ville.

Phot. Moreau, Albert. @ ECPAD. 24 mars 1917. Réf. SPA 181 M 3614.

Figure 24

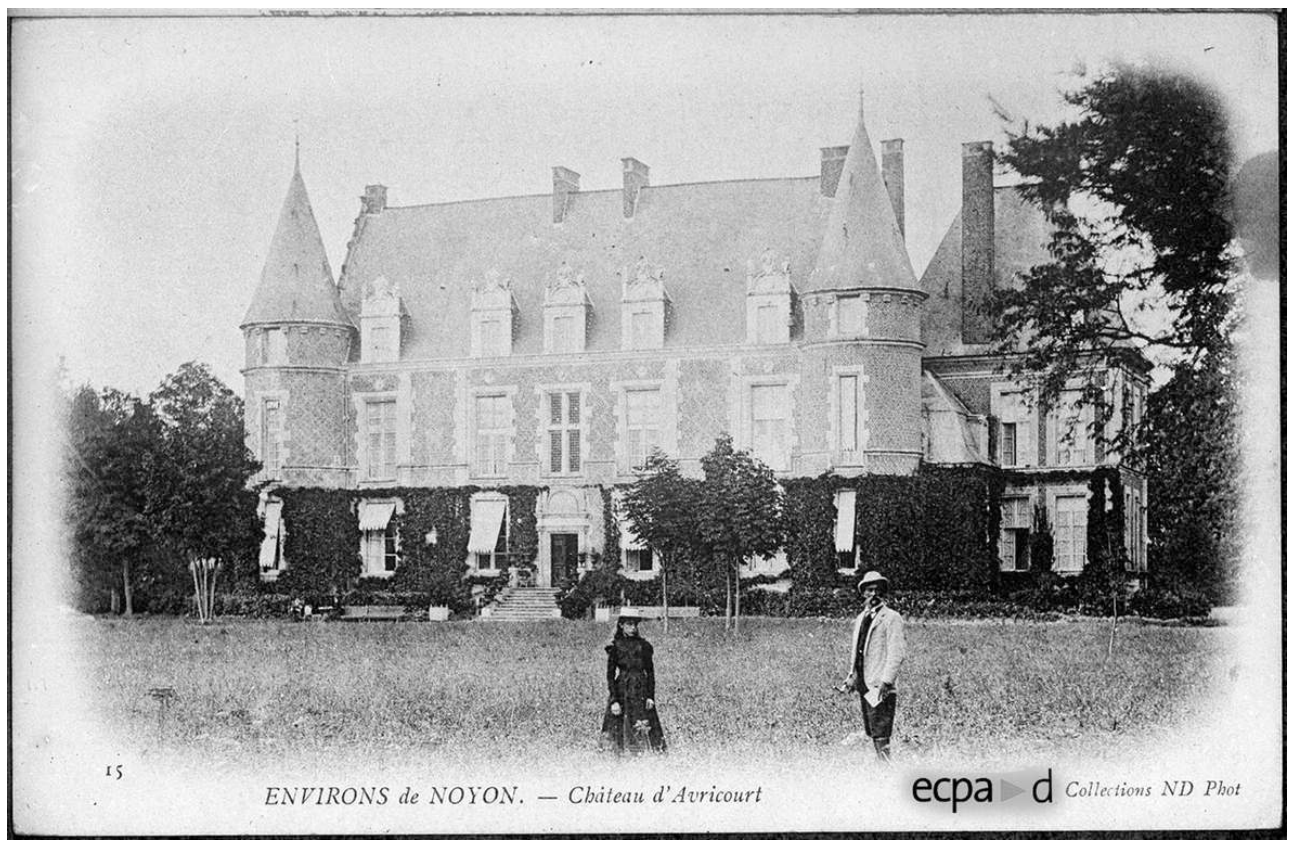

Avricourt (Oise), château.

PHOT. CARTE POSTALE. @ C ECPAD. RÉF. SPA 67 ct 3877-3878. 
Figure 25

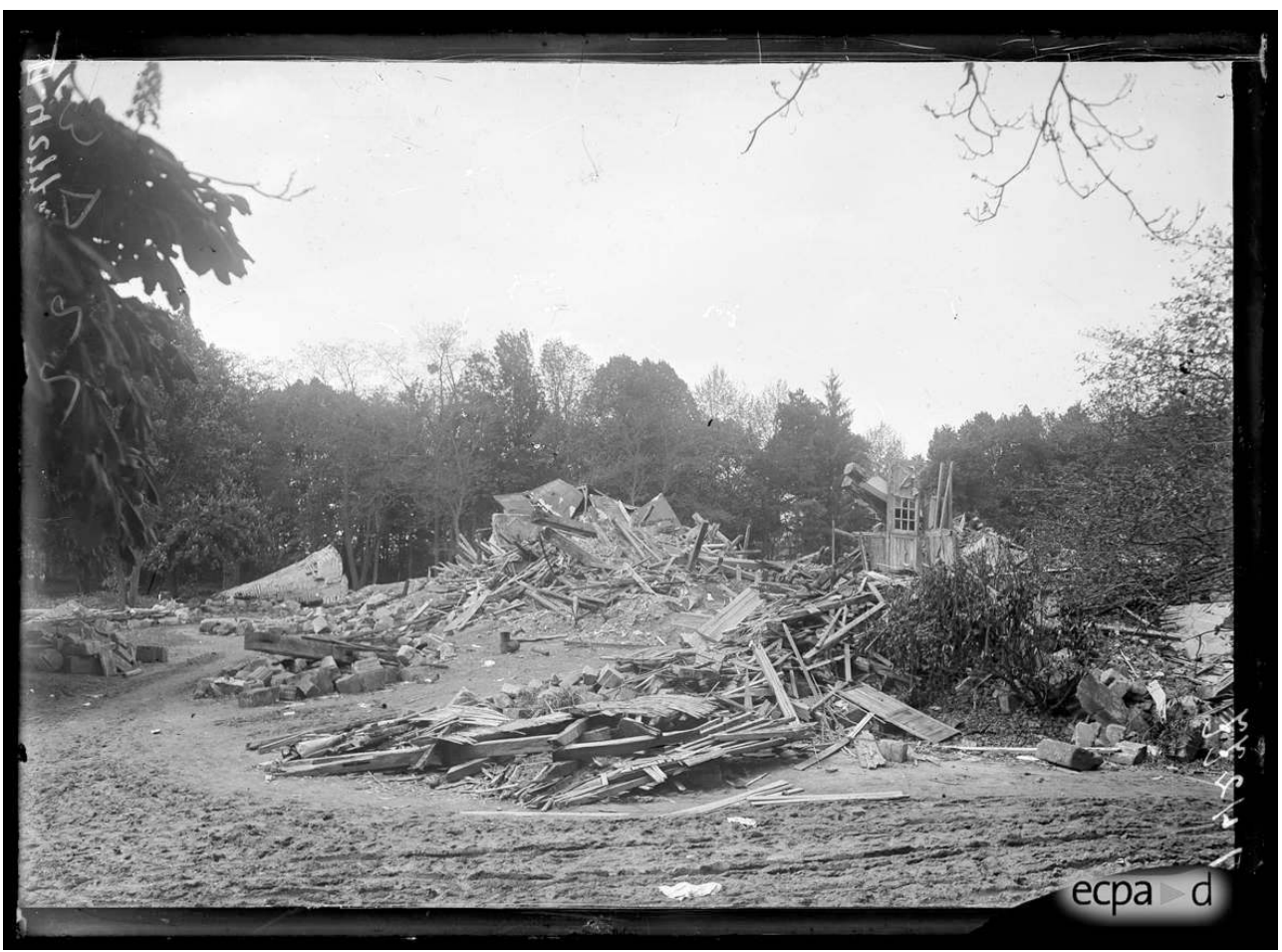

Avricourt (Oise), autre aspect du château.

Phot. Brissy, Édouard. (c) ECPAD. 20 mai 1917. Réf. SPA 58 D 4277.

\section{Figure 26}

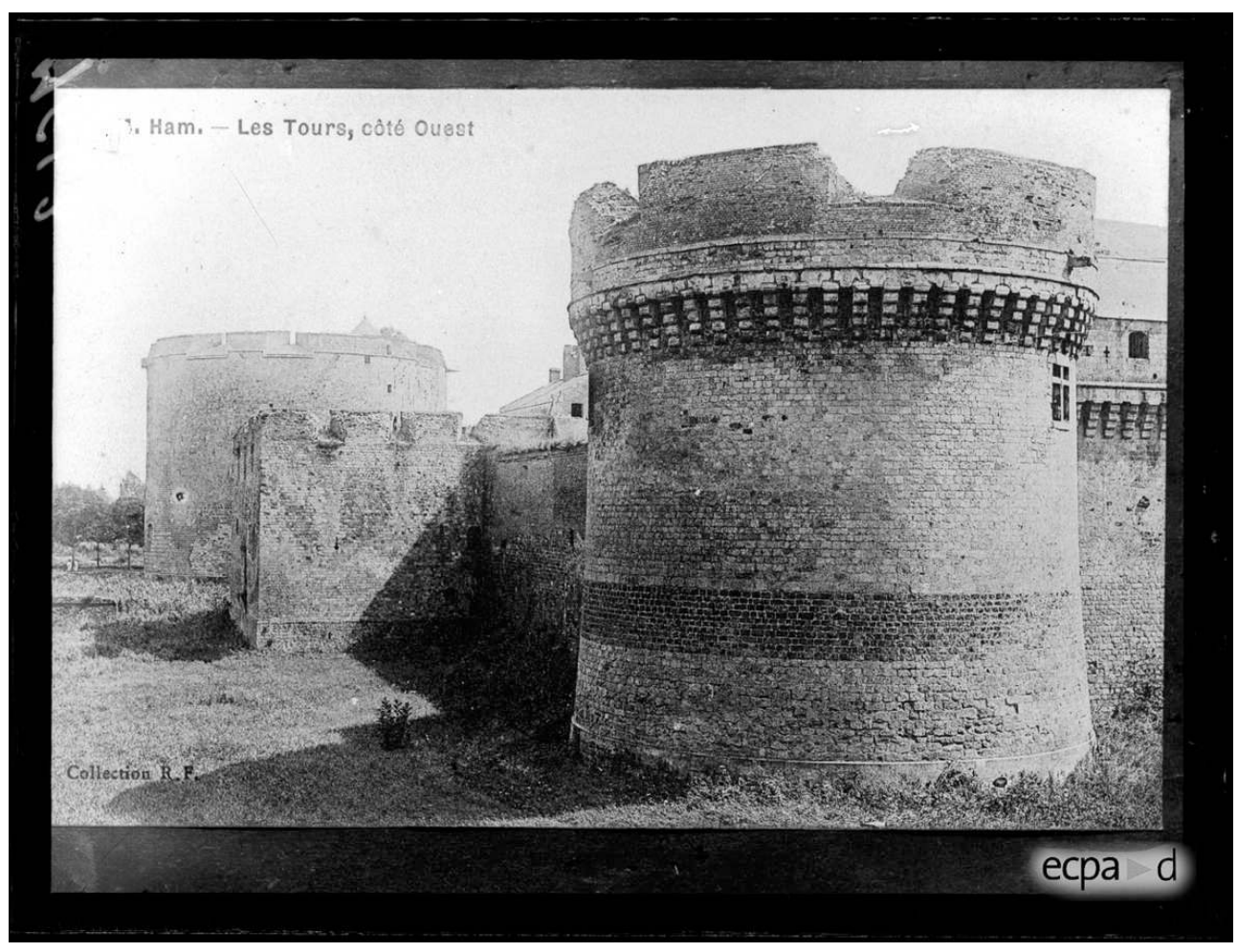

Ham (Somme), forteresse

Phot. carte postale. (C) ECPAD. Non daté. Réf. SPA 118 CT 7643. 


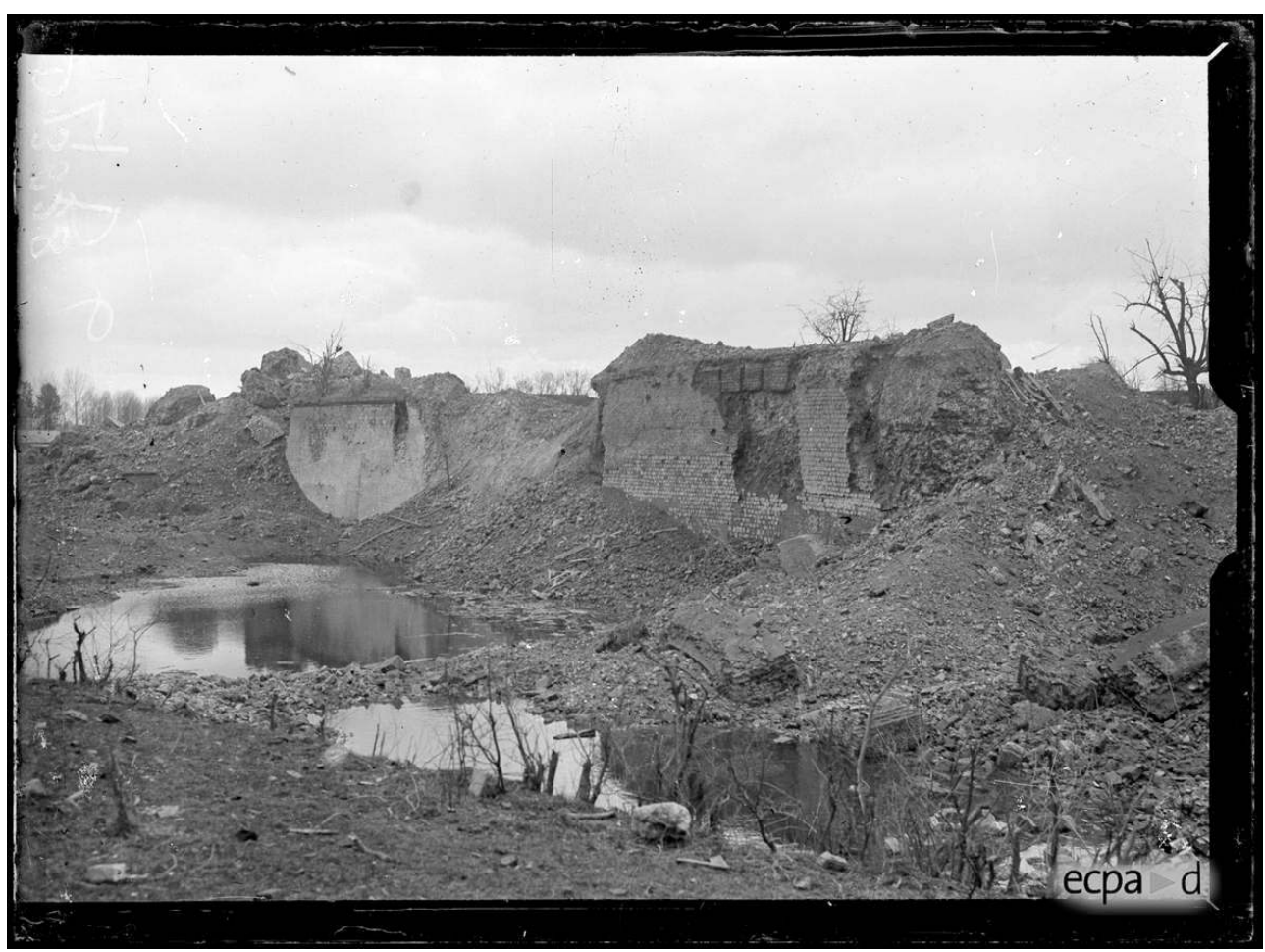

Ham (Somme), forteresse.

Phot. Brissy, Édouard. @ ECPAD. 21 mars 1917. Réf. SPA 46 D 3628.

\section{INVENTORIER LE PATRIMOINE NÉ DE LA gUERRE}

À la première mission d'inventorier le patrimoine en ruine s'en ajoute une deuxième, commanditée par le ministère de l'Instruction publique et des Beaux-Arts, en accord avec le ministère de la Guerre, celle d'assurer la sauvegarde des vestiges issus du conflit luimême. Peu de temps après le repli des troupes allemandes sur la ligne Hindenburg, la question du devenir des marques laissées par la guerre et les combattants se pose au plus haut niveau de l'État. Avec le départ de l'ennemi, de nombreux lieux grêlés par les combats des années 1914, 1915 et 1916 en Picardie se retrouvent désormais à l'arrière du front. De nombreux vestiges de guerre témoignent de l'âpreté des combats et des sacrifices consentis par des milliers de soldats. Pour répondre au besoin de conserver ces nombreuses " cicatrices ", une commission est constituée en mai 1917 sous l'égide des ministères de la Guerre et de l'Instruction publique et des Beaux-Arts ${ }^{37}$. Elle est dirigée par le général Savatier, le commandant Viel et André Ventre, architecte en chef des Monuments historiques. À charge pour ses membres de répertorier et de classer les vestiges de guerre qui laisseront aux générations futures les traces de la Grande Guerre. De ce fait, la SPCA joue un rôle essentiel dans ce travail d'inventaire du patrimoine engendré par les combats. En effet, aux mois de mai et juin 1917, l'opérateur Paul Queste accompagne la visite entreprise par la commission sur le front de Picardie et dresse l'inventaire photographique des principaux lieux marquants de «l'ancien front» de la Somme, de l'Oise et de l'Aisne. La commission relève plusieurs noms de lieux emblématiques, tels que le village de Tracy-le-Val, le plateau de la ferme de Quennevières, 
les entonnoirs de mine de Beuvraignes et de Cessier, la position du Plémont ou encore le bois d'Orval, significatifs pour la place qu'ils ont tenue dans le conflit et par les stigmates des combats de 1914-1917, encore visibles de nos jours. D'autres lieux sont visités et photographiés, tels que les carrières des Cinq Piliers situées sur le territoire de la commune de Ribécourt-Dreslincourt (Oise), l'abri allemand bétonné de Nampcel (Oise) ou les ruines de la ferme fortifiée de Confrécourt (Aisne). Les images réalisées par Paul Queste servent de base de travail aux dessins et aux plans exécutés par André Ventre. En effet, le château de Plessis-de-Roye, situé au sud de Lassigny, attire l'attention de la commission. L'une d'elles, réalisée sur négatif de format 13 x $18 \mathrm{~cm}$ (fig. $\mathbf{n}^{\circ} 28$ ) est déclinée par André Ventre sous la forme d'un dessin, lui-même contretypé par le service des archives de la SPCA et conservé dans la série Z (fig. $\mathbf{n}^{\circ} \mathbf{2 9}$ ). Un autre exemple de ce type d'inventaire se matérialise par la présence de nombreuses vues de cimetières et de graffitis allemands. Ces images de la SPCA sont prises dans de nombreux cantonnements allemands abandonnés où les murs gardent les peintures exécutées par les soldats. Dans leurs tournées, les opérateurs Paul Queste, Albert Moreau, Édouard Brissy ou Edmond Famechon découvrent de nombreux vestiges, telles ces peintures murales réalisées sur les murs de la mairie de Suzoy dans l'Oise, aménagée en casino pour officiers : l'une d'elles représente une scène satirique où des soldats alliés sont tenus en respect et tournés en ridicule par deux soldats allemands qui arborent les traits de personnages issus de la mythologie gréco-romaine (fig. $\mathbf{n}^{\circ} \mathbf{3 0}$ ). Ces peintures furent également filmées quelques jours plus tard par l'opérateur René Meunier ${ }^{38}$.

\section{Figure 28}

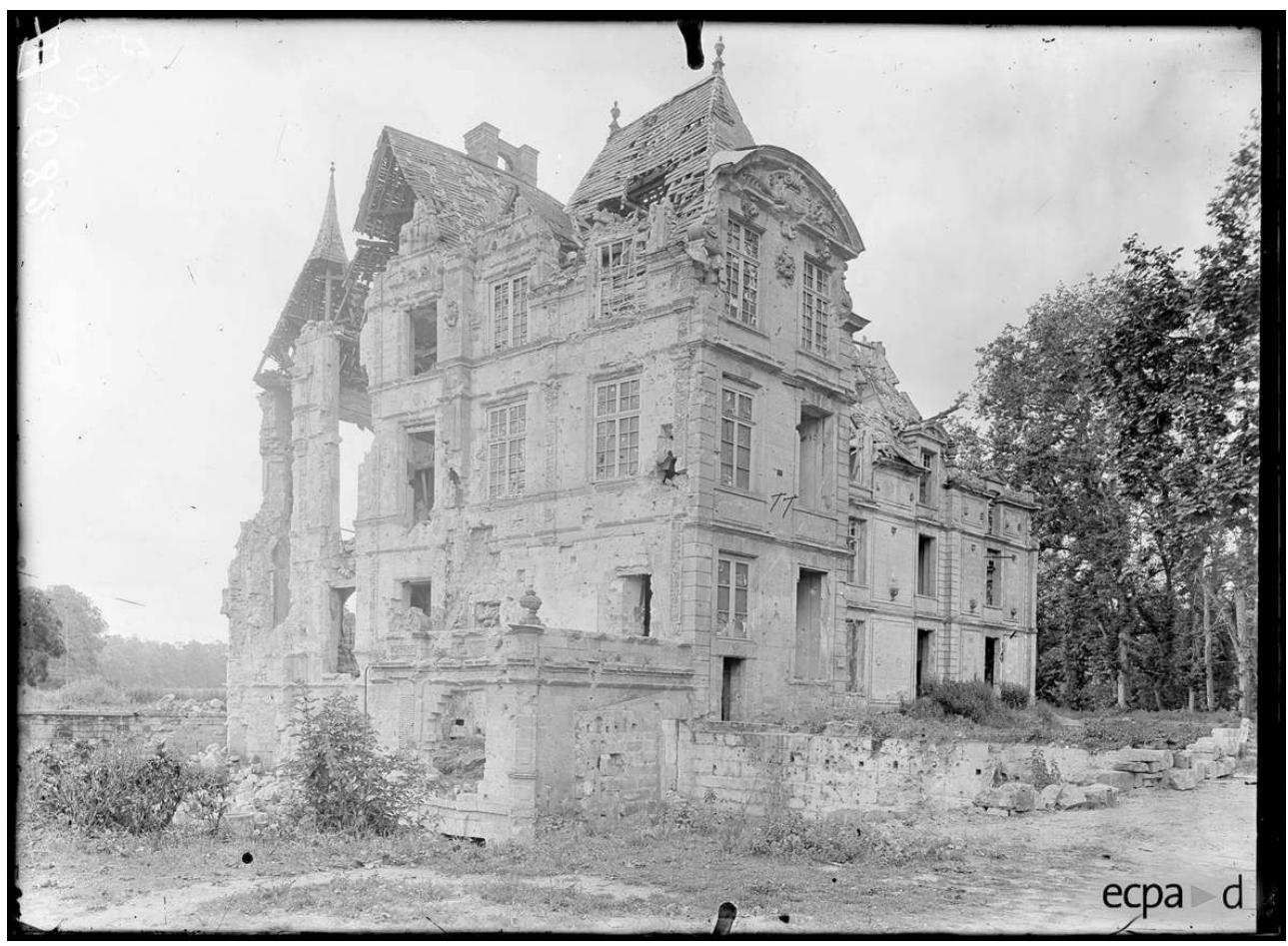

Plessis-de-Roye (Oise), château.

Phot. Queste, Paul. @ ECPAD. Juin 1917. Réf. SPA 102 B 5682. 
Figure 29

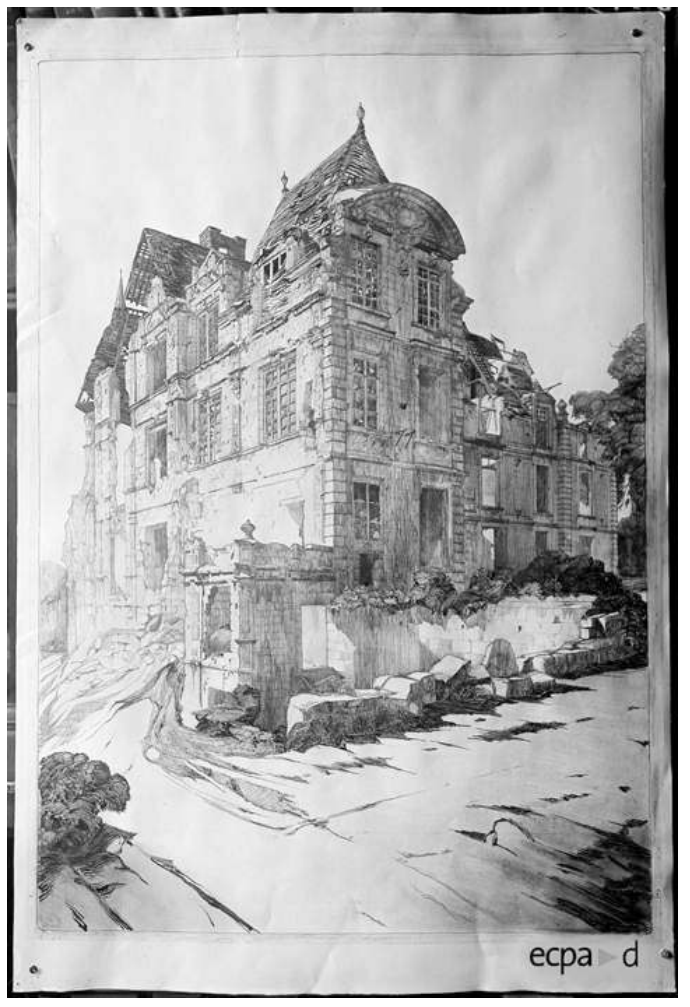

Plessis-de-Roye (Oise), château, dessin d'André Ventre. (c) ECPAD. Janvier 1918. Réf. SPA 175 Z 5979. 
Figure 30

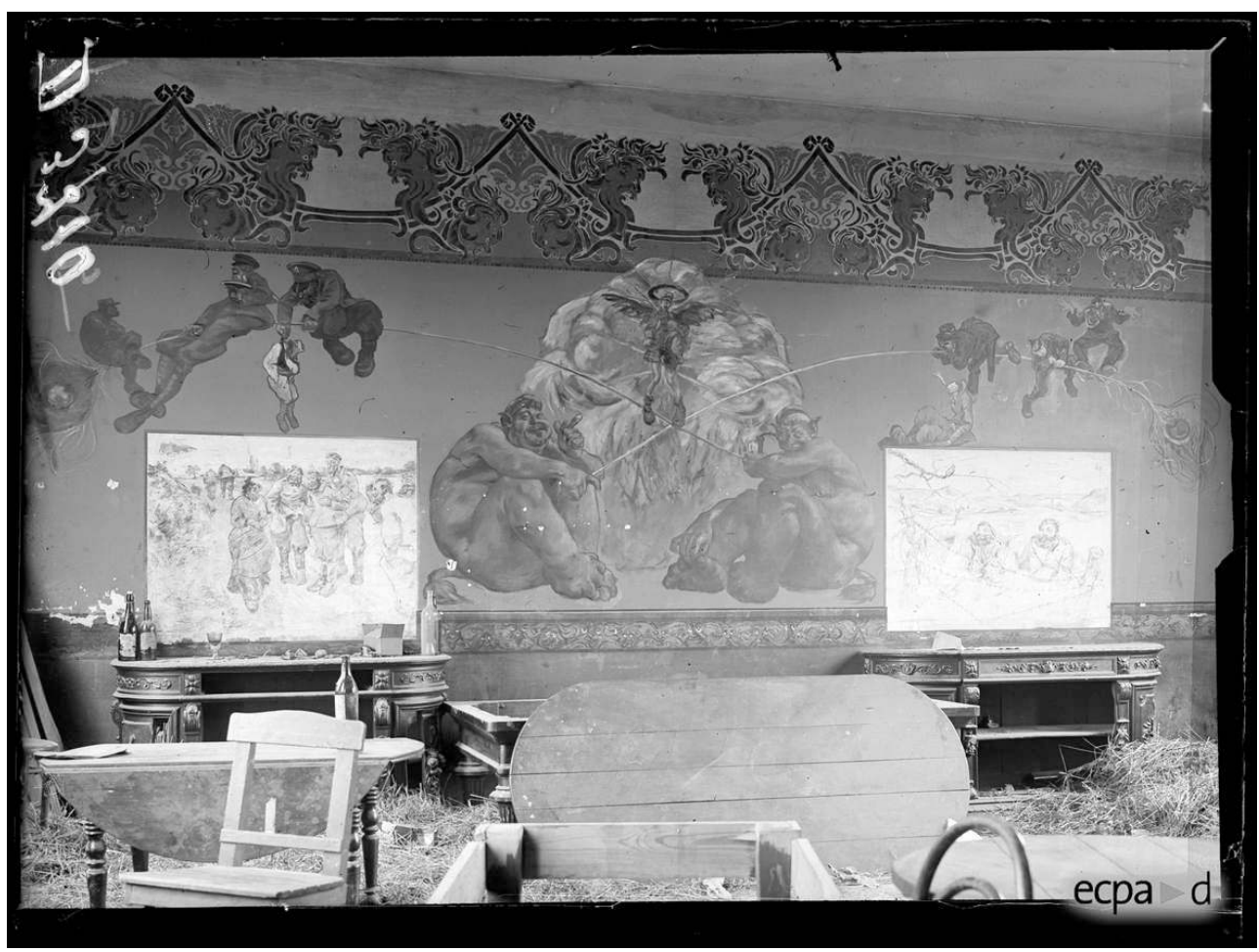

Suzoy (Oise), mairie, peintures murales réalisées par les Allemands (ancien casino).

PHOT. BRISSY, ÉDOUARD. (C) ECPAD. 26 MARS 1917. RÉF. SPA 48 D 3710.

Ces photographies, prises au lendemain du repli allemand de mars 1917, constituent autant de sources précieuses pour la connaissance du patrimoine et de l'histoire des départements frappés par la Grande Guerre. L'œuvre entreprise par la SPCA, sous la tutelle du ministère de l'Instruction publique et des Beaux-Arts et du ministère de la Guerre, vise un objectif à portée patrimoniale et mémorielle. Elle constitue un corpus d'images destinées d'une part à la restauration et à la reconstruction des lieux endommagés par la guerre et d'autre part, à la préservation d'un nouveau patrimoine engendré par le conflit, tentant ainsi de "figer» les espaces à jamais marqués par les combats. En outre, cette action documentaire connaît pendant et après la guerre une déclinaison commerciale. Les champs de bataille ainsi «sacralisés » font dès le mois de septembre 1917 l'objet de circuits touristiques, promus par la société Michelin à travers la publication des Guides illustrés des champs de bataille, tous publiés sous le patronage du ministère de l'Instruction publique et des Beaux-Arts et du ministère des Affaires étrangères. Les images produites par la SPCA s'inscrivent naturellement en illustration des propos. Les paysages de ruines tiennent une place de choix, ils y sont présentés comme autant de preuves accusatrices contre l'Allemagne, appuyées par l'avertissement adressé aux lecteurs: "Toutes les ruines qu'on vient de constater et qu'on observera plus loin ont été faites méthodiquement $»^{39}$.

Édité en 1921, un volume est consacré au front de Noyon, Roye et Lassigny ${ }^{40}$. Les villes en ruines sont exposées comme les martyres d'une France "héroïque », dénonçant par la même occasion "l'infériorité morale » de l'ennemi, présenté comme dédaigneux du respect des lois de la guerre. Les images reproduites dans le guide ont été produites par la SPCA, notamment celles prises lors de la mission que Paul Queste a effectuée aux côtés 
d'André Ventre. On peut ainsi y retrouver le cliché réalisé par Paul Queste au château de Plessis-de-Roye (voir fig. nº28) en juin 1917.

\section{De l'inculpation à la dénonciation : les images de la SPCA dans l'action de propagande}

Restant avant tout aux ordres du ministère de la Guerre, la SPCA répond sans nul doute à des impératifs dictés par l'effort de guerre. L'œuvre patrimoniale et pédagogique entreprise par le gouvernement s'associe à une action de propagande qui vise à fustiger et à condamner les actes commis par l'armée allemande lors de l'opération Alberich.

\section{LES IMAgES DE LA SPCA, PIÈCES À CONVICTION D'UN « DOSSIER D'INCULPATION ॥}

Les opérateurs de la SPCA explorent les départements dévastés de Picardie, accompagnant les travaux d'enquêtes diligentées par des commissions de sénateurs et de députés originaires de ces départements. En effet, à l'annonce du repli allemand de mars 1917, plusieurs délégations visitent le front pour constater les dégâts et les préjudices commis au détriment des populations et de leurs biens. L'objectif est de dresser la liste des réparations que pourront réclamer les Alliés auprès de l'Allemagne en cas de victoire ${ }^{41}$. Les visites sénatoriales et parlementaires font l'objet d'une couverture organisée par la SPCA, comme en témoignent les images de l'opérateur Édouard Brissy au cours de l'une d'entre elles, le 27 mars 1917 (fig. $\mathbf{n}^{\mathbf{0}} \mathbf{3 1}$ ).

Figure 31

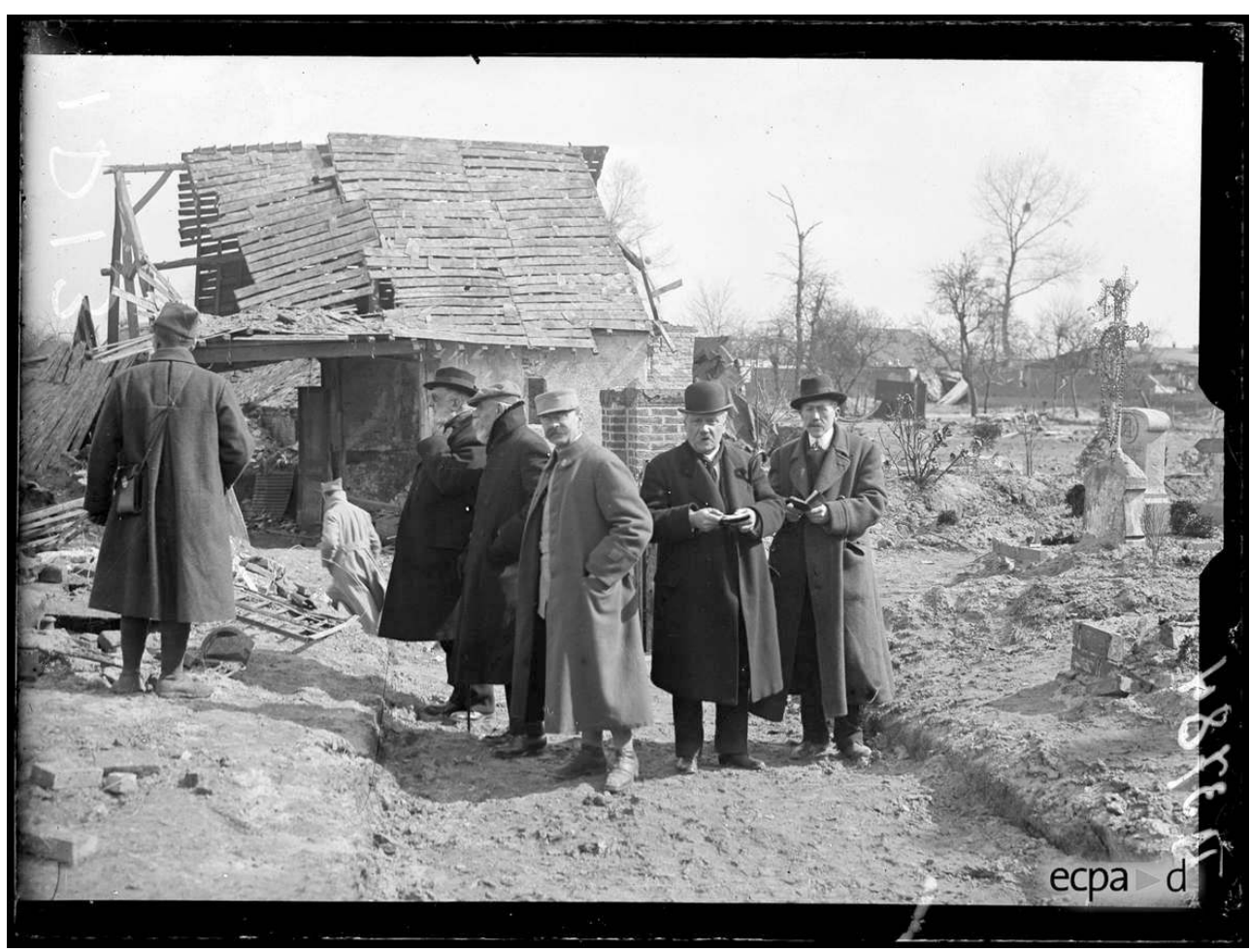

Margny-aux-Cerises (Oise), la commission sénatoriale visitant les ruines.

Phot. Brissy, Édouard. (c) ECPAD. 27 mars 1917. Réf. SPA 49 D 3784 
Aux mois de mai et juin 1917, une délégation de la Cour des comptes, dirigée par son président Georges Payelle ${ }^{42}$, entreprend la rédaction d'un rapport dénonçant les actes de vandalisme commis par l'occupant allemand. Le groupe sillonne les départements picards récemment libérés, collectant également des témoignages d'habitants. Ainsi, nombre d'images de la SPCA reflètent-elles précisément les renseignements rapportés par cette commission où sont mis en exergue plusieurs cas de violences perpétrées sur la population, dénonçant les réquisitions abusives et les destructions systématiques organisées par les forces ennemies avant leur repli. Dans ce rapport, Georges Payelle souligne :

Ces dommages proviennent, sans conteste, d'actes criminels car il n'y a aucune trace de bombardement sur ces lieux. Après les pillages, les maisons, châteaux et fermes ont été détruits par minage à l'explosif ou furent incendiés voire démolis à la barre à mine. À Margny-aux-Cerises, la démolition a été réalisée avec l'aide d'un puissant bélier mécanique. Annois, Flavy-le-Martel, Jussy, Frières-Faillouël et Villequier-Aumont n'existent plus. Chauny, ville industrielle de près de 11000 habitants, n'est plus qu'un tas de ruines, à l'exception du faubourg du Brouage.

Dans un autre passage, il relève dans un passage précédent plusieurs cas de profanation de sépultures en de nombreux villages de la Somme, de l'Oise et de l'Aisne :

Chacun s'interroge avec stupéfaction pour savoir comment l'armée d'une nation qui se prétend civilisée peut avoir commis de tels actes mais encore plus consternant est de constater que ces soldats ont même violé les sépultures des morts. [...] À Candor, deux témoins ont surpris des Allemands en train de casser les tombes des familles Trefcon et Censier, de visiter le caveau de la famille Mazier dont le couvercle a été forcé.

41 Les exemples mentionnés par Georges Payelle trouvent leur pendant illustré dans les reportages exécutés par la SPCA à la même période, au printemps 1917. Lors de son entrée dans le village de Margny-aux-Cerises, Édouard Brissy photographie le fameux bélier utilisé par les Allemands pour enfoncer les portes des maisons du village (fig. $\mathbf{n}^{\circ} \mathbf{3 2}$ ) - Quelques semaines plus tard, au mois de mai 1917, Edmond Famechon, qui produit une importante série de photographies sur les destructions, montre l'état de ruine des localités entourant les villes de Ham dans la Somme ou de Tergnier dans l'Aisne, ellesmêmes entièrement rasées par les incendies et les dynamitages allemands. À Flavy-leMartel, dans l'Aisne, il réalise une série de paysages révélant la dévastation de l'ensemble des habitations, des bâtiments publics et de l'hôpital (fig. $\mathbf{n}^{\circ}{ }^{33}$ ). Plusieurs détails semblent confirmer le rôle de "témoin à charge » conféré à la SPCA, dont le travail illustre parfaitement les réquisitoires menés à l'encontre de l'armée allemande. L'opérateur Famechon se rend ensuite à Candor, dans l'Oise, pour photographier le village en ruines. Dans le cimetière communal, il prend un cliché de la sépulture profanée des familles Trefcon et Censier (fig. $\mathbf{n}^{\circ} \mathbf{3 4}$ ) précisément mentionnée dans le rapport. 
Figure 32

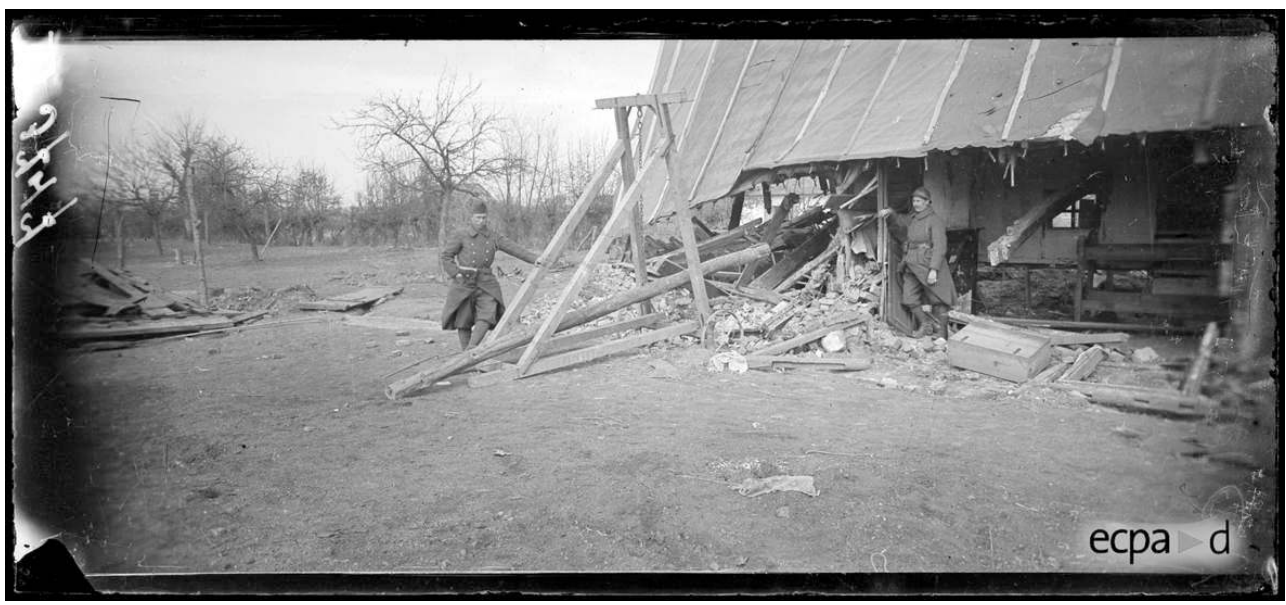

Margny-aux-Cerises (Oise), bélier allemand pour enfoncer les portes des maisons.

Phot. Brissy, Édouard. (c) ECPAD. 27 mars 1917. Réf. SPA 49 D 3747.

Figure 33

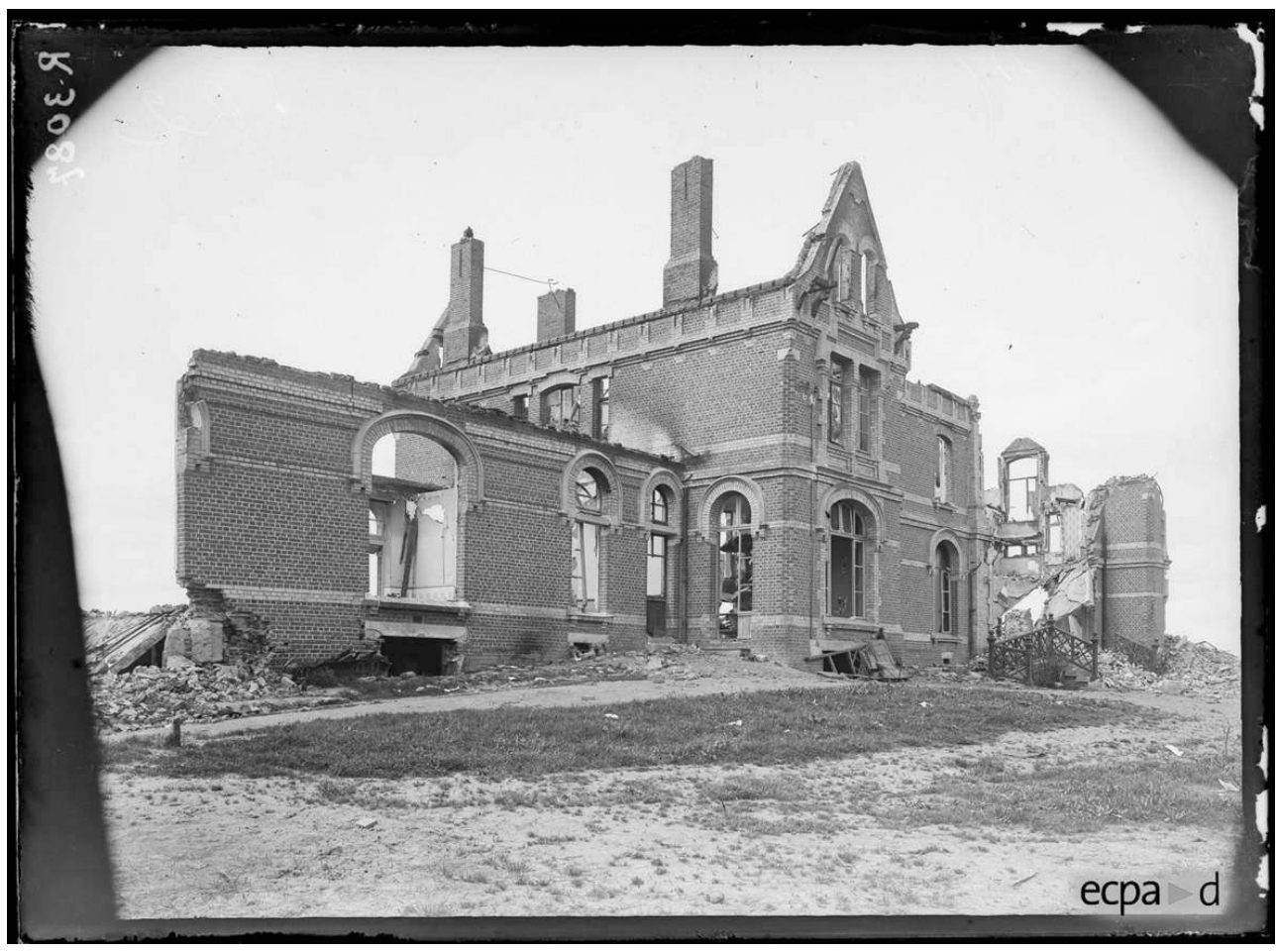

Flavy-le-Martel (Aisne), les ruines de l'hôpital Saint-Charles.

Phot. Famechon, Edmond. (C) ECPAD. Mai 1917.Réf. SPA 87 R 3087. 


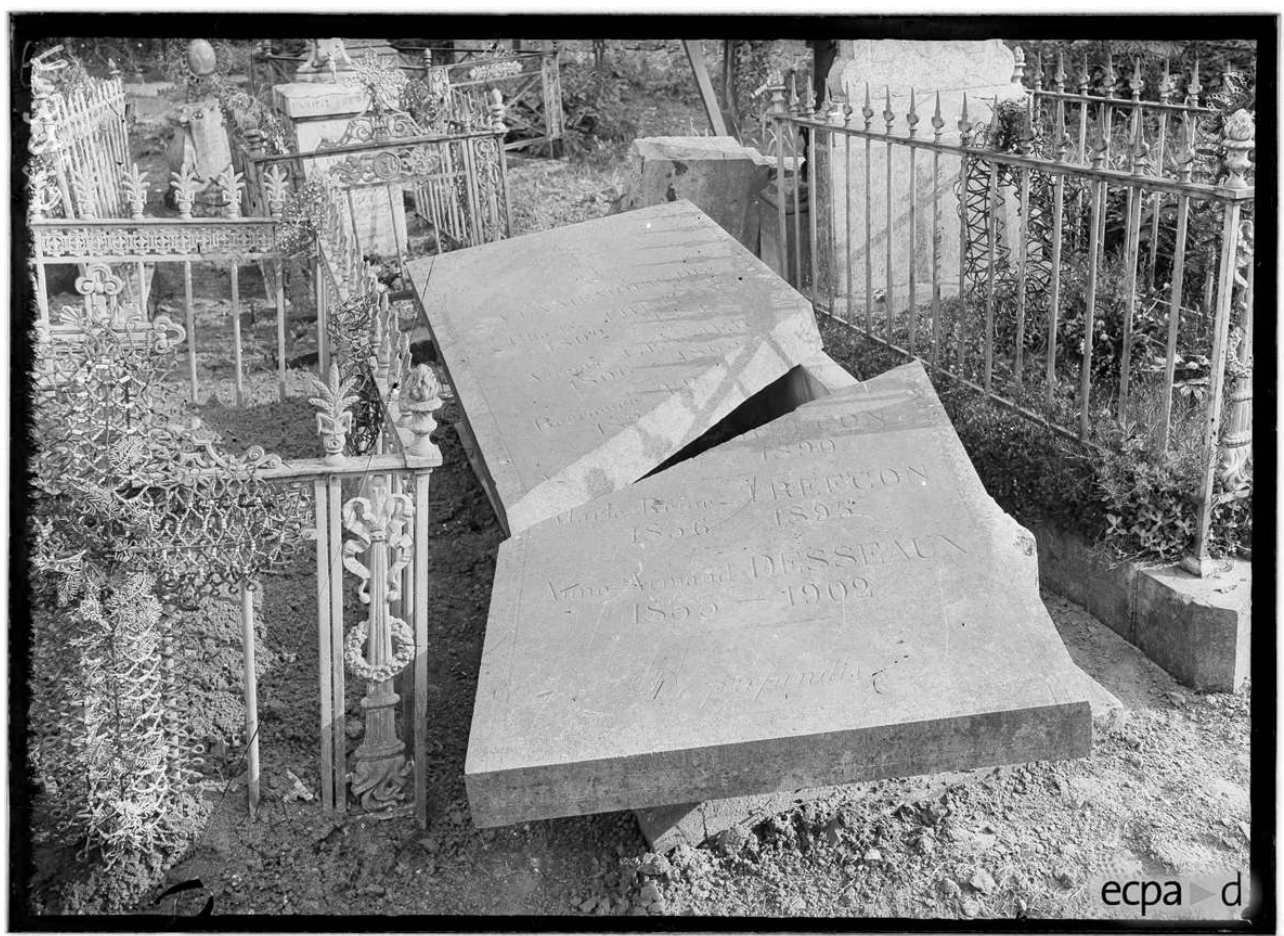

Candor (Oise), une tombe profanée de la famille Trefcon et Censier.

PHOT. FAMECHON, EDMOND. (C) ECPAD. MAI 1917. RÉF. SPA 90 R 3275.

42 Le rapport Payelle insiste également sur la mise à sac des outils de production industriels et agricoles de la Picardie. Là encore, les reportages de la SPCA s'apparentent à la chronique en images des observations faites dans le rapport, où il est énoncé :

À Roye, par exemple, où les combats ont causé des dégâts irréparables, ils [les Allemands] mirent le feu à la raffinerie de sucre et planifièrent la ruine des industries, en saisissant d'abord le bronze, zinc, plomb, cuivre et étain, puis en enlevant tous les mécanismes de valeur et en détruisant tous les moules et pièces fondues.

Effectivement, dans cette ville dévastée, plusieurs usines sont photographiées par Edmond Famechon, affichant l'enchevêtrement de matériels et de machines-outils sabotés ou incendiés. Un autre exemple traité est celui de la manufacture de tissage de Chiry-Ourscamp, dans l'Oise, établie dans l'ancienne abbaye cistercienne d'Ourscamp, qui fait l'objet de plusieurs reportages photographiques par Brissy en avril 1917 et Famechon en mai 1917 (fig. $\mathbf{n}^{\circ} \mathbf{3 5}$ ). Grande région agricole, la Picardie est profondément atteinte dans ses sols et ses moyens de production agricole. Des milliers d'hectares de terres agricoles sont lacérés par les tranchées, les bombardements et les destructions menées lors du repli. Pour le seul département de l'Oise, la surface de terre dévastée est estimée à 162781 hectares $^{43}$. Plusieurs dizaines de documents de la SPCA témoignent également de l'état catastrophique des installations de l'industrie sucrière. Florissante dans la région depuis le XIX ${ }^{\mathrm{e}}$ siècle, la fabrication du sucre à partir des betteraves comptait avant 1914 une soixantaine d'établissements ${ }^{44}$. En 1918, l'ensemble de cette branche d'activité se retrouve ruinée par la guerre et de nombreux sites sont rendus inutilisables par les bombardements, les pillages et les dynamitages. Près de Roye, Famechon réalise plusieurs vues des décombres des usines sucrières (fig. $\mathbf{n}^{\circ} \mathbf{3 6}$ ). 
Figure 35

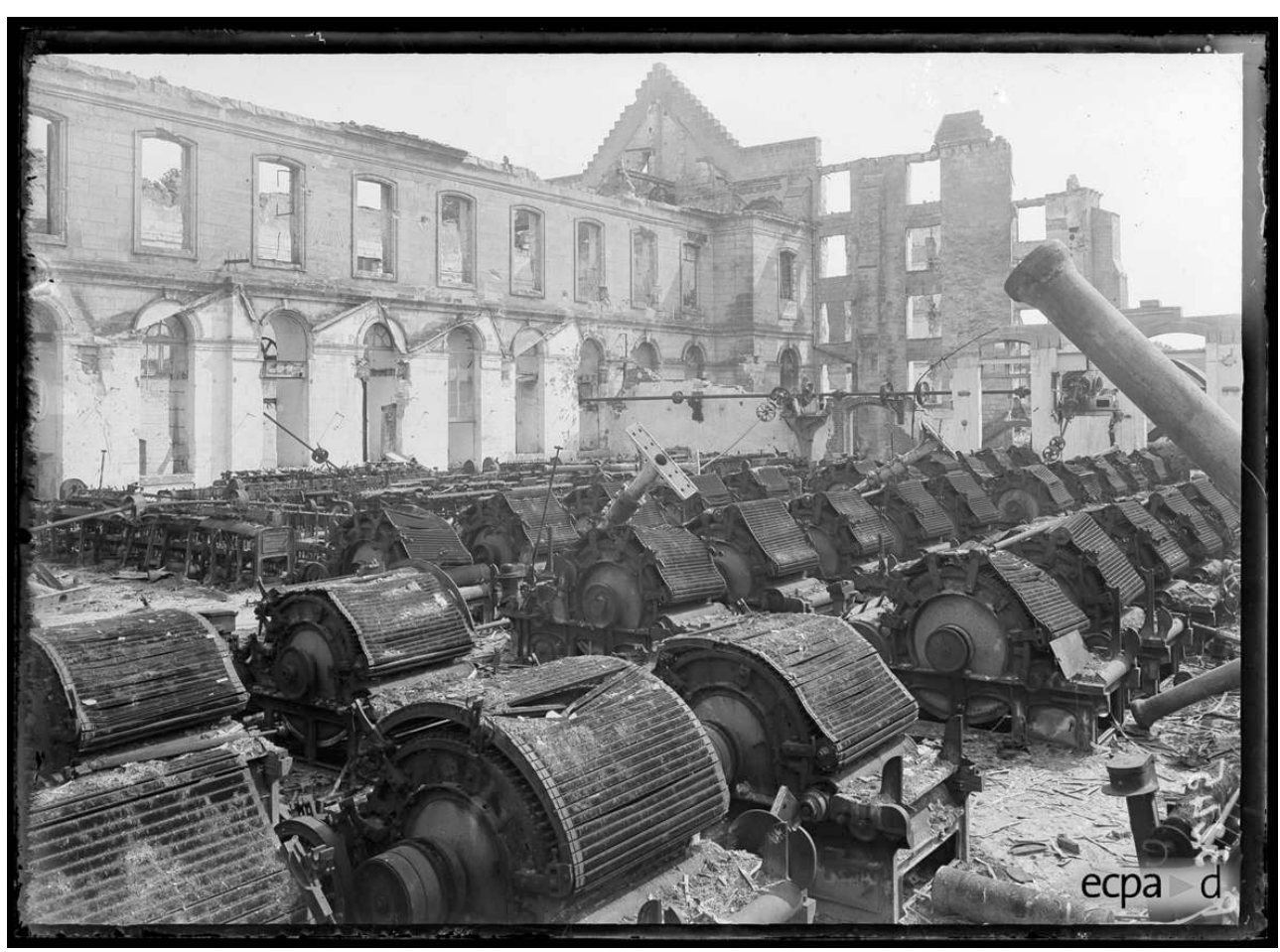

Chiry-Ourscamp (Oise), l'usine de filature et de tissage. La génératrice de l'usine. Phot. Famechon, Edmond. (c) ECPAD. Mai 1917. Réf. SPA 90 R 3245.

Figure 36

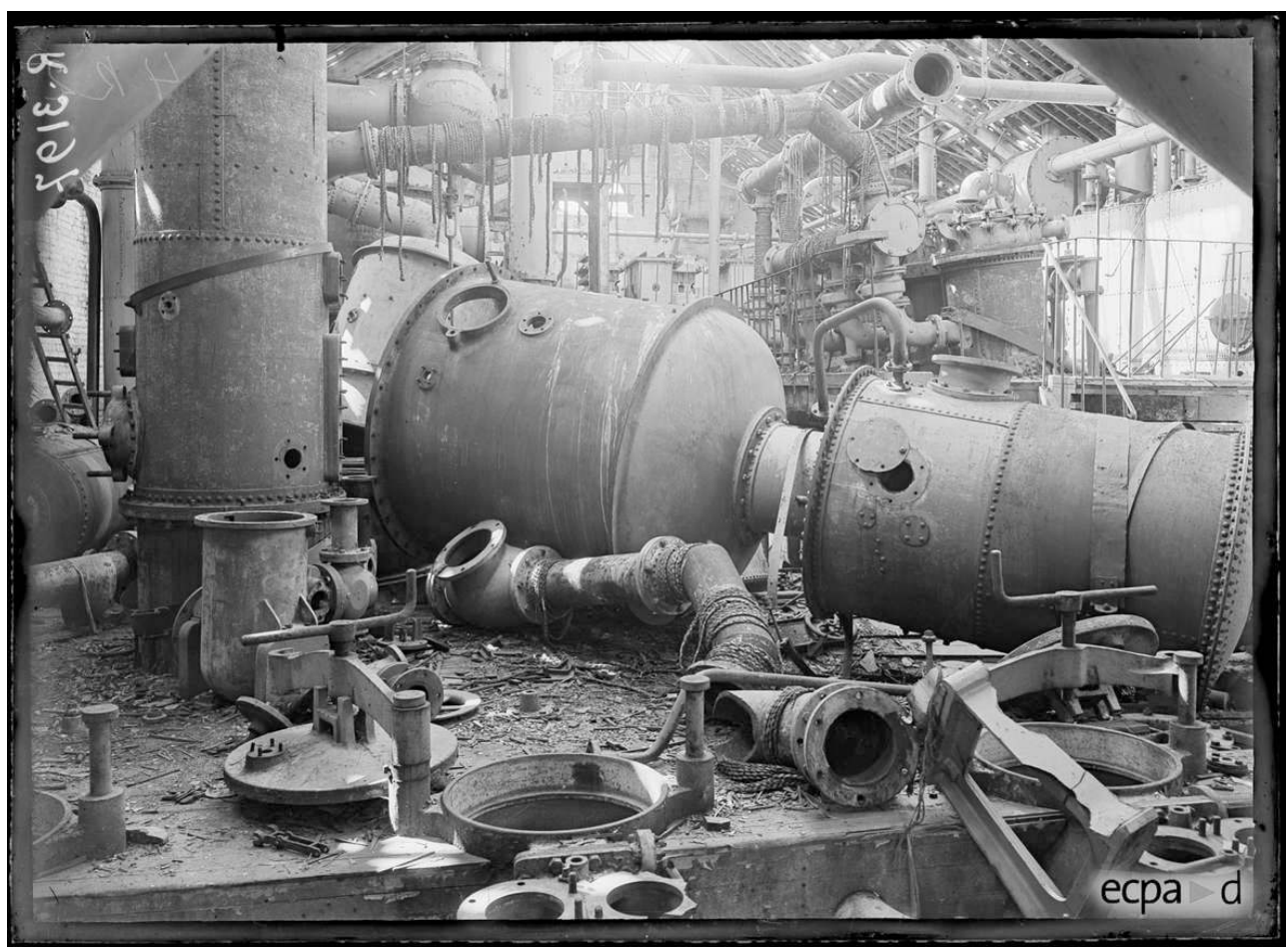

Roye (Somme), la sucrerie Mandron, les contrepoids de vidange des diffuseurs. PHOT. FAMECHON, EDMOND. (C) ECPAD. MAI 1917. RÉF. SPA 89 R 3197. 
me des arbres coupés et de la nature outragée occupe également une large place dans le travail laissé par les opérateurs de la SPCA. Des documents saisis sur pellicule ou plaque de verre insistent sur la mise à sac de nombreux vergers ou parcs, où les arbres ont été délibérement sciés par les soldats ennemis. Le photographe Maurice Boulay réalise de nombreuses vues de ce type dans les vergers de l'Aisne dévastés (fig. n³7).

Figure 37

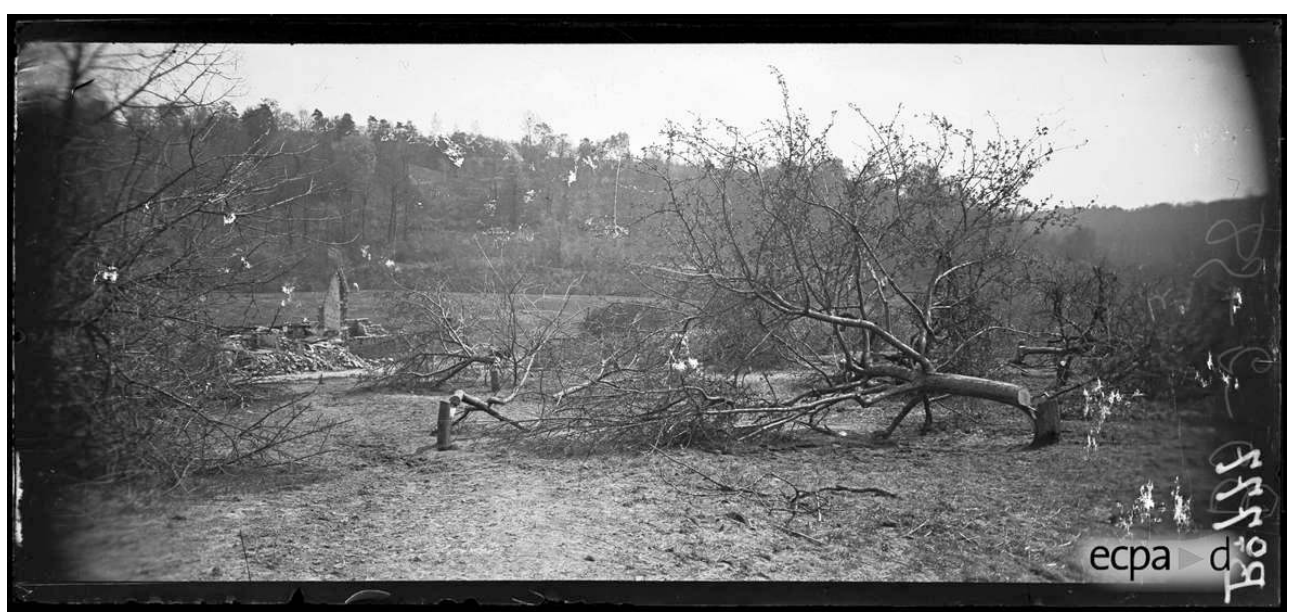

Juvigny (Aisne), un arbre fruitier en fleurs scié.

Phot. Boulay, Maurice. (c) ECPAD. 9 mai 1917. Réf. SPA 15 BO 777.

\section{LA SPCA, FER DE LANCE D'UNE ACTION DE PROPAgANDE : DÉNONCER LES DESTRUCTIONS DE L'ENNEMI FAITES SUR LE PATRIMOINE}

Utilisées à des fins de preuve par les commissions officielles, les images produites par la SCPA se retrouvent en toute logique employées aussi comme documents à charge pour accuser l'armée allemande de "barbarie » et dénoncer les crimes perpétrés contre le patrimoine, qu'il soit culturel, religieux, industriel ou rural. Amplifiée par la presse dès le début des hostilités, cette rhétorique s'appuie en grande partie sur la convention de La Haye de 1907 et son annexe qui concerne " les lois et coutumes de la guerre sur terre », où sont proscrites toutes les actions militaires dirigées contre des monuments ou des bâtiments contenant des biens culturels, religieux ou destinés à soigner les populations ${ }^{45}$. Elle est destinée, d'une part, à isoler l'Allemagne sur le plan international en privant son gouvernement de tout soutien extérieur et, d'autre part, à émouvoir et mobiliser les esprits en France et à l'étranger, et plus particulièrement aux États-Unis, en démontrant par les récits et par les images que les destructions de bâtiments historiques découlent d'une volonté systématique des armées allemandes.

Pour répondre à ces accusations, l'Allemagne constitue dès octobre 1914, sur l'ensemble des fronts où combat son armée, des unités chargées de protéger le patrimoine menacé par la guerre. Cette politique de sauvegarde, appelée Kunstschut $z^{46}$, met en œuvre d'importants moyens pour inventorier et évacuer les œuvres menacées par les bombardements. Les troupes allemandes déploient, à l'instar de la SPCA, des moyens de prise de vue pour parfaire ce travail d'inventaire et, par la même occasion, valoriser par une action de propagande le message qui s'oppose aux réquisitoires prononcés par la France et relayés par sa presse ${ }^{47}$. 

Journal ou L'Humanitéte ${ }^{48}$ rendent compte, au jour le jour, de la progression des forces françaises et britanniques. Peu d'éléments visuels y apparaissent pour témoigner de l'ampleur des destructions rapportées par les communiqués officiels de l'armée. De nombreux périodiques illustrés, tels que Le Miroir ou L'Illustration, qui connaissent depuis le début de la guerre un essor important ${ }^{49}$, favorisent dans les semaines suivantes la publication de documents visuels rapportés par les opérateurs de l'armée, complétant le flot de documents pris par les soldats eux-mêmes ainsi que les agences de presse étrangères.

Le travail initial d'inventaire du patrimoine en danger mené par la SPCA est inévitablement confronté aux impératifs de la communication en temps de guerre. Il importe de démontrer aux opinions publiques, par les images de dynamitages et d'incendies, que l'adversaire est prêt à commettre les pires actes pour emporter la décision sur le champ de bataille. Plusieurs exemples illustrés sont mis en exergue dans la presse, notamment dans le journal illustré Le Miroir, et dénoncent, par les commentaires qui les accompagnent, la lâcheté des exactions allemandes. Les cas des dynamitages du château de Coucy, dans l'Aisne, et de la forteresse de Ham, dans la Somme, semblent à eux seuls incarner cette rhétorique utilisée pour dénoncer les crimes allemands commis sur le patrimoine, à l'image de la bibliothèque de Louvain en Belgique en août 1914 et de la cathédrale de Reims en septembre de la même année ${ }^{50}$.

Classée au titre des Monuments historiques depuis 1862, la forteresse de Coucy est située à une quinzaine de kilomètres au nord de Soissons, dans l'Aisne. Dominant la vallée de l'Ailette, elle présente les caractéristiques d'une architecture militaire médiévale remontant au XIII ${ }^{e}$ siècle. En effet, le donjon circulaire de Coucy est l'un des plus importants d'Europe, avec ses trente-et-un mètres de diamètre et cinquante-quatre mètres de hauteur. Le 27 mars 1917, les troupes allemandes, qui évacuent la région, décident sa destruction, utilisant plus de trente tonnes d'explosifs pour venir à bout de l'édifice. Le photographe Édouard Brissy et le caméraman Alfred Machin arrivent sur les lieux dès le 30 mars 1917 et réalisent plusieurs séries de plans et de clichés des décombres ${ }^{51}$. Ces images sont reprises par les journaux illustrés tels que Le Miroir qui leur consacre une double page de son numéro du 22 avril 1917 (fig. n³8), utilisant deux clichés pris par Brissy (fig. $\mathbf{n}^{\circ}{ }^{39}$ ) (fig. $\mathbf{n}^{\circ} \mathbf{4 0}$ ). L'exemple de la forteresse de Ham est également emblématique. Ce château du XIII ${ }^{e}$ siècle, réaménagé au XVI ${ }^{e}$ siècle, connut plusieurs modifications à l'instigation de Vauban. Disposant d'une enceinte remarquablement défendue par une série de tours, la forteresse est dynamitée le 19 mars 1917 à l'aide de plusieurs tonnes d'explosifs. Comme le château de Coucy, le fort de Ham devient au cours des mois suivants un lieu de visite où l'on conduit les délégations étrangères qui découvrent les anciens champs de bataille. En octobre 1917, le président de la République portugaise, Bernardino Machado, accompagné du président Raymond Poincaré, parcourt ces ruines. Édouard Brissy couvre la visite présidentielle (fig. $\mathbf{n}^{\circ} \mathbf{4 1}$ ) et réalise plusieurs documents photographiques. Un document illustrant cette visite, non produit par la SPCA, est publié dans Le Miroir du 28 octobre 1917 (fig. $\mathbf{n}^{\circ} \mathbf{4 2}$ ). Une observation attentive permet de deviner la présence d'Édouard Brissy, de dos. 
Figure 38

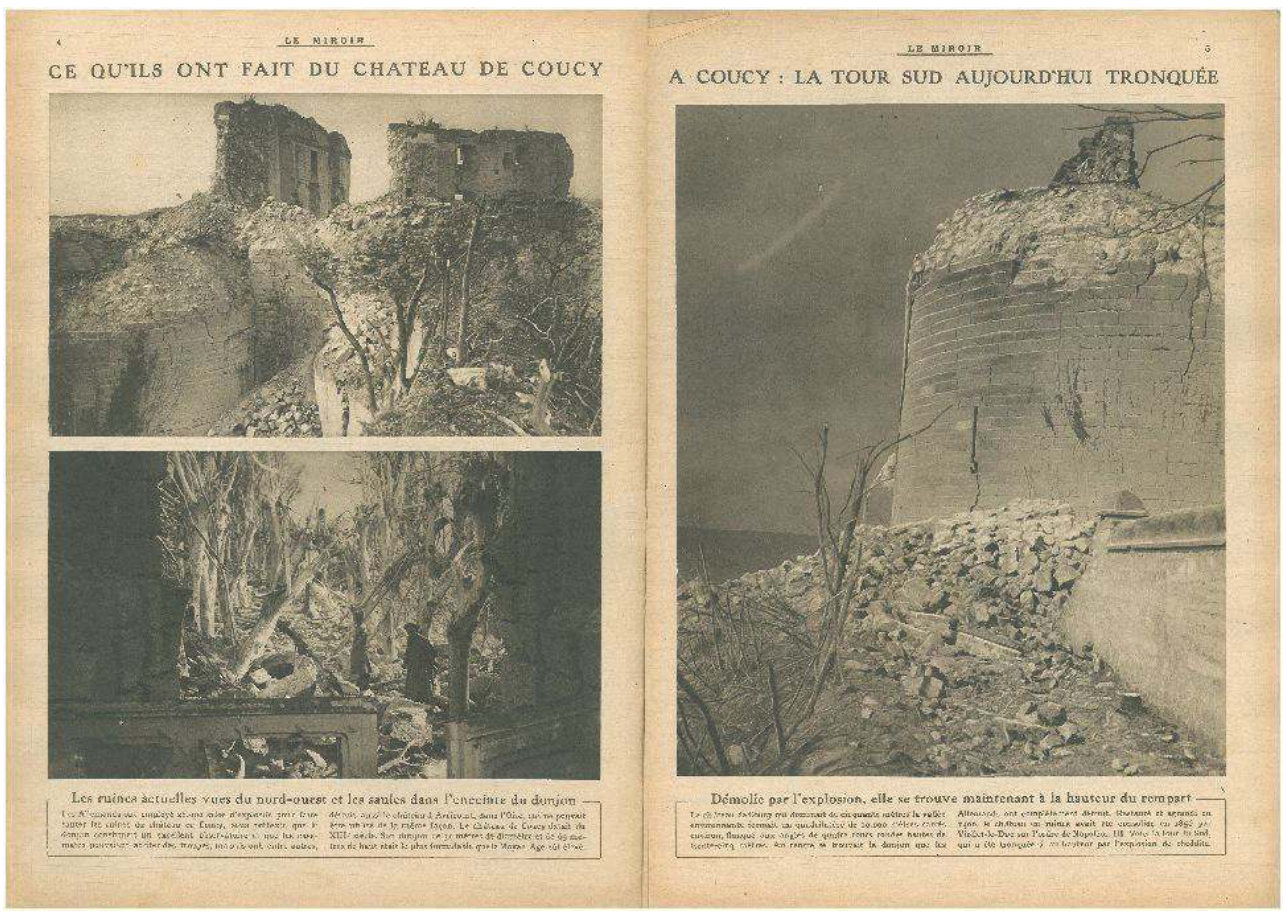

s.n. « Ce qu'ils ont fait du château de Coucy ». Le Miroir, n¹75, 22 avril 1917, p. 4-5.

Figure 39

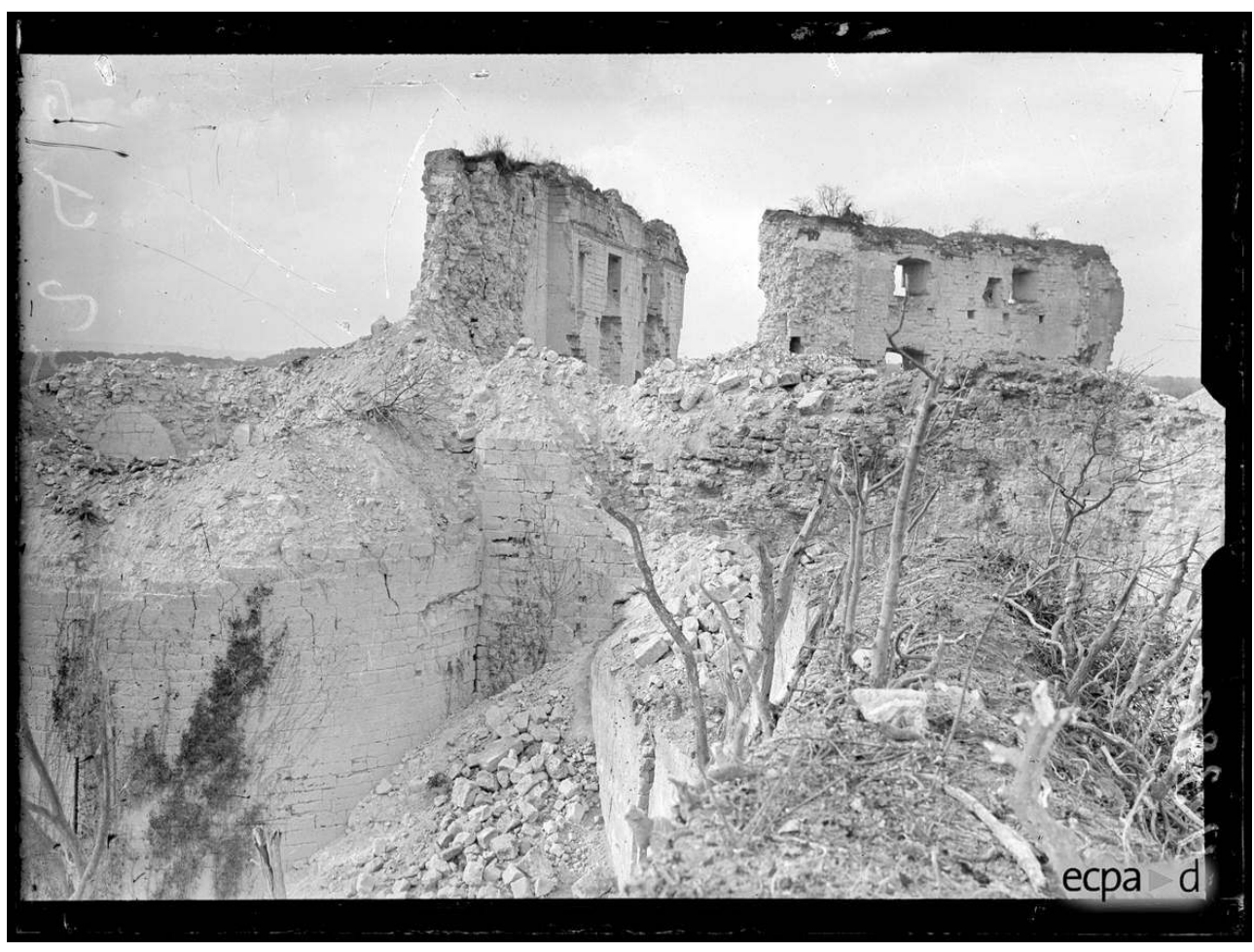

Coucy-le-Château (Aisne), avec les ruines du donjon.

Phot. Brissy, Édouard. (C) ECPAD. 31 mars 1917. Réf. SPA 51 D 3860. 


\section{Figure 40}

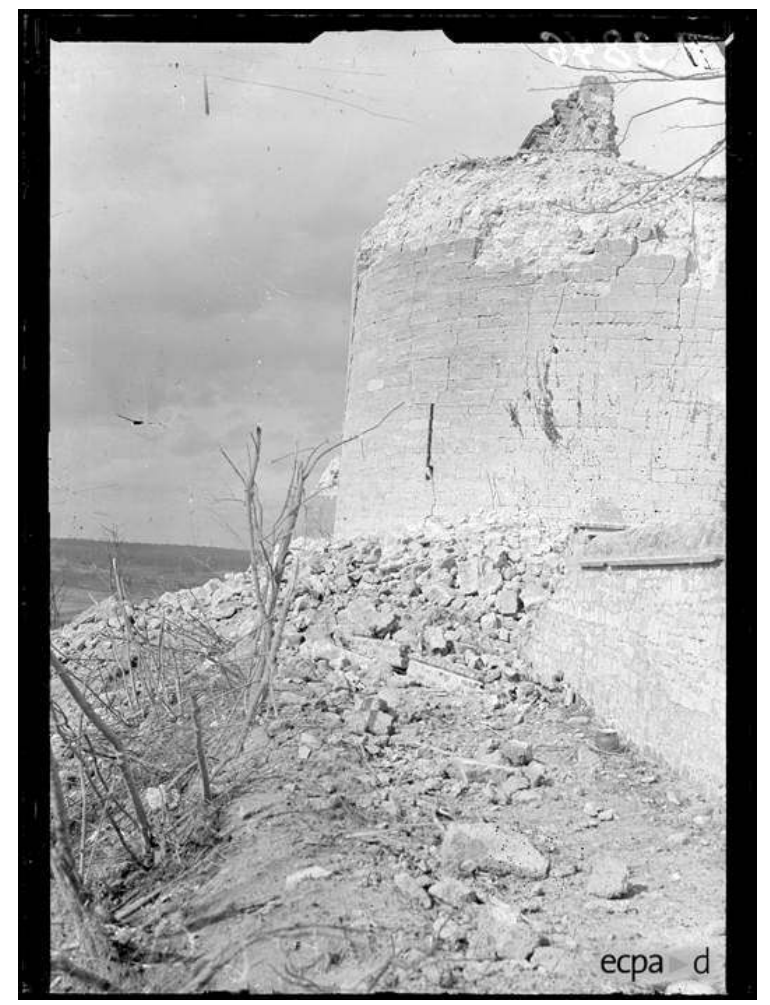

Coucy-le-Château (Aisne), le pied du donjon (vue extérieure), 31 mars 1917.

Phot. Brissy, Édouard. (c) ECPAD. Réf. SPA 51 D 3846. 
Figure 41

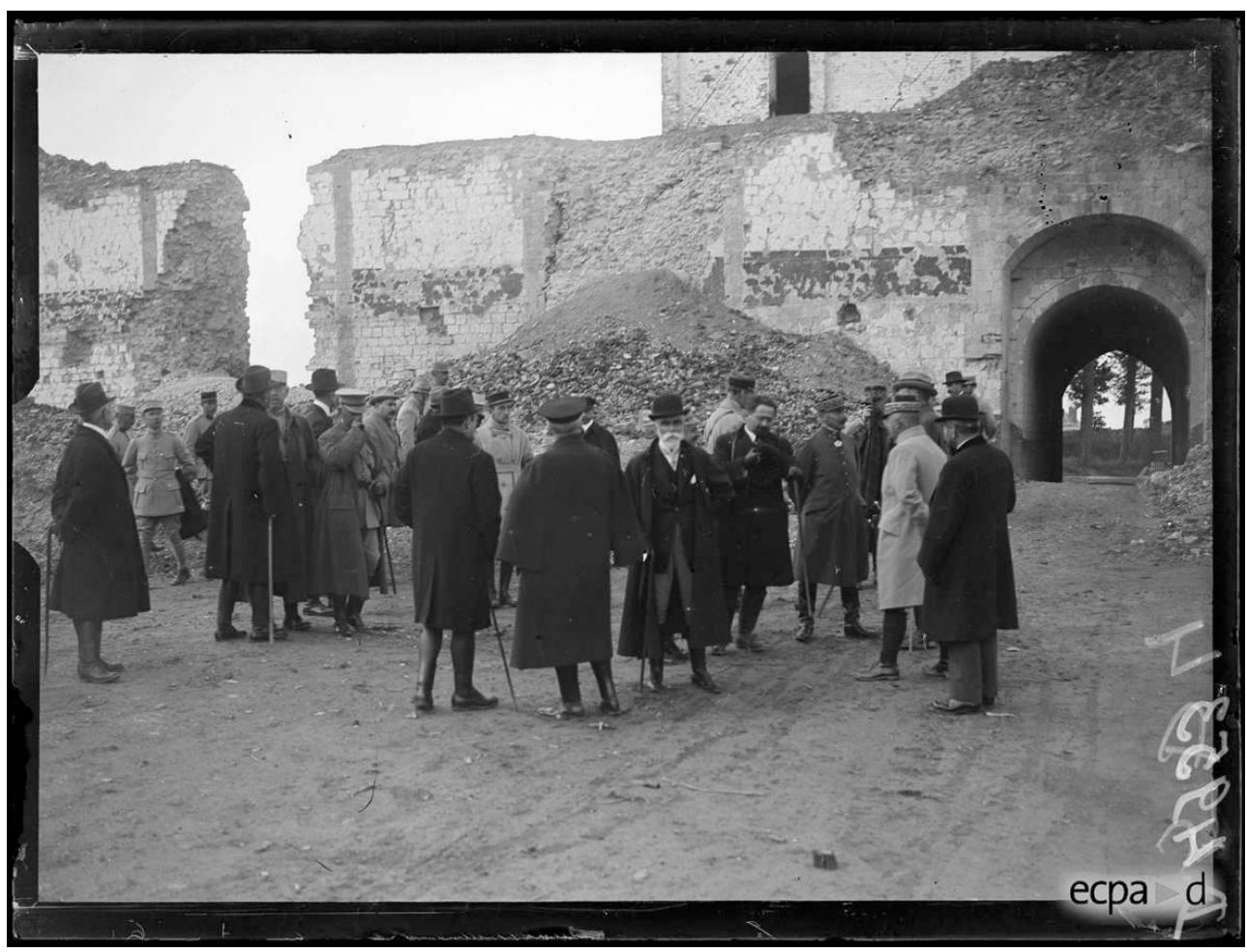

Ham (Somme), visite du président de la République portugaise au château

Phot. Brissy, Édouard. (c) ECPAD. 11 octobre 1917. Réf. SPA 78 D 4953. 


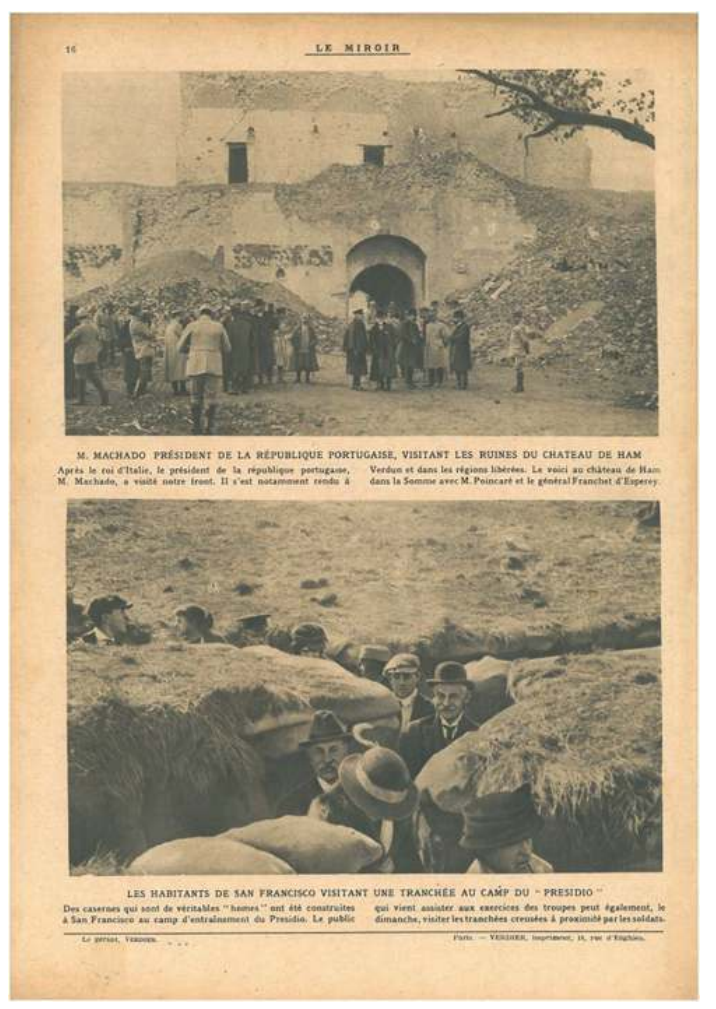

S.n. «M. Machado président de la République portugaise visitant les ruines du château de Ham ». Le Miroir, $n^{\circ} 205,28$ octobre 1917. $4^{e}$ de couverture.

Le même constat peut être dressé pour les films d'actualités traitant de l'événement. Dans un numéro spécial réalisé à l'occasion du repli allemand de Picardie, la SPCA présente sur les écrans français les conséquences de l'opération allemande. Intitulé Le territoire français libéré par la retraite allemande en mars 1917 (fig. $\mathbf{n}^{\circ} \mathbf{4 3}$ ), ce film, d'une durée de vingt minutes, est monté à partir des images tournées en mars et avril 1917 par Alfred Machin et René Meunier. Cette bande d'actualités en deux parties propose aux spectateurs de découvrir les destructions commises par l'armée allemande dans les villes et villages de Picardie tels que Roye, Noyon, Ham, Chauny, Tergnier ou encore Nesle. Le patrimoine endommagé par l'ennemi occupe une place omniprésente. Le sort funeste réservé aux églises et à de nombreux châteaux et bâtiments publics qui présentent un caractère historique certain est montré à l'écran. À Lassigny, le film présente les ruines de l'église, précisant qu'elle a été pillée et incendiée par les Allemands. Le vocabulaire employé dans les intertitres qui introduisent chaque séquence tend à personnifier les décombres, rappelant par la même occasion au public leur intérêt historique. Les exemples du dynamitage du château de Coucy et de celui de Ham apparaissent aux côtés de termes tels que les "pierres mortes" de Tergnier et les "misères de Chauny ", inscrivant cette catastrophe dans une référence historique liée à la série des Grandes misères de la Guerre ${ }^{52}$, du graveur nancéien Jacques Callot. Ces commentaires sous-entendent que les forces allemandes ne s'en sont pas seulement pris aux infrastructures de transport et de communication pour ralentir l'avancée des Alliés, mais aussi qu'elles se sont acharnées contre le corps et l'âme de la région, matérialisée par son patrimoine légué par les siècles. Ce constat de "victimisation» du patrimoine, qui englobe également la notion de patrimoine culturel, s'associe à une dénonciation de la « culture allemande ». 
Figure 43

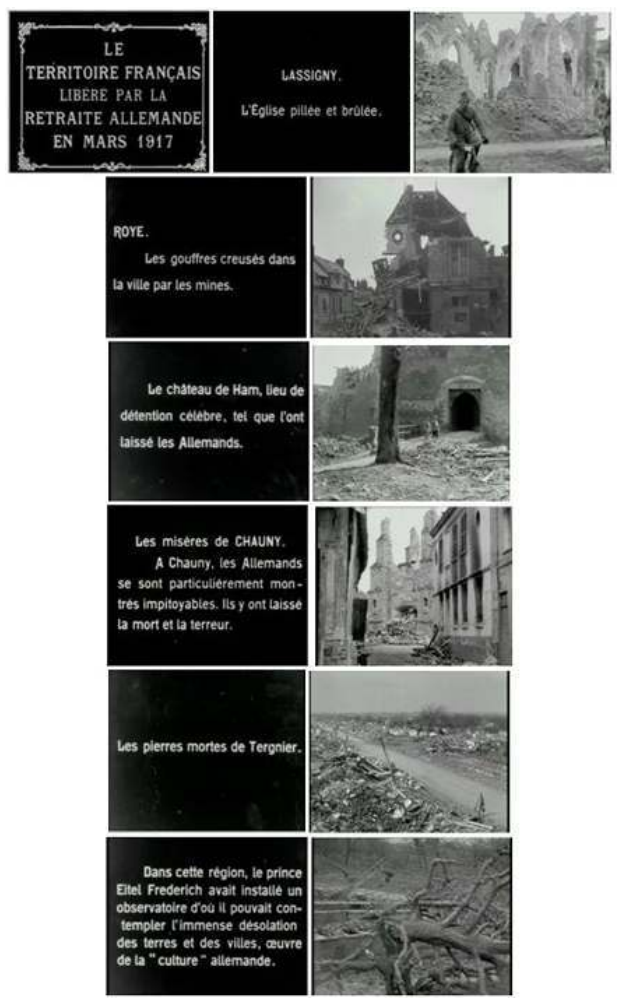

Photogrammes du film Le territoire français libéré par la retraite allemande en mars 1917. Durée 20 min 30 sec. Noir et blanc, muet. Réalisation SCA. Réf. 14.18 A 129.

51 Cette rhétorique, utilisée dès le début de la guerre, se retrouve dans l'exemple des destructions de Picardie. Les journaux écrits et filmés propagent la théorie selon laquelle l'idée de civilisation, relayée par le concept de justice et incarnée par les gouvernements de l'Entente, s'oppose à la «culture allemande ", également mentionnée sous le terme de « Kultur », qui est synonyme dans les organes de presse français de destruction et de mort ${ }^{53}$. Le film réalisé par la SPCA mentionne bien le terme de "culture allemande » (voir fig. $\mathbf{n}^{\circ}$ 43) pour dénoncer la mise à sac des terres de Picardie, montrant notamment l'observatoire du prince Eitel à Frières-Faillouël, dans l'Aisne, où l'ensemble des arbres qui entouraient l'ancien relais de chasse transformé en poste d'observation ont été abattus.

\section{LA RECONQUÊTE DES RUINES OU LA RÉAPPROPRIATION DU PATRIMOINE}

52 Après l'œuvre de dénonciation des crimes commis à l'encontre du patrimoine de Picardie, un autre discours apparaît dans la presse écrite et filmée de l'époque. Il expose la démarche suivante: les localités et les lieux précédemment occupés par les forces allemandes doivent faire l'objet d'une réappropriation par les autorités de la République, par l'action de son armée et de ses représentants locaux ou nationaux. Au constat initial de désolation et de mort causées par les troupes allemandes succède un sentiment de victoire, de retour à la vie. Plusieurs films d'actualités réalisés par la SPCA à partir du 
mois d'avril 1917 se font l'écho de cette catharsis destinée à effacer les traces de l'occupation et de la guerre pour mieux préparer l'œuvre de reconstruction.

Ainsi, dans son numéro 2 des Annales de la guerre daté du 25 mars 1917, la SPCA relate la visite de la ville de Noyon par le président Poincaré. Se déroulant le 24 mars, ce voyage officiel est présenté dans son titre principal comme un acte pour « le salut de la Nation » (fig. $\mathbf{n}^{\circ} \mathbf{4 4 )}$. Le président de la République rencontre et décore le maire de Noyon, Ernest Noël, et plusieurs personnalités présentes durant l'occupation de la ville. Quelques jours avant la visite présidentielle, un numéro spécial des actualités de la SPCA intitulé Les Allemands ne sont plus à Noyon ${ }^{54}$ témoigne de l'arrivée du général Nivelle dans la ville dévastée. Le commandant en chef des armées du Nord et du Nord-Est assiste au défilé des troupes du $92^{\mathrm{e}}$ régiment d'infanterie et salue plusieurs personnalités de la ville, où les habitants et les soldats entonnent la Marseillaise. Cet événement daté du 20 mars est également présenté grâce aux images prises par Maurice Boulay (fig. $\mathbf{n}^{\circ} \mathbf{4 5}$ ) et diffusées dans l'édition du $1^{\mathrm{er}}$ avril $1917 \mathrm{du}$ journal Le Miroir (fig. $\left.\mathbf{n}^{\circ} 46\right)$. Un autre symbole photographié par Brissy lors de son arrivée dans Ham le 21 mars 1917 (fig. $\mathbf{n}^{\circ}$ 47) expose aux lecteurs du Miroir du 8 avril 1917 la levée du drapeau tricolore sur un mât télégraphique par un jeune garçon de la ville de Ham (fig. $\mathbf{n}^{\circ} \mathbf{4 8}$ ).

Figure 44
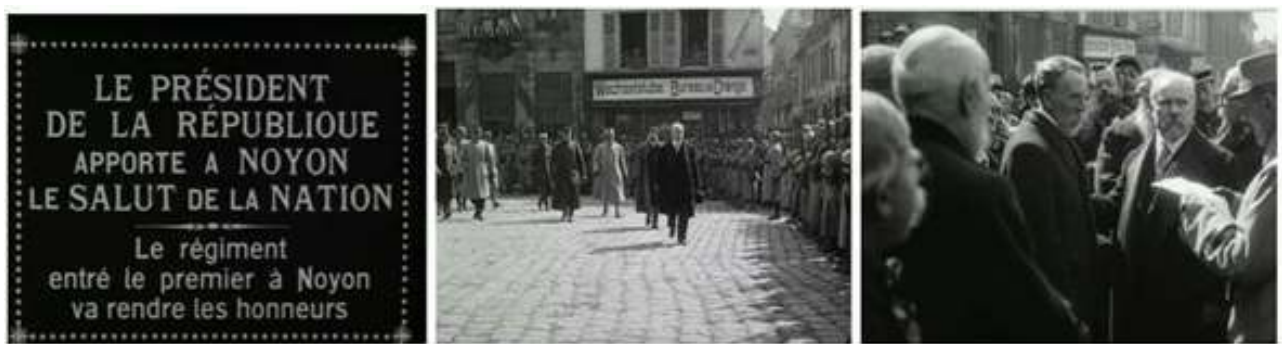

Captures visuelles du sujet : Le président de la République apporte à Noyon le salut de la Nation. Extraits des Annales de la guerre, $n^{\circ} 2$ du 25 mars 1917. Durée 3 min 30 s. Noir et blanc, muet, réal. SPCA. Réf. 14.18 B 2.

Figure 45

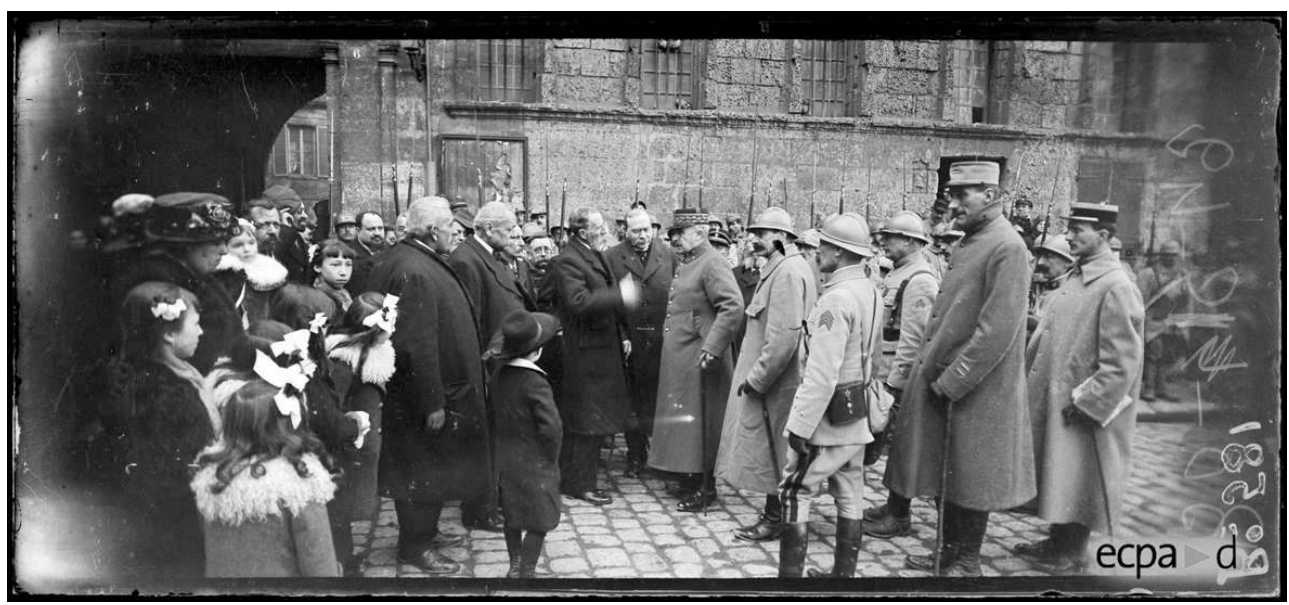

Noyon (Oise). La municipalité reçoit le général Nivelle. Le maire prononçant un discours.

Phot. Boulay, Maurice. (c) ECPAD. 20 mars 1917. Réf. SPA 11 BO 581. 


\section{Figure 46}

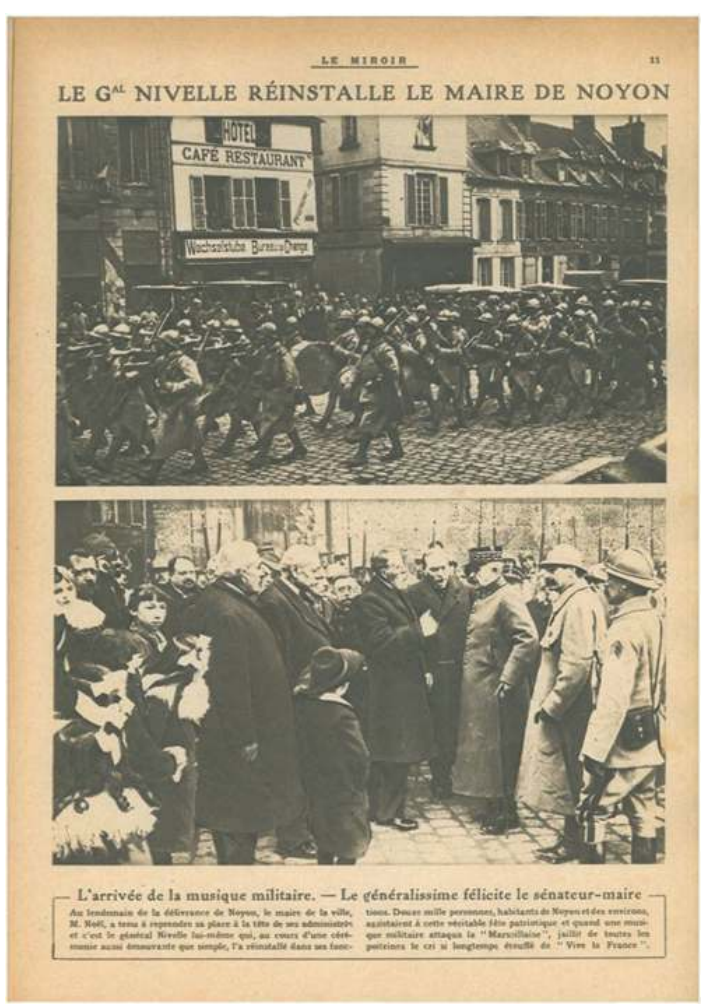

s.n. Le général Nivelle réinstalle le maire de Noyon. Le Miroir, n¹75, $7^{\text {er }}$ avril 1917. 
Figure 47

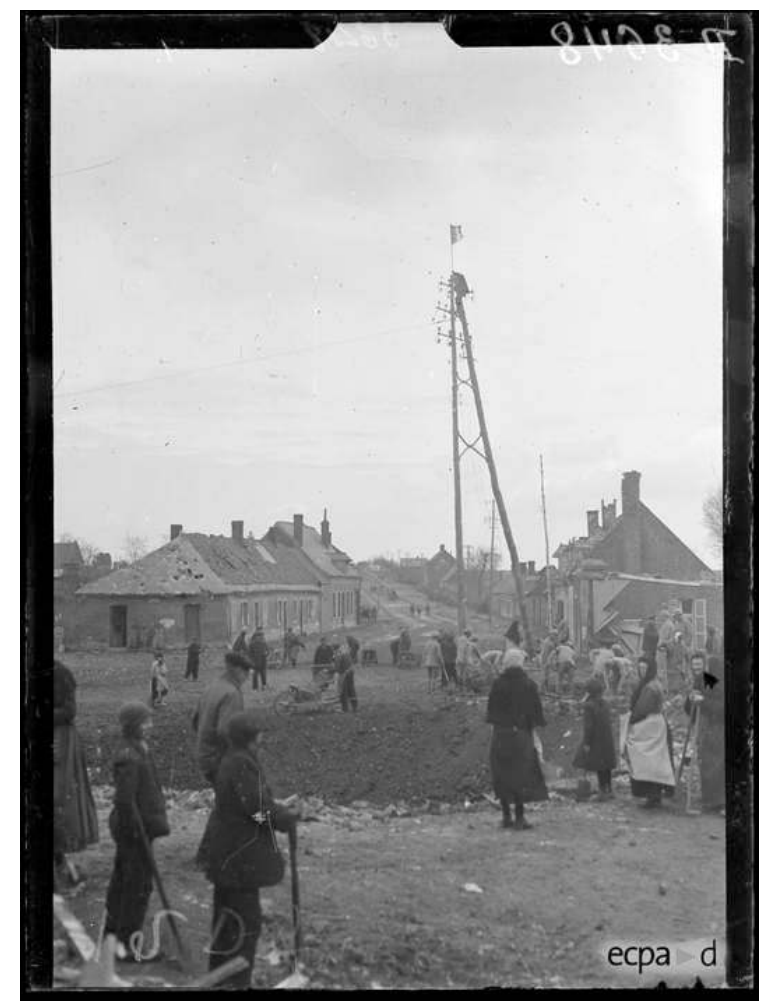

Ham (Somme), petit garçon allant accrocher le drapeau français au sommet d'un poteau télégraphique.

Phot. Brissy, Édouard. (c) ECPAD. 21 mars 1917. Réf. SPA 47 D 3648. 


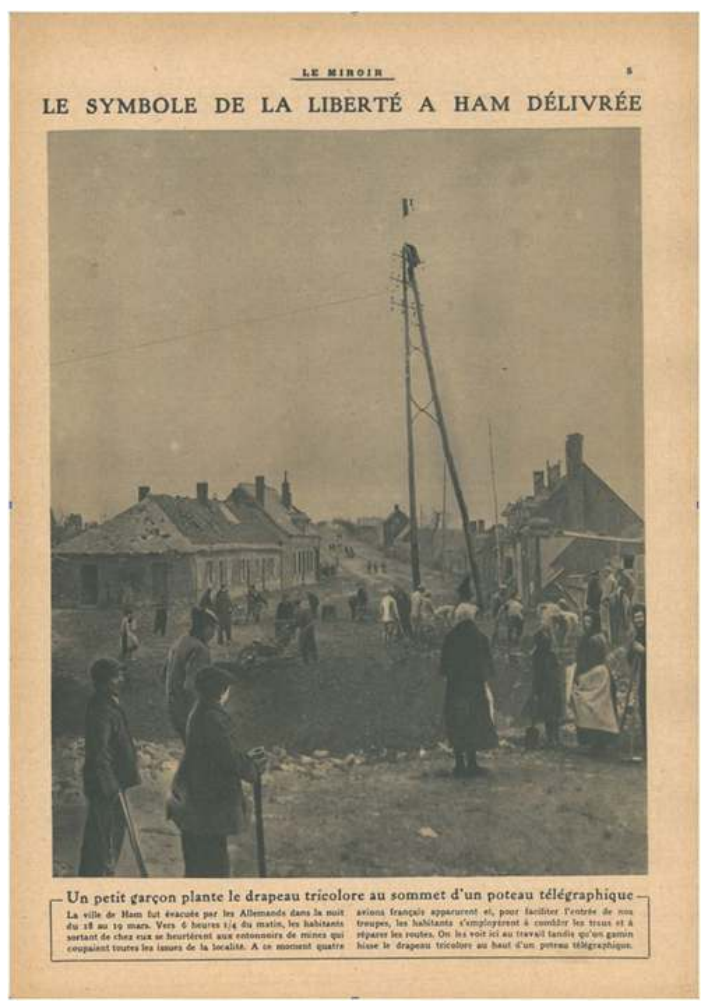

S.n, « Le symbole de la liberté à Ham délivrée ». Le Miroir, n¹76, 8 avril 1917.

Ce discours cathartique voulant conjurer le mal se fonde sur des actions de réoccupation des ruines ou de déblaiement préparant le travail de reconstruction. Dans les éditions $n^{\circ} 6$ et n 8 des Annales de la guerre datées d'avril 1917, les opérateurs de la SPCA témoignent de l'occupation des ruines du village d'Happencourt dans l'Aisne. Cet acte est présenté comme un retour à la vie des vieilles pierres (fig. $\mathbf{n}^{\circ}{ }^{499)}$ ). À l'inverse, dans le numéro 8 des actualités de la SPCA, les soldats sont clairement présentés dans les cartons du film comme «achevant» les ruines de la ville de Chauny dans l'Aisne, détruite lors du repli allemand (fig. $\mathbf{n}^{\circ} \mathbf{5 0}$ ). De nombreux reportages de la SPCA attestent de cette action de reconstruction, mettant l'accent sur les initiatives publiques et privées qui vont permettre à la population de regagner ses villages. Nombre de reportages filmés et photographiés par la SPCA montrent l'emploi des prisonniers de guerre allemands dans la reconstruction de nombreuses maisons ou la remise en état des champs (fig. $\mathbf{n}^{\circ} \mathbf{5 1}$ ). L'aide américaine est également associée à cette œuvre de reconstruction d'urgence. Les actions menées par le comité américain de Blérancourt, dans l'Aisne, animé par Ann Morgan, fille et héritière $\mathrm{du}$ banquier américain John Pierpont Morgan, sont couvertes par le photographe Édouard Brissy et le caméraman Charles Blanc ${ }^{55}$. Ces derniers témoignent du travail des bénévoles qui fournissent aux habitants de Picardie une aide matérielle et sanitaire. Des engins agricoles modernes sont importés des États-Unis pour accélérer la remise en état des terres cultivables ${ }^{56}$, également filmés et photographiés par les opérateurs de l'armée. 

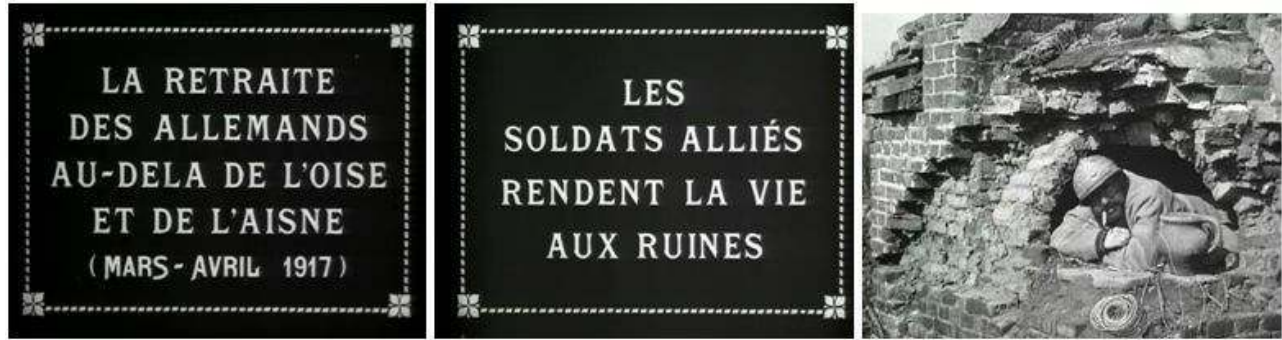

Photogrammes extraits du film La retraite des Allemands au-delà de l'Oise et de l'Aisne (mars-avril 1977). Les Annales de la guerre, n6. Durée : 9 min 58 sec. Noir et blanc. Réal. SPCA. réf. 14.18 B 6.

Figure 50
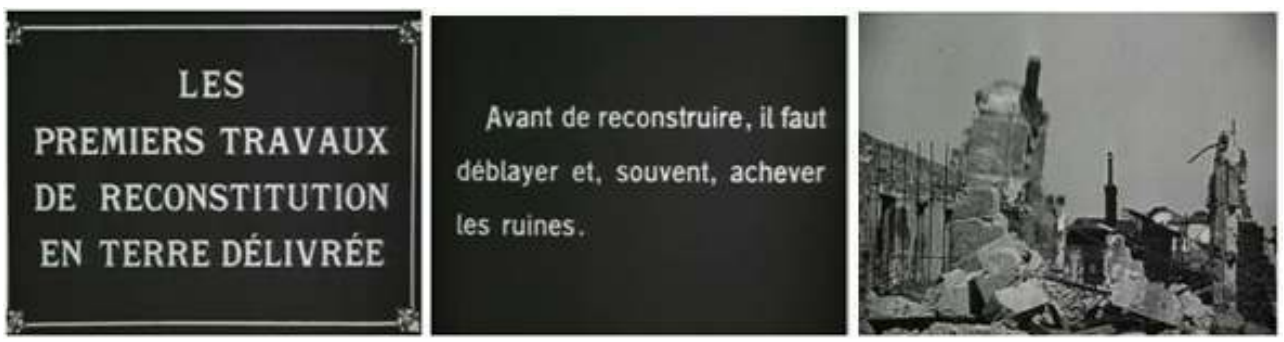

Photogrammes extraits du film Les premiers travaux de reconstruction en terre délivrée. Les Annales de la guerre, $n^{\circ} 8$. Durée : 7 min 41 sec. Noir et blanc. Réal. SPCA. Réf. 14.18 B 8.

Figure 51

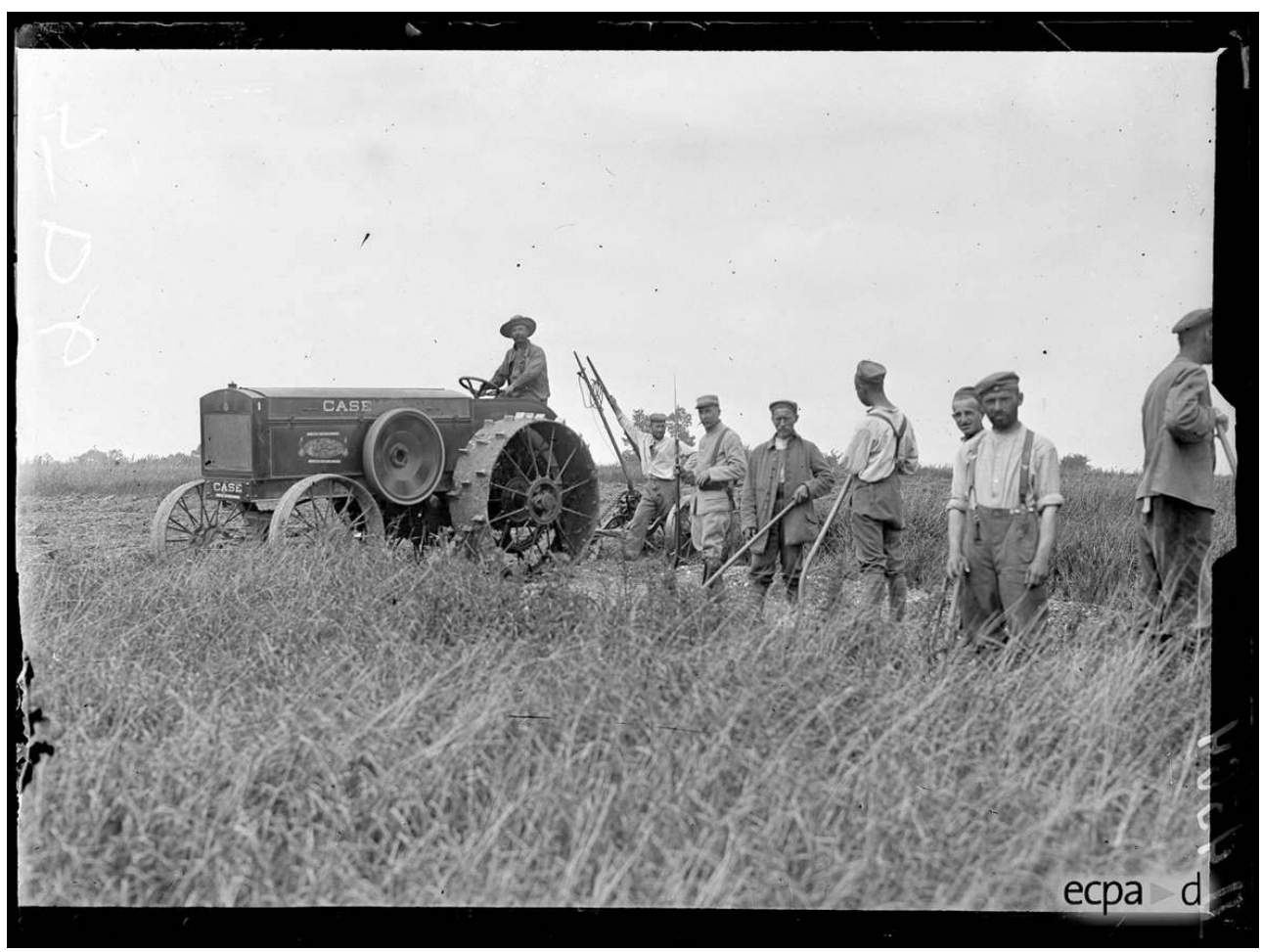

Près de Roye (Somme), prisonniers allemands bouchant des tranchées pour permettre la mise en culture du terrain récupéré.

Phot. Brissy, Édouard. (c) ECPAD. 16 juin 1917. Réf. SPA 58 D 4364. 
Enfin, cette collaboration entre la France et les États-Unis au sujet des ruines laissées par l'armée allemande en Picardie prend une tournure inattendue. La SPCA est sollicitée pour participer à un travail de prise de vue pour le compte du réalisateur américain David Wark Griffith. Auteur notamment des films Naissance d'une nation (1915) et Intolérance (1916), D. W. Griffith a pour projet, en cette année 1917, de mettre en œuvre un nouveau film. Intitulé Coeurs du monde (Hearts of the World), il met en scène l'histoire d'amour entre un romancier américain et une jeune Française dont l'idylle est brisée par la guerre. Après une demande de l'ambassadeur des États-Unis à Paris, D. W. Griffith obtient du Grand Quartier général français les autorisations et les moyens de tourner plusieurs scènes sur le front. L'opérateur Alfred Machin est ainsi mobilisé pour accueillir, le 30 avril 1917, le réalisateur américain dans la région de Lassigny, dans l'Oise. Tous deux y réalisent plusieurs plans des ruines. Seule une trace dans les archives de la SPCA atteste ce tournage ${ }^{57}$ dont les images furent par la suite montées dans le film, qui fut distribué en France.

$56 \mathrm{Au}$ lendemain de la délivrance de Noyon, le maire de la ville, $\mathrm{M}$. Noël, a tenu à reprendre sa place à la tête de ses administrés et c'est le général Nivelle lui-même qui, au cours d'une cérémonie aussi émouvante que simple, l'a réinstallé dans ses fonctions. Douze mille personnes, habitants de Noyon et des environs, assistaient à cette véritable fête patriotique et quand une musique militaire attaqua la «Marseillaise », jaillit de toutes les poitrines le cri si longtemps étouffé de «Vive la France».

La ville de Ham fut évacuée par les Allemands dans la nuit du 18 au 19 mars. Vers 6 heures $1 / 4$ du matin, les habitants sortant de chez eux se heurtent aux entonnoirs de mines qui coupaient toutes les issues de la localité. À ce moment quatre avions français apparurent et, pour faciliter l'entrée de nos troupes, les habitants s'employèrent à combler les trous et à réparer les routes. On les voit ici au travail tandis qu'un gamin hisse le drapeau tricolore au haut d'un poteau télégraphique.

\section{CONCLUSION}

Véritable cataclysme en Picardie, la Première Guerre mondiale bouleverse de façon irrémédiable les paysages et les localités de l'Aisne, de l'Oise et de la Somme, qui avaient conservé avant 1914 un patrimoine architectural et culturel très riche. Plus que n'importe quel autre conflit, la Grande Guerre a laissé de façon indélébile des traces qui témoignent, encore de nos jours, de l'ampleur des destructions et du sacrifice de plusieurs générations. de l'année 1915, entreprend sur l'ensemble du front un travail d'inventaire de l'état de ruine dans lequel se trouvent de nombreux édifices sacrés ou profanes, militaires, industriels ou agricoles. Le déclenchement de l'opération Alberich en mars 1917 marque un tournant dans la réalisation de ce recensement par l'image car, face à l'ampleur des destructions, la SPCA doit envoyer plusieurs équipes pour couvrir l'ensemble des territoires de Picardie.

Tout au long de l'année 1917, les opérateurs de l'armée se concentrent sur la prise de vue de ruines d'églises, de châteaux et autres édifices. Cette mission, encadrée par le soussecrétariat d'État aux Beaux-Arts, a pour finalité la préparation des futurs travaux de restauration ou de reconstruction des villes et villages de Picardie et de leur patrimoine 
architectural. Ce travail s'associe à une autre mission confiée à la SPCA, consistant à inventorier par l'image les anciens champs de bataille à préserver au nom du « devoir de mémoire ». Ces documents constituent par la suite la documentation visuelle (iconographique ?) pour la publication des Guides illustrés des champs de bataille édités par la société Michelin, faisant la promotion d'une mémoire combattante qui s'incarne dans les images de ruines « héroïques ", preuves des souffrances endurées par la patrie, mais éloignant pour de longues années encore la vision plus réaliste de la brutalité des combats et les souffrances subies par les hommes.

61 Ces premières opérations de sauvegarde du patrimoine engagées du printemps à l'automne 1917 sont remises en cause par les événements militaires. En mars 1918, les forces allemandes s'élancent dans une nouvelle offensive, tentant le tout pour le tout afin de percer le front en direction d'Amiens. Les combats de l'été 1918, notamment lors de la contre-offensive générale des Alliés, achèvent la dévastation complète de localités. De nombreux éléments du patrimoine jusqu'alors épargnés finissent par tomber, la Picardie sortant ainsi totalement exsangue de quatre années de guerre. Les images prises par la SPCA sont une source précieuse pour saisir au mieux l'envergure titanesque des chantiers de reconstruction qui attendent les habitants de Picardie au lendemain de la guerre. Le conflit entraîne des changements irréversibles dans les paysages, modifiant par exemple les modes de construction en matière d'habitation: face à l'urgence du relogement, les matériaux industriels sont privilégiés par rapport aux matériaux traditionnels qui conféraient une spécificité régionale appréciée dans de nombreuses localités picardes, et dont les cartes postales éditées avant la guerre constituent les dernières traces visuelles.

62 À la différence de conflits précédents, la Grande Guerre, grâce aux nouvelles techniques de la photographie et du cinéma, met en lumière l'enjeu culturel que représente le patrimoine pour les belligérants, à la fois pour sa possession et sa destruction. Le concept de " patrimoine historique $»^{58}$, qui s'associe à l'idée de nation à partir du XIX siècle, offre aux contemporains le reflet de sa puissance passée et est « héroïsé » durant la Première Guerre mondiale. Les images réalisées par la SPCA visant à dresser l'inventaire des ruines vont également alimenter une action de propagande où leur mise en exergue tend à nourrir la «haine contre l'adversaire $~^{59}$. Ces images de désolation pèseront sans nul doute dans l'opinion publique lors de la signature du traité de Versailles en 1919 et véhiculeront pendant plusieurs décennies l'image d'une armée allemande adepte (portée au ?) du pillage et de l'incendie des monuments ${ }^{60}$.

63 La Seconde Guerre mondiale voit cette rhétorique réapparaître, exposant l'image d'un patrimoine devenu l'enjeu de luttes, visant à mobiliser ou à briser la résistance des populations.

\section{NOTES}

1. - DEPERCHIN, Annie. "Des destructions aux reconstructions». Dans BECKER, Jean-Jacques, AUDOUIN-ROUZEAU, Stéphane. Encyclopédie de la Grande Guerre 1914-1918. Paris : éd. Bayard, 2004, p. 1125-1137. 
2. - VÉRAY, Laurent. Les films d'actualités français de la Grande Guerre. Paris : éd. SIRPA/AFRHC, 1995 , p. 28.

3. - Note n`3527 datée du 9 mai 1915 : le général commandant en chef annonce la création de la Section photographique de l'armée. GUILLOT, Hélène. Photographier la Grande Guerre, les soldats de la mémoire, 1915-1919. Thèse de doctorat d'histoire contemporaine, université de Paris 1 PanthéonSorbonne, juillet 2012, sous la direction de Myriam Tsikounas, p. 48-49.

4. - JAILLET, contrôleur adjoint de l'armée, Rapport sur la création, le fonctionnement, les résultats de la section photographique et cinématographique de l'armée. 10 octobre 1917. Document original conservé aux archives de la Médiathèque de l'architecture et du patrimoine (MAP) au fort de Saint-Cyr, dans les Yvelines. Copies également disponibles à l'ECPAD.

5. - Pierre-Marcel Lévi est docteur en histoire de l'art à la Sorbonne en 1903. En 1905, il devient le secrétaire de l'École des hautes études sociales, devenant l'un des collaborateurs de la revue Athéna et chargé des cours d'histoire du dessin à l'université de la Sorbonne. En 1911, il devient le responsable des inventaires des dessins aux musées du Louvre et de Versailles, puis, en 1912, membre de la Société de l'histoire de l'art français, et par ailleurs président du conseil supérieur de l'enseignement des beaux-arts. Il fonde en 1921 les Presses universitaires de France avec Maurice Caullery. Il est remplacé en 1937. Pendant la Seconde Guerre mondiale, il est écarté par les lois anti-juives du gouvernement de Vichy et part pour Lyon où il écrit pour le compte d'un journal de la Résistance, Le Patriote Lyonnais. En 1945, il devient secrétaire général de l'Entraide française. Il décède en 1953. GUILLOT, Hélène. Photographier la Grande Guerre, les soldats de la mémoire, 1915-1919. Thèse de doctorat d'histoire contemporaine, université de Paris 1 Panthéon-Sorbonne, juillet 2012, sous la direction de Myriam Tsikounas, p.48-49.

6. - LÉVI, Pierre-Marcel. «L'histoire de la Grande Guerre, des archives, des documents, des preuves ». Les Annales politiques et littéraires, $n^{\circ} 1673$, 18 juillet 1915, p. 72 . Extrait de la thèse de GUILLOT, Hélène, ibid. p. 49.

7. - VÉRAY, Laurent. Les films d'actualités français de la Grande Guerre. Paris : éd. SIRPA/AFRHC, 1995, p. 32.

8. - Un conflit d'intérêts oppose rapidement les chambres syndicales et le commandement de la SPA et de la SCA. En raison de divergences d'intérêts financiers et personnels, la collaboration entre le monde professionnel et l'armée prend une tournure inattendue. En effet, la question de l'obéissance des opérateurs, rattachés à leurs maisons d'origine, se pose dans ces termes: comment faire confiance à des photographes, certes soumis aux obligations militaires, mais demeurant rattachés à une société privée qui recherche un profit dans la vente de documents? Plusieurs tentatives de déstabilisation sont organisées contre la personne du directeur de la SPA, accusé par la chambre syndicale de la photographie de détournements de fonds. Une enquête écarte tout soupçon, blanchissant Pierre-Marcel Lévi. «Rapport sur la création, le fonctionnement, les résultats de la section photographique et cinématographique de l'armée », 10 octobre 1917.

9. - Un exemple de punition est mis en avant dans le travail réalisé par Hélène Guillot dans sa thèse consacrée au fonctionnement de la Section photographique de l'armée. Un document conservé dans les archives du SHD (Service historique de la défense) (SHD/GR 5 N 550) fait apparaître qu'un caporal détaché auprès de la SPA a été puni le 27 juillet 1915 au motif d'avoir photographié des officiers allemands prisonniers malgré l'avis contraire de l'officier d'état-major qui encadrait la mission. Le caporal Gratouillet s'est vu infliger huit jours de prison.

10. - Le contrôle de la presse durant la Première Guerre mondiale s'organise autour des cadres législatifs anciens et spécialement mis en place à la déclaration de guerre, avec la loi du 5 août 1914. Le contrôle de l'information passe par plusieurs organismes qui dépendent du ministère de la Guerre, du ministère des Affaires étrangères et du ministère de l'Intérieur. Ils organisent à leur niveau les paliers de contrôle du travail des correspondants de guerre, de leur visite sur le champ de bataille à la publication de leur article. Voir l'ouvrage de MAURIN, Jean- 
Louis. Combattre et informer, l'armée française et les médias pendant la première guerre mondiale. Paris : éd. Codex, 2009.

11. - Le plan de classement adopté à l'époque est une cotation par série alphabétique, allant de la lettre $\mathrm{A}$ à $\mathrm{Z}$. Chaque lettre représente le travail d'un ou plusieurs opérateurs photographes. Ce système perdure à l'ECPAD pour renseigner le fonds d'images fixes de la Première Guerre mondiale.

12. - Note du général Lyautey, ministre de la Guerre, concernant la fusion des sections photographique et cinématographique de l'armée, 6 février 1917, SHD/GR 5 N 346.

13. - Avant la date de 1917, l'armée ne possède pas les rushes qui sont conservés par les sociétés partenaires de la SCA, tels que Pathé, Gaumont, Éclipse et Éclair. Le SCA ne conserve que le montage final diffusé en salle par l'intermédiaire des circuits commerciaux que possèdent ces mêmes firmes cinématographiques.

14. - BUfFETAUT, Yves. Arras, Vimy, Le Chemin des Dames, les grandes offensives du printemps 1917. Paris : éd. Histoire et Collections, 1997, p. 14.

15. - BUfFETAUT, Yves. "Opération Alberich, le repli allemand sur la ligne Hindenburg". Tranchée, un regard nouveau sur la Grande Guerre. Novembre 2012, hors-série n4, p. 14-25.

16. - Le soldat Édouard Brissy, matricule 770, travaille au sein de la Section photographique de l'armée à partir du mois de mai 1915, c'est-à-dire dès le début de la création de la SPA. Photographe, il réalise une centaine de reportages au cours de la guerre, soit plusieurs milliers de documents. Lors de cette mission dans la Somme, Édouard Brissy photographie l'explosion d'une mine française placée sous les lignes allemandes de Beuvraignes, village de la ligne de front situé au sud de Roye. Lors de cette explosion, déclenchée le 27 décembre 1916, il réalise cinq clichés montrant le départ et l'immense gerbe de terre provoquée par la charge explosive. Il sera alors cité à l'ordre de la $3^{\mathrm{e}}$ armée pour son action, faisant preuve de sang-froid et d'une «belle crânerie » face au feu intense de l'ennemi. Source : ordre n'18 extrait du livre d'ordre de la SPCA, non coté, conservé à la Médiathèque de l'architecture et du patrimoine (MAP), au fort de SaintCyr de Montigny-le-Bretonneux.

17. - En effet, certains documents présents dans les archives de la SPCA témoignent de la diversité du matériel utilisé par les opérateurs lors de leur reportage. Des listes d'inventaires conservées dans les archives de la Médiathèque de l'architecture et du patrimoine au fort de Saint-Cyr mentionnent plusieurs types d'appareils, dont les appareils à magasin de la marque Gaumont Spido $9 \times 12 \mathrm{~cm}$, ainsi que de nombreux modèles allemands dont ceux de la firme Curt Bentzin de Görlitz, tous accompagnés de leurs focales fixes Carl Zeiss.

18. - En effet, l'appareil Gaumont Spido $6 \times 13 \mathrm{~cm}$ peut effectuer des vues stéréoscopiques pour la vision en relief, mais peut également réaliser des vues panoramiques. Une petite cloison située dans la chambre de l'appareil est rabattable, masquant ainsi l'une des deux optiques. Lors de la prise de vue, la lumière passant par l'optique non obturée frappe le négatif couché sur la plaque de verre.

19. - Le carnet de perception de matériel pour les opérateurs cinématographes est également conservé à la MAP au fort de Saint-Cyr. Ce carnet mentionne les noms de Machin et Meunier, précisant pour ces derniers les matériels utilisés : caméra Gaumont, équipée d'objectifs KraussTessar $40 \mathrm{~mm}, 50 \mathrm{~mm}$ et $75 \mathrm{~mm}$. Voir le site: http://cinematographes.free.fr/gaumontnegatif.html.

20. - Alfred Machin (1877-1929), chef opérateur de la maison Pathé, devient opérateur pour le SCA dès la création du service au printemps. Avant la guerre, il réalise plusieurs tournages en Afrique en 1907. À son retour, il occupe la place de chef opérateur pour la firme Pathé et participe à la réalisation de plusieurs longs métrages, et aux actualités filmées du Cinéjournal. Pour son travail effectué lors de la retraite allemande, il est cité à l'ordre de l'armée par le général Humbert. Voir: LACASSIN, Francis. Alfred Machin, de la jungle à l'écran. Paris: éd. Dreamland, 2001, p. 107. 
21. - Voir le reportage référencé SPA 11 BO : L'avance française entre Ribécourt et Noyon après le repli allemand sur la ligne Hindenburg en mars 1917. Daté du 19 au 24 mars 1917.

22. - Voir le reportage référencé SPA $181 \mathrm{M}$, intitulé : La ville de Péronne et les environs de Tracy-leVal lors du repli allemand de mars 1917 sur la « ligne Hindenburg ». Daté du 23 au 24 mars 1917.

23. - Voir le reportage référencé SPA $184 \mathrm{M}$ : État des lieux dans la Somme, l'Oise et l'Aisne après le repli allemand (mouvement Alberich) sur la ligne Hindenburg en avril 1917.

24. - Voir le site Internet de la fondation Albert Kahn : http://albert-kahn.hauts-de-seine.net/.

25. - Procédé photographique mis au point en 1903 par les frères Louis et Auguste Lumière. Commercialisé en 1907, l'autochrome devient un succès international, étant largement utilisé par les équipes de photographes travaillant pour Albert Kahn au sein de son projet humaniste des Archives de la planète.

26. - En 1921, l'économiste Alfred Sauvy avance le chiffre de trente-quatre milliards de francs-or de pertes provoquées sur les biens, hors les pertes de production agricole et industrielle. Les chiffres des destructions sont colossaux : 11000 édifices publics, 350000 maisons, 2500000 ha de terre, 569000 ha de terrains à bâtir, $62000 \mathrm{~km}$ de routes, $1858 \mathrm{~km}$ de canaux et $5000 \mathrm{~km}$ de chemin de fer pour l'ensemble des territoires sur lesquels s'étend le front. DEPERCHIN, Annie. «Des destructions aux reconstructions ». Dans Encyclopédie de la Grande Guerre 1914-1918, op cit., p. 1125.

27. - NIVET, Philippe. La France occupée : 1914-1918. Paris : éd. Armand Colin, 2011.

28. - CAPPRONNIER, Jean-Charles, FOURNIS, Frédéric, GERARD, Alexandra et TOUZET, Pascale. "L'art sacré entre les deux guerres: aspects de la première reconstruction en Picardie ». [Document électronique]. Dans Le patrimoine religieux des $\mathrm{XIX}^{\mathrm{e}}$ et $\mathrm{XX}^{\mathrm{e}}$ siècles, $2^{\mathrm{e}}$ partie. Dans In Situ Revue des patrimoines, 2009. [Date de consultation 14/04/2013].

29. - Voir précédemment partie sur le rôle de la SPA et de la SCA, supra, p. 3.

30. - Note de Pierre-Marcel Lévi, chef du service, concernant la photographie des églises, 13 juillet 1917. Original conservé dans les archives de la Médiathèque de l'architecture et du patrimoine (MAP) du fort de Saint-Cyr, ministère de la Culture et de la Communication. Non coté. 31. - L'interrogation de la base de données de l'ECPAD permet de relever, pour une période allant des années 1915 à 1919, plus de 1100 photographies clairement identifiées à l'aide des éléments d'archives disponibles à l'ECPAD. Cependant, il existe encore des centaines de reportages photographiques qui contiennent des documents montrant des églises en ruine.

32. - MARTONNE, Emmanuel de. « Nécrologie ». Dans Annales de géographie, 1930, vol. 39, n²21, p. 549-553. Voir le site: http://www.persee.fr/web/guest/home/. [Date de consultation 04/05/2013].

33. - Cette collection est référencée sous les lettres $\mathrm{CT}$, signifiant «contretype ». Il existe plus d'une centaine de reportages contretypés. En effet, ces documents sont dupliqués sur négatif avant d'être archivés au même titre que le reste de la production.

34. - Voir dans la base Mérimée : notice Mérimée PA00116231. [Date de consultation 18/05/2013]. L'église fut reconstruite en intégrant des éléments en béton armé, comme de nombreux monuments reconstruits dans les années d'après-guerre. Elle connaît de nouveaux dommages en 1940. Voir également CAPPRONNIER, Jean-Charles, FOURNIS, Frédéric, GERARD, Alexandra et TOUZET, Pascale. Op. cit.

35. - Musée établi à l'hôtel de ville de Péronne en 1877 et qui regroupait l'une des plus importantes collections de pièces et de trésors archéologiques datant de l'époque gallo-romaine. La collection fut en grande partie pillée par les troupes allemandes, à l'exception de quelques objets cachés par le conservateur en 1914.

36. - Dans un premier temps, le panneau fut traduit par la phrase suivante : « Ne vous fâchez pas, admirez simplement ». Or, des historiens allemands ont découvert le véritable sens de cette phrase: «La guerre est insensée et c'est comme ça!» exprimant ainsi le cynisme des 
combattants allemands à l'égard des soldats britanniques qui ont libéré la ville de Péronne. Voir le site : http://www.historial.org/. [Date de consultation 18/05/2013].

37. - LONGEARD, Gwladys. «La lettre du 4 septembre 1917 relative au classement des vestiges de guerre dans la Somme». [Document électronique]. Dans Revue historique des Armées (RHA), 242/2006, dossier " 1916 les grandes batailles et la fin de la guerre européenne ». Cote du document SHD armée de Terre: 17 N 305. Voir le site: http://rha.revues.org/ index4272.html\#ftn2.

38. - Épreuves de tournage effectuées par le caméraman René Meunier, entre le 16 et le 24 avril 1917, intitulées Aux châteaux de Moyembrie et de Folembray. Scènes du front. Construction de ponts pour l'ALGP. Dans les ruines reconquises. Durée 00:21:02, noir et blanc, muet. @ ECPAD. Réf. 14.18 A 275.

39. - AUVRAY, Michel. "La guerre après la guerre, représentations photographiques de la première guerre mondiale dans les guides des champs de bataille". Dans Voir ou ne pas voir la guerre. Paris : Somogy, 2009, p. 283-287. Citation extraite du Guide illustré des champs de bataille, La Marne (1914) tome I, l'Ourcq, Chantilly, Senlis, Meaux. Clermont-Ferrand: Michelin propriétaireéditeur, 1917, « avertissements aux lecteurs ", p. 110-111.

40. - Guide illustré des champs de bataille. Noyon, Roye, Lassigny. Clermont-Ferrand: Michelin propriétaire-éditeur, 1921.

41. - Au Sénat, un groupe réunissant des sénateurs et des députés des départements envahis est constitué dès le mois d'octobre 1914. Sous l'impulsion de Léon Bourgeois et Paul Hayez, ce groupe se donne pour objectifs d'étudier les mesures nécessaires pour assurer la vie des habitants des régions envahies et de relever les destructions commises sur les territoires du Nord et de l'Est, en vue de dresser la liste des réparations. Sources : archives en ligne du Sénat de la Première Guerre mondiale : http://www.senat.fr/histoire/1914_1918. [Date de consultation 15/05/2013].

42. - Au cours du conflit, plusieurs commissions dirigées par Georges Payelle font état, au sein de rapports et de procès-verbaux d'enquête, des actes commis par les troupes allemandes en violation du droit des gens. Au moment du repli allemand de Picardie, la commission Payelle se rend dans les territoires dévastés, rendant un nouveau rapport. Voir le site: http:// webverman.pagesperso-orange.fr/payelle.htm. [Date de consultation 15/05/2013].

43. - BOULANGER, Philippe. "Le paysage de la guerre dans le canton de Lassigny (Oise)». [Document électronique]. Dans Ruralia, revue de l'Association des ruralistes français, août 2001, mis en ligne le 24 janvier 2009 : http://ruralia.revues.org/216. [Date de consultation 16/05/2013].

44. - Service régional de l'Inventaire. "Les sucreries de Picardie ». Dans Picardia, l'encyclopédie picarde. Région de Picardie, publié le 13/03/2008. Voir le site: http:// www.encyclopedie.picardie.fr/index.php/Les_sucreries_de_Picardie». [Date de consultation 05/05/2013].

45. - DANCHIN, Emmanuelle. "Destruction du patrimoine et figure du soldat allemand dans les cartes postales de la Grande Guerre » [document en ligne]. Dans Amnis, octobre 2011, mise en ligne le $1^{\mathrm{er}}$ mai 2010. [date de consultation 05/06/2013].

46. - KOTT, Christina. Préserver l'art de l'ennemi ? Le patrimoine artistique en Belgique et en France occupées, 1914-1918. Bruxelles : P. Lang, coll. Comparatisme et société, 2006.

47. - KOTT, Christina. «'Inventorier pour mieux contrôler?' L'inventaire photographique allemand du patrimoine culturel belge entre recherche historique et politique d'occupation ». Dans JAUMAIN, Serge, AMARA, Michaël, MAJERUS, Benoît, VRINTS, Antoon (dir.). Une guerre totale? La Belgique dans la première guerre mondiale. Nouvelles tendances de la recherche historique (Actes du colloque international organisé à l'ULB du 15 au 17 janvier 2003), (Études sur la Première Guerre mondiale/Studie over de Eerste Wereldoorlog, $\left.\mathrm{n}^{\circ} 11\right)$, Archives Générales du Royaume, Bruxelles, 2004, p. 283 sq.

48. - Consultables sur le site de la Bibliothèque nationale de France (BNF) : http://gallica.bnf.fr. [Date de consultation 25/05/2013]. 
49. - Les journaux illustrés, dont l'articulation fait une place plus importante à l'image qu'au texte, publient au cours de la guerre une forte proportion de documents supposés amateurs, réalisés par les soldats eux-mêmes. En effet, peu d'instantanés pris par les opérateurs de la SPCA apparaissent dans Le Miroir, où un concours de photographie invite les lecteurs, malgré l'interdiction faite aux combattants de prendre des clichés sans autorisation, à faire parvenir leurs clichés à la rédaction, avec, à la clé, la possibilité d'empocher une somme d'argent. Pour préserver l'anonymat de leurs sources, Le Miroir publie les photographies sans le nom de l'auteur du cliché. BEURIER, Joëlle. «L'apprentissage de l'événement». Études photographiques, 20 juin 2007, [En ligne], mis en ligne le 19 septembre 2008 : http:// etudesphotographiques.revues.org/index1162.html. [Date de consultation 25/05/2013].

50. - DANCHIN, Emmanuelle. «Destruction du patrimoine et figure du soldat allemand dans les cartes postales de la Grande Guerre »[document en ligne]. Dans Amnis, octobre 2011, mise en ligne le $1^{\mathrm{er}}$ mai 2010. [date de consultation 05/06/2013].

51. - Édouard Brissy: [Le village de Coucy-le-Château, mars 1917]. Réf. SPA 51 D. C) ECPAD. 30 mars 1917. Formats de négatifs $9 \times 12$ et $6 \times 13 \mathrm{~cm}$. Noir et blanc. Voir également le tournage réalisé par Alfred Machin : Coucy-le-Château. Réf. 14.18 B 195. ㅇ ECPAD. Durée 8 min 56 sec. Noir et blanc, muet, format $35 \mathrm{~mm}$.

52. - Les Grandes misères de la guerre sont éditées en 1633. C'est un ensemble de dix-huit eaux fortes exécutées par le graveur nancéien Jacques Callot (1592-1635) qui relate les événements de la guerre de Trente Ans. Elle présente la vie quotidienne du soldat, dans ses misères et ses dépravations. Cette série évoque ainsi les châtiments qui attendent tout soldat reconnu coupable de destructions, de pillage et de viol. Voir: Jacques Callot, 1592-1635. Catalogue de l'exposition. Nancy: Musée historique lorrain, juin-septembre 1992. Paris : éd. Réunion des Musées nationaux, 1992. 53. - DANCHIN, Emmanuelle. Op cit.

54. - Les Allemands ne sont plus à Noyon. Réalisation SPCA, 20 mars 1917. Durée 7 min et 34 sec. Noir et blanc, muet, format $35 \mathrm{~mm}$. Réf. 14.18 B 120. (C ECPAD.

55. - Voir les reportages photographiques d'Édouard Brissy: Le comité américain de Blérancourt. Scierie canadienne à Quesmy. Réf. SPA 77 D. C C ECPAD. Du $1^{\text {er }}$ au 5 octobre 1917. Noir et blanc, formats de négatifs $9 \times 12$ et $6 \times 13 \mathrm{~cm}$. Région de Blérancourt, reconstruction des infrastructures. Du 19 octobre au 20 novembre 1917. Noir et blanc. Format de négatifs 9 x $12 \mathrm{~cm}$. Réf. SPA 79 D. (C) ECPAD. Voir le film L'œuvre du comité américain à Blérancourt. Octobre 1917. Réal. SPCA. Durée 10 min $52 \mathrm{sec}$. Noir et blanc, muet, format $35 \mathrm{~mm}$. Réf. 14.18 A 1304. C ECPAD.

56. - L'opérateur Roger Le Baron, photographe de la SPCA, se rend au début du mois de mars 1918 dans la région de Lassigny pour suivre les efforts établis par les œuvres de bienfaisance américaines en faveur des populations rurales. Or, le 21 mars 1918, une nouvelle offensive allemande se dirige dans le secteur, jetant à nouveau sur les routes les civils et détruisant derechef les habitations reconstruites. Les combats libérateurs de l'été 1918 ajoutent de nouvelles destructions, laissant la région entièrement dévastée.

57. - Les comptes rendus originaux de la section film de la SPCA sont conservés à la Bibliothèque de documentation et d'information contemporaine (BDIC) des Invalides. Les comptes rendus numérotés 189, 190 et 191, intitulés « film spécial pour M. Griffith », ou "film spécial pour Américain ", stipulent que 238 mètres de pellicule $35 \mathrm{~mm}$ ont été utilisés pendant le tournage. LACASSIN, Francis. Alfred Machin, de la jungle à l'écran. Paris, éd. Dreamland, 2001, p. 110 et 111.

58. - CHOAY, Françoise. L'allégorie du patrimoine. Paris : éd. Seuil, 1992.

59. - AUVRAY, Michel. «La guerre après la guerre, représentations photographiques de la première guerre mondiale dans les guides des champs de bataille». Dans Voir ou ne pas voir la guerre. Paris : Somogy, 2009, p. 283-287.

60. - KOTT, Christina. Op. cit. 


\section{RÉSUMÉS}

En mars 1917, les troupes allemandes procèdent à un large repli stratégique de leurs forces présentes en Picardie. Baptisée Alberich, cette opération est lourde de conséquences pour la région car, avant son départ, l'armée allemande détruit de nombreux châteaux, églises, routes, ponts, usines ou fermes, emportant à jamais un part notable du patrimoine, souvent ancien. La Section photographique et cinématographique de l'armée (SPCA) est mobilisée pour dresser un inventaire en images des dégâts subis par le territoire picard, réalisant une importante production photographique et cinématographique qui d'une part, contribue à l'œuvre de restauration menée après la guerre et, d'autre part, alimente la propagande contre l'Allemagne, jugée seule responsable des ruines.

In March 1917, the German troops undertook a broad, strategic retreat of their forces present in Picardy. Baptised Alberich, this operation had dramatic consequences for the Picardy region: prior to their departure, the German army destroyed many churches, stately homes, roads, bridges, factories or farms, destroying for ever elements of the heritage which were often very old. The French Section photographique et cinématographique de l'armée (SPCA) was mobilized to draw up an image inventory of the ruins of Picardy, contributing, on the one hand, to the work of restoration carried out after the war, but also feeding propaganda against the Germans, held accountable for the ruins.

\section{AUTEUR}

\section{LIEUTENANT DAVID SBRAVA}

Établissement de communication et de production audiovisuelle de la Défense (ECPAD) fort d'Ivry-sur-Seine, chargé de collection, responsable du fonds photographique et cinématographique de la Première Guerre mondiale David.SBRAVA@ecpad.fr 